STANLEY EIDI TOKUNO

ANÁLISE DE MODELOS E APLICAÇÃO DO UPFC EM SISTEMA DE $138 \mathrm{KV}$

SÃo PAULO

2016 
STANLEY EIDI TOKUNO

\section{ANÁLISE DE MODELOS E APLICAÇÃO DO UPFC EM SISTEMA DE} $138 \mathrm{KV}$

Dissertação apresentada à Escola Politécnica da Universidade de São Paulo para obtenção do título de Mestre em Ciências. 


\section{ANÁLISE DE MODELOS E APLICAÇÃO DO UPFC EM SISTEMA DE $138 \mathrm{KV}$}

Dissertação apresentada à Escola Politécnica da Universidade de São Paulo para obtenção do título de Mestre em Ciências.

Área de Concentração: Sistemas de Potência

Orientador: Luiz Cera Zanetta Junior 
Este exemplar foi revisado e corrigido em relação à versão original,sob responsabilidade única do autor e com a anuência de seu orientador.

São Paulo,19 de Setembro de 2016.

Assinatura do autor:

Assinatura do orientador:

Catalogação-na-publicação

TOKUNO, STANLEY

ANÁLISE DE MODELOS E APLICAÇÃO DO UPFC EM SISTEMA DE 138

KV / S. TOKUNO -- versão corr. -- São Paulo, 2016. $108 \mathrm{p}$.

Dissertação (Mestrado) - Escola Politécnica da Universidade de São Paulo. Departamento de Engenharia de Energia e Automação Elétricas.

1.CE625.3.1 - SISTEMAS ELÉTRICOS DE POTÊNCIA 2.CE625.3.1.1.5 DISTRIBUIĈ̃O DE ENERGIA ELÉTRICA 3.CE625.3.1.1.5.1 - REDES DE DISTRIBUIÇÃO DE ENERGIA ELÉTRICA I I.Universidade de São Paulo. Escola Politécnica. Departamento de Engenharia de Energia e Automação Elétricas II.t. 
Aos meus pais e irmã À minha esposa e filhos 


\section{AGRADECIMENTOS}

Ao Professor Luiz Cera Zanetta Jr., cuja orientação foi fundamental para a elaboração deste trabalho.

À minha família que sempre incentivou meus estudos, me ensinando que esta é uma das maiores heranças que os pais podem deixar aos filhos.

À minha esposa e filhos pela compreensão e motivação para a realização deste trabalho.

A todos os amigos pelo incentivo e colaboração, contribuindo direta e indiretamente para o meu desenvolvimento profissional e produção do presente trabalho. 
Os investimentos em conhecimento geram os melhores dividendos.

(Benjamin Franklin) 


\section{RESUMO}

Este trabalho trata do UPFC (Unified Power Flow Controller), que corresponde a um dos mais promissores dispositivos FACTS de última geração, pois apresenta a capacidade de controle independente de todos os parâmetros básicos do sistema elétrico de potência (tensão, impedância e ângulo de fase). Com base nos modelos já propostos para representação deste equipamento em regime permanente, é realizada análise e proposta de um modelo que permite uma abordagem prática, para simulação do UPFC em softwares de fluxo de potência comerciais que não possuem modelos dedicados para este dispositivo. São revisitados os conceitos associados ao UPFC, com apresentação dos modelos analisados e seus respectivos parâmetros, assim como os equipamentos instalados e estimativa de custos para implantação. Através de simulações utilizando o modelo de transformador ideal associado à impedância do transformador série e compensador estático, são obtidos os parâmetros para o modelo de injeção de potências e realizadas simulações que demonstram a equivalência entre estes modelos. Finalmente, é realizada a análise de aplicação do UPFC em um sistema de distribuição de alta tensão, onde há forte presença de geração distribuída com sua sazonalidade característica e linhas que realizam a interligação entre diferentes fontes do sistema, havendo a necessidade de controle do fluxo de potência e melhoria dos níveis de tensão em função dos critérios técnicos e aspectos regulatórios.

Palavras-chave: Sistemas de Potência, FACTS, UPFC, Sistemas de distribuição de alta tensão, Planejamento da expansão do sistema elétrico. 


\begin{abstract}
This work is about UPFC which corresponds to one of the most promising last generation FACTS device, for it presents independent control in all basic parameters of the electrical power system (voltage, impedance and phase angle). Based on models that have already been proposed to represent this equipment in steady state, an analysis has been made and a model that permits practical approach is proposed to simulate the UPFC in commercial power flow softwares that do not yet support this device. The associated UPFC concepts are revisited with the presentation of analyzed models and their respective parameters as well as the installed equipments and cost estimate for implementation. Through simulations using ideal transformer associated to the series transformer impedance and static Var compensator model, parameters are obtained for the power injection model and simulations were run that showed a similarity between these models. Finally, a UPFC application analysis was done for a region of high voltage distribution system, where there is a strong presence of distributed generation typically seasonal and lines which connect different sources of the system, having the necessity of controlling the power flow and improvement of the voltage levels due to the technical criteria and regulatory aspects.
\end{abstract}

Keywords: Power Systems, FACTS, UPFC, High-voltage distribution system, Electric system expansion planning. 


\section{LISTA DE FIGURAS}

Figura 1 - Complementaridade anual das diversas fontes de geração .....................17

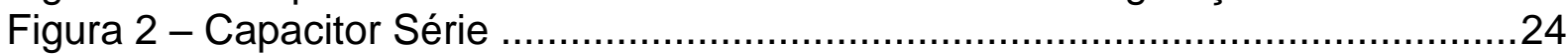

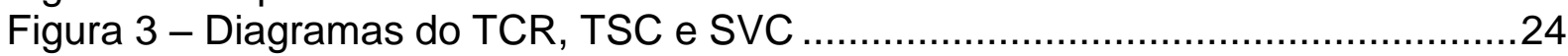

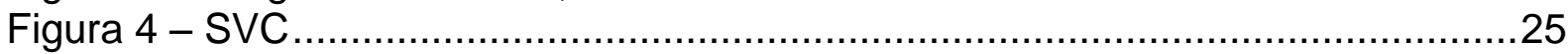



Figura 6 - Statcom

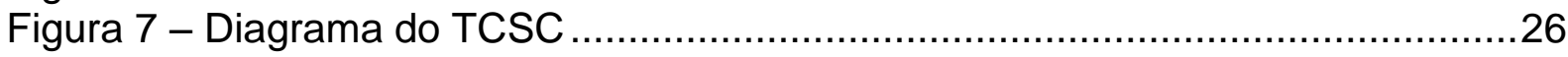

Figura 8 - Sistema simplificado com duas máquinas ..........................................28

Figura 9 - Sistema de duas máquinas com a fonte Vpq representando o UPFC .....29

Figura 10 - Regiões de controle do sistema com o UPFC......................................30

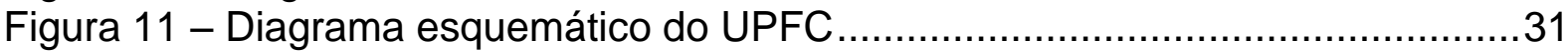

Figura 12 - Sistema de duas máquinas com inserção de transformador defasador.32

Figura 13 - Regiões de controle do sistema para o transformador defasador e o

UPFC

Figura 14 - Configuração do IPFC para compensação de 'n' linhas de transmissão 34

Figura 15 - Modelo tipo fonte de tensão para o IPFC

Figura 16 - Modelo do UPFC como fonte de tensão inserida na linha de transmissão

Figura 17 - Representação unifilar do UPFC....................................................36

Figura 18 - Modelo de UPFC (PQ-PV) proposto por Nabavi-Niaki e Iravani .............36

Figura 19 - Representação do conversor série...................................................37

Figura 20 - Substituição da fonte de tensão pela fonte de corrente .........................38

Figura 21 - Modelo de injeção de potências para o conversor série .........................39

Figura 22 - Modelo de injeção de potências (PIM) do UPFC …….........................40

Figura 23 - Modelo do UPFC através de admitâncias shunt ..................................41

Figura 24 - Modelo do UPFC com transformador defasador e barra PV ..................42

Figura 25 - Modelo do UPFC com transformador defasador e reatância variável ....42

Figura 26 - Foto UPFC Inez..................................................................45

Figura 27 - Foto inversores UPFC Inez - GTO …………..............................45

Figura 28 - Diagrama do sistema da Coreia e ponto de instalação do UPFC ..........46

Figura 29 - Diagrama unifilar do CSC em Nova lorque .........................................47

Figura 30 - Foto CSC em Nova lorque ..........................................................4

Figura 31 - Estimativa de custos para SVC e Statcom .....................................48

Figura 32 - Estimativa de custos para Capacitor Série (FSC), TCSC e UPFC ..........48

Figura 33 - Modelo do UPFC com transformador defasador com a respectiva

reatância, e reatância shunt variável ..................................................................51

Figura 34 - Modelo do UPFC com transformador defasador, impedância série e SVC

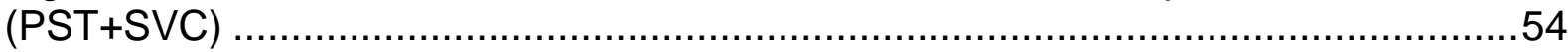

Figura 35 - Modelo de injeção de potências (PIM) do UPFC .................................54

Figura 36 - Modelo com barra de carga e gerador (PQ+PV) do UPFC ..................55

Figura 37 - Caso 1: Diagrama unifilar simplificado do sistema de $138 \mathrm{kV}$ com inserção do UPFC entre as subestações 4 e 5 ……..........................................56

Figura 38 - Caso 1: Diagrama de simulação com os modelos analisados ...............57

Figura 39 - Caso 2: Diagrama unifilar simplificado do sistema de $138 \mathrm{kV}$ com a

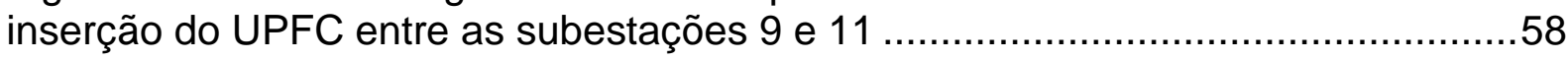

Figura 40 - Caso 2: Diagrama de simulação com os modelos analisados ................59 
Figura 41 - Diagrama unifilar simplificado com as distâncias entre as principais subestações em km e geração distribuída em MW

Figura 42 - Gráfico do fluxo de potência nas fronteiras x carga da área

Figura 43 - Fluxo de potência ativa (MW) - carga média - período de entressafra..64 Figura 44 - Carregamento das linhas de 138 kV (\%) - carga média - período de entressafra.

Figura 45 -Tensão nos barramentos (pu) - carga média - período de entressafra ..66

Figura 46 - Fluxo de potência ativa (MW) - carga leve - safra

Figura 47 - Carregamento das linhas de 138 kV (\%) - carga leve - período de safra

Figura 48 - Indicação dos pontos com restrição de tensão e carregamento - em azul

Figura 49 - Diagrama unifilar simplificado da região com a alternativa avaliada ......70

Figura 50 - Alternativa com UPFC - Fluxo de potência ativa (MW) - carga média período de entressafra

Figura 51 - Alternativa com UPFC - carregamento das linhas de 138 kV (\%) - carga

média - período de entressafra.................................................................. 75

Figura 52 - Alternativa com UPFC - tensão nos barramentos (pu) - carga média -

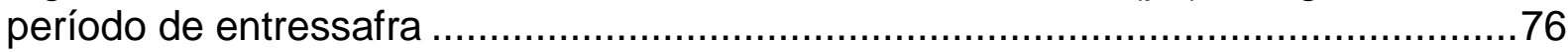

Figura 53 - Alternativa com UPFC - fluxo de potência ativa (MW) - carga leve -

período de safra ............................................................................................ 77

Figura 54 - Alternativa com UPFC - carregamento das linhas de 138 kV (\%) - carga

leve - período de safra........................................................................... 78

Figura 55 - Alternativa com UPFC - carregamento da linha de $138 \mathrm{kV}$ em

contingência (\%) - controle UPFC $70 \mathrm{MW}$.

Figura 56 - Alternativa com UPFC - carregamento da linha de $138 \mathrm{kV}$ em

contingência (\%) - controle UPFC $150 \mathrm{MW}$

Figura 57 - Gráfico de variação do fluxo de potência nas fronteiras em função do

ajuste do UPFC

Figura 58 - Diagrama unifilar simplificado da região com a alternativa de conexão com o sistema de $500 \mathrm{kV}$

Figura 59 - Alternativa $500 \mathrm{kV}$ - fluxo de potência ativa (MW)....

Figura 60 - Alternativa 500 kV - carregamento das linhas de $138 \mathrm{kV}$ (\%) ................84

Figura 61 - Alternativa 500 kV - tensão nos barramentos (pu) ...............................85

Figura 62 - Alternativa $500 \mathrm{kV}$ - fluxo de potência ativa (MW) .............................86

Figura 63 - Alternativa $500 \mathrm{kV}$ - carregamento das linhas de $138 \mathrm{kV}(\%)$...............87

Figura 64 - Fluxo de potência ativa (MW) - carga média - período de entressafra ..96

Figura 65 - Fluxo de potência reativa (Mvar) - carga média - período de entressafra

Figura 66 - Carregamento das linhas de $138 \mathrm{kV}$ (\%) - carga média - período de entressafra

Figura 67 - Tensão nos barramentos (pu) - carga média - período de entressafra .98

Figura 68 - Fluxo de potência ativa (MW) - carga leve - safra ..............................98

Figura 69 - Fluxo de potência reativa (Mvar) - carga leve - período de safra ..........99

Figura 70 - Carregamento das linhas de 138 kV (\%) - carga leve - período de safra

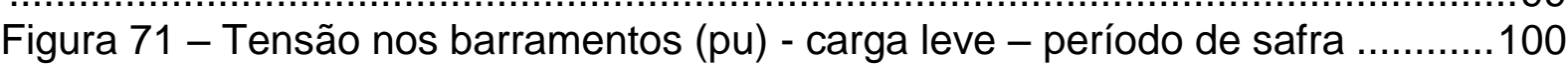

Figura 72 - Alternativa com UPFC - Fluxo de potência ativa (MW) - carga média -

entressafra 
Figura 73 - Alternativa com UPFC - Fluxo de potência reativa (Mvar) - carga média entressafra

Figura 74 - Alternativa com UPFC - carregamento das linhas (\%) - carga média -

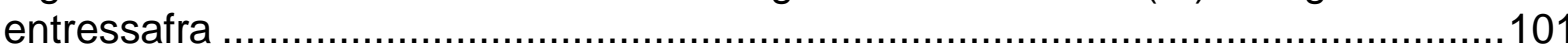

Figura 75 - Alternativa com UPFC - tensão nos barramentos (pu) - carga média entressafra ........................................................................................... 102 Figura 76 - Alternativa com UPFC - fluxo de potência ativa (MW) - carga leve período de safra 102 Figura 77 - Alternativa com UPFC - fluxo de potência reativa (Mvar) - carga leve safra 103

Figura 78 - Alternativa com UPFC - carregamento das linhas de 138 kV (\%) - carga leve -safra.

Figura 79 - Alternativa com UPFC - tensão nos barramentos $(\mathrm{pu})$ - carga leve - safra

Figura 80 - Alternativa 500 kV - fluxo de potência ativa (MW) - carga média entressafra 104

Figura 81 - Alternativa 500 kV - fluxo de potência reativa (Mvar) - carga média entressafra 104

Figura 82 - Alternativa 500 kV - carregamento das linhas de 138 kV (\%) - carga média - entressafra 105

Figura 83 - Alternativa 500 kV - tensão nos barramentos (pu) - carga média entressafra

Figura 84 - Alternativa $500 \mathrm{kV}$ - fluxo de potência ativa (MW) - carga leve - safra 106 Figura 85 - Alternativa 500 kV - fluxo de potência reativa (Mvar) - carga leve - safra 106

Figura 86 - Alternativa 500 kV - carregamento das linhas de 138 kV (\%) - carga leve - safra 107

Figura 87 - Alternativa 500 kV - tensão nos barramentos (pu) - carga leve - safra 108 


\section{LISTA DE TABELAS}

Tabela 1 - Gerações de dispositivos FACTS 22

Tabela 2 - Caso 1: Resultados de simulação dos modelos de UPFC no ANAREDE

Tabela 3 - Caso 2: Resultados de simulação dos modelos de UPFC no ANAREDE

Tabela 4 - Alternativa de aplicação do UPFC - estimativa de custos ........................88

Tabela 5 - Alternativa de conexão ao sistema de $500 \mathrm{kV}$ - estimativa de custos .....89

Tabela 6 - Perdas incrementais das alternativas avaliadas [MW] ............................89 


\section{LISTA DE ABREVIATURAS E SIGLAS}

$\begin{array}{ll}\text { ANAREDE } & \text { Programa Análise de Redes Elétricas do CEPEL } \\ \text { ANEEL } & \text { Agência Nacional de Energia Elétrica } \\ \text { CAA } & \text { Condutor de Alumínio com Alma de Aço } \\ \text { CSC } & \text { Convertible Static Compensator } \\ \text { FACTS } & \text { Flexible Alternating Current Transmission System } \\ \text { FSC } & \text { Fixed Series Capacitor } \\ \text { GTO } & \text { Gate Turn-Off Thyristor } \\ \text { IGBT } & \text { Insulated Gate Bipolar Transistor } \\ \text { IPFC } & \text { Controlador de Fluxo de Potência de Múltiplas Linhas } \\ \text { IPFC } & \text { Interline Power Flow Controller } \\ \text { MUST } & \text { Montante de Uso do Sistema de Transmissão } \\ \text { PQ } & \text { Barra de carga } \\ \text { PV } & \text { Barra com tensão controlada } \\ \text { PIM } & \text { Power Injection Model } \\ \text { PST } & \text { Phase Shifter Transformer } \\ \text { PCHs } & \text { Pequenas Centrais Hidrelétricas } \\ \text { SIN } & \text { Sistema Interligado Nacional } \\ \text { SC } & \text { Series Capacitor } \\ \text { SSSC } & \text { Static Synchronous Series Compensator } \\ \text { STATCOM } & \text { Static Synchronous Compensator } \\ \text { SVC } & \text { Static Var Compensator } \\ \text { TCPAR } & \text { Thyristor Controlled Phase Angle Regulator } \\ \text { TCR } & \text { Thyristor Controlled Reactor } \\ \text { TCVR } & \text { Thyristor Controlled Voltage Regulator } \\ \text { TCSC } & \text { Thyristor Controlled Series Capacitor } \\ \text { TSC } & \text { Thyristor Switched Capacitor } \\ \text { UHE } & \text { Usina Hidrelétrica } \\ \text { UPFC } & \text { Unified Power Flow Controller } \\ \text { UTE } & \text { Usina Termelétrica } \\ & \end{array}$




\section{SUMÁRIO}

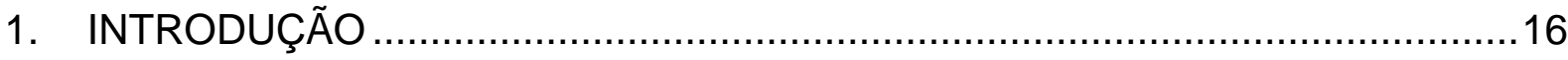

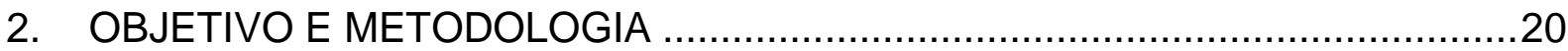

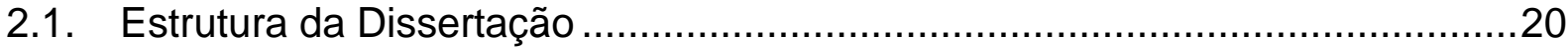

3. DISPOSITIVOS FACTS: REVISÃO DA LITERATURA .................................22

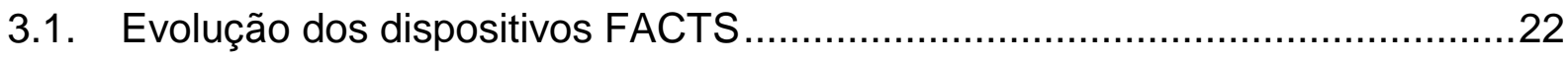

3.2. Unified Power Flow Controller (UPFC) ............................................28

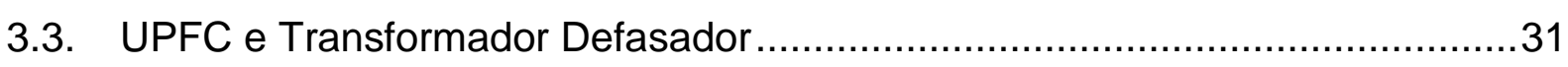

3.4. Interline Power Flow Controller (IPFC) ............................................ 33

3.5. Modelos do UPFC em regime permanente .......................................... 35

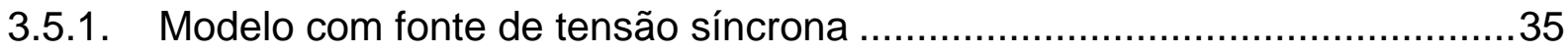

3.5.2. Modelo com barra de carga e gerador (PQ+PV) .................................. 36

3.5.3. Modelo de injeção de potências (PIM - Power Injection Model) ....................37

3.5.4. Modelo de admitância shunt ...........................................................40

3.5.5. Modelo de transformador ideal e reatância shunt ..................................4 41

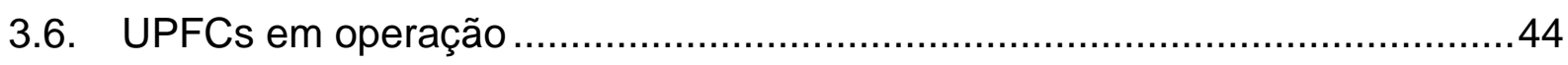

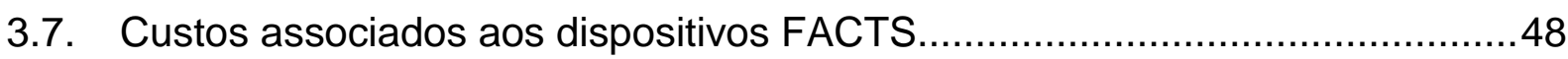

4. ANÁLISE DE MODELOS DO UPFC PARA SIMULAÇÃO EM REGIME PERMANENTE

4.1. Modelo de Transformador Defasador e Compensador Estático (PST - Phase Shifter Transformer + SVC - Static Var Compensator) .......................................51

4.2. Simulações utilizando os modelos de UPFC em regime permanente .............53

5. ANÁLISE DE APLICAÇÃO DO UPFC NO SISTEMA DE DISTRIBUIÇÃO DE



5.1. Sistema de distribuição interligado com influência de geração distribuída ......60

5.1.1. Sistema atual: carga média - período de entressafra ...........................64

5.1.2. Sistema atual: carga leve - período de safra .....................................66

5.1.3. Sistema atual: restrições previstas ................................................68

5.2. Análise de aplicação do UPFC no sistema de distribuição de alta tensão ......69

5.2.1. Alternativa com UPFC: carga média - período de entressafra ..................73

5.2.2. Alternativa com UPFC: carga leve - período de safra ...............................76

5.2.3. Alternativa com UPFC: avaliação e operação em contingência ...................78

5.3. Alternativa de conexão ao sistema de $500 \mathrm{kV}$.......................................... 81

5.3.1. Alternativa $500 \mathrm{kV}$ : carga média - período de entressafra.........................83

5.3.2. Alternativa $500 \mathrm{kV}$ : carga leve - período de safra ...............................85

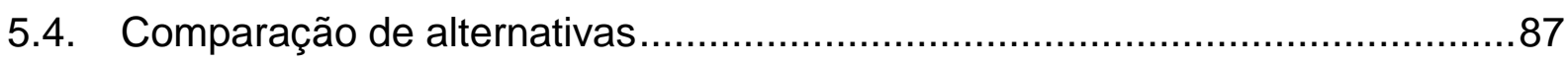

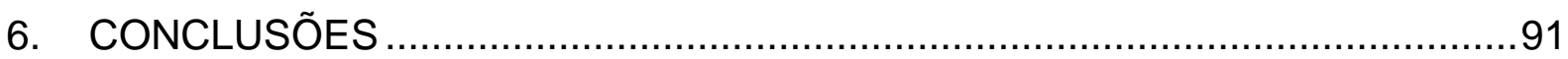




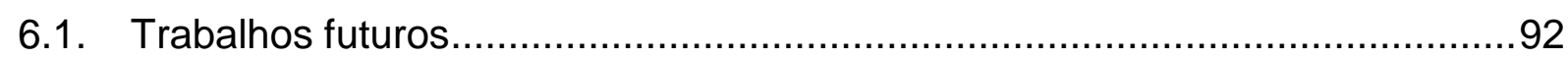



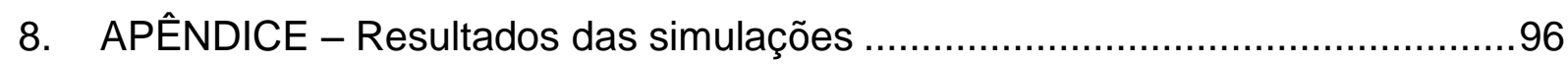

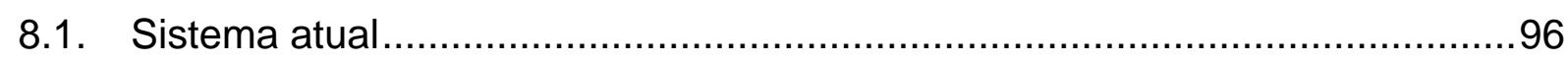

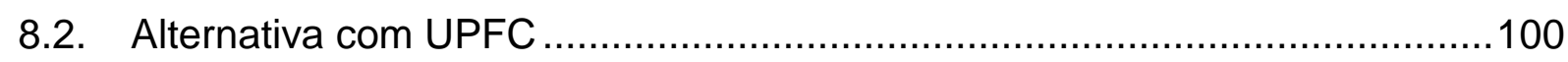

8.3. Alternativa com conexão ao sistema de 500 kV ......................................104 


\section{INTRODUÇÃO}

Atualmente, um dos principais pontos de atenção dos sistemas elétricos de potência corresponde ao sistema de transmissão de energia elétrica.

Este sistema, fundamental no transporte da energia e integração entre os segmentos de geração e distribuição, apresenta uma grande complexidade relacionada ao seu planejamento e operação, representando muitas vezes o fator limitante dos sistemas elétricos. Estas limitações no sistema de transmissão não permitem a operação em condições de máximo aproveitamento dos recursos disponíveis, elevando o risco de desligamentos no sistema elétrico.

A expansão do sistema de transmissão através da construção de novas linhas, reconstrução ou repotencialização das linhas existentes, que correspondem às alternativas comumente avaliadas para expansão da capacidade do sistema, apresenta muitas vezes dificuldades associadas a questões técnicas e ambientais.

Atualmente, a análise de expansão do sistema de transmissão deve considerar novos fatores que influenciam na proposta e definição das alternativas que serão implantadas.

Um importante fator que influencia o planejamento e operação dos sistemas elétricos corresponde à geração distribuída, representada pelas Pequenas Centrais Hidrelétricas (PCHs), Usinas a Biomassa e a Gás, Usinas Fotovoltaicas e Usinas Eólicas, além da minigeração e microgeração, regulamentadas recentemente no Brasil. Esta geração distribuída apresenta grandes variações ao longo do período, seja horário, diário ou mensal. No caso da geração fotovoltaica, a geração e consequente exportação de energia para o sistema elétrico estão associadas ao período de incidência solar. A geração eólica apresenta variação associada ao regime de ventos. A geração a biomassa, mais especificamente a geração a biomassa associada à indústria sucroalcooleira, apresenta dois períodos bastante distintos ao longo do ano: o período de safra, que corresponde ao período de produção de açúcar e álcool com geração de energia elétrica associada ao processo produtivo, e o período de entressafra, onde ocorre parada da produção e consequente interrupção na geração de energia elétrica. A figura 1 mostra a sazonalidade típica ao longo do ano das fontes de geração hidráulica, eólica e biomassa da cana-de-açúcar. 
Figura 1 - Complementaridade anual das diversas fontes de geração

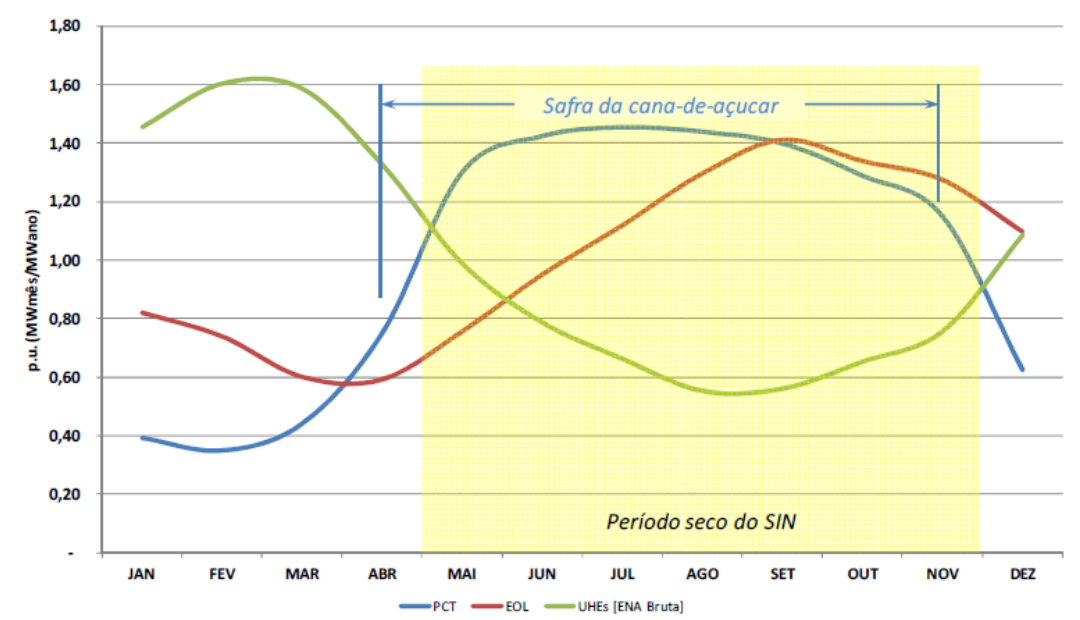

Fonte: (ONS)

Esta sazonalidade da geração distribuída altera significativamente o fluxo de potência no sistema de transmissão, modificando os carregamentos nas linhas e perfil de tensão nos barramentos, gerando cenários bastante distintos e que devem ser avaliados.

Particularmente, no caso dos sistemas de transmissão de propriedade das distribuidoras, associado ao efeito provocado pela geração distribuída, existe a questão regulatória representada pelos limites de demanda de potência que devem ser respeitados nas fronteiras entre este sistema com o sistema das transmissoras. Estes limites devem atender às regras estabelecidas na Resolução Normativa nº66 de 2015 da Agência Nacional de Energia Elétrica (ANEEL), que regulamenta a contratação do uso do sistema de transmissão, definindo penalização e multa em caso de descumprimento.

Nesta condição, a expansão da geração distribuída eleva a quantidade de variáveis e cenários que devem ser avaliados para definição dos valores de demanda de potência nas fronteiras do sistema de distribuição.

Estas demandas de potência contratadas pelas distribuidoras em todos os pontos de fronteira com o sistema de transmissão correspondem aos Montantes de Uso do Sistema de Transmissão (MUST). No caso das distribuidoras de energia elétrica que possuem como ativo de sua propriedade uma extensa rede de linhas de transmissão em níveis de tensão abaixo de $230 \mathrm{kV}$, as quais são classificadas como redes de distribuição de alta tensão, estes sistemas possuem como fontes de suprimento os 
pontos de fronteira com a Rede Básica do Sistema Interligado Nacional (SIN), formados por subestações transformadoras de 500 kV, 440 kV, 345 kV e 230 kV para os níveis de tensão de distribuição.

Esta contratação, assim como sua apuração, foi regulamentada pela ANEEL, sendo definidas as formas de cálculo dos encargos correspondentes e respectivas penalidades em caso de violação dos valores de demanda contratados ou contratação de valores acima dos registros apurados.

Os valores considerados para acompanhamento levam em conta o valor médio registrado a cada 15 minutos. Nestas condições, todas as violações apuradas mensalmente acima da margem de tolerância são passíveis de penalização, com multas equivalentes a três vezes a tarifa do ponto de conexão multiplicada pela demanda de ultrapassagem (acima de $110 \%$ ).

Caso não sejam verificados ao menos uma vez no ano, valores de demanda acima de $90 \%$ do valor contratado em cada ponto também estão sujeitos a penalização equivalente a doze vezes a tarifa do ponto de conexão multiplicada pela diferença entre o máximo valor medido no ano e $90 \%$ do valor contratado, podendo representar milhões de reais em multas às distribuidoras.

Considerando o sistema de distribuição de alta tensão como um sistema radial, possuindo um único ponto de fronteira com o sistema de transmissão como fonte e a conexão exclusivamente de cargas, a estimativa de valores para contratação pode ser realizada com relativa precisão.

Entretanto, para sistemas de distribuição de alta tensão que possuem interligação entre dois ou mais pontos de conexão com a Rede Básica, além de um elevado volume de geração distribuída conectado e sua sazonalidade característica, o fluxo nas fronteiras varia de acordo com as condições operativas do sistema externo à distribuidora.

Nestas condições, existe a necessidade de mudança nas características do sistema elétrico, de elemento passivo para um sistema que possibilite ações de controle de acordo com cada cenário possível.

Deste modo, a aplicação de equipamentos que realizam o controle ativo dos parâmetros do sistema elétrico surge como uma alternativa para expansão e melhor aproveitamento do sistema existente, realizando o direcionamento do fluxo de potência associado à geração distribuída no sistema ao qual está conectado, possibilitando ao mesmo tempo o controle da potência nas fronteiras entre os 
sistemas de transmissão e distribuição. Dentre os possíveis equipamentos utilizados com esta finalidade, destaca-se a aplicação da eletrônica de potência, presente nos dispositivos FACTS (Flexible Alternating Current Transmission System).

O conceito de dispositivos FACTS (Flexible AC Transmission System) surgiu em 1988, conforme artigo publicado por Hingorani (1988), no qual o autor previa a evolução dos dispositivos de eletrônica de potência e a expansão da sua aplicação nos sistemas elétricos, permitindo o controle eletrônico dinâmico dos parâmetros de ângulo de fase, tensões e impedâncias, em substituição aos controles eletromecânicos, citando também a utilização desta tecnologia para integração das gerações eólicas e fotovoltaicas.

A aplicação dos dispositivos FACTS, apesar da restrição associada aos elevados custos destes equipamentos quando comparados às atuais opções existentes, poderá se tornar viável em um horizonte próximo, em função dos custos atribuídos à operação e expansão do sistema com a necessidade de controle dos parâmetros do sistema elétrico (fluxo de potência ativa, reativa e tensão), aliada aos fatores que atualmente já viabilizam sua aplicação, como a solução de problemas de estabilidade transitória e resposta dinâmica para controle de intercâmbio de potência entre os subsistemas de transmissão.

A utilização da tecnologia FACTS e sua atuação imediata em condições de emergência no sistema, com tempos de controle inferiores aos tempos de atuação dos dispositivos de proteção (milissegundos), também permite sua aplicação no suporte às contingências do sistema, como desligamentos de linhas e transformadores. 


\section{OBJETIVO E METODOLOGIA}

O objetivo deste trabalho é avaliar a aplicação de modelos em regime permanente do UPFC (Unified Power Flow Controller), que corresponde a um dos mais promissores dispositivos FACTS de última geração, pois apresenta a capacidade de controle de todos os parâmetros básicos do sistema elétrico de potência (tensão, impedância e ângulo de fase) em um software de fluxo de potência comercial para realização de análises de planejamento e operação no sistema de distribuição de alta tensão.

Com base nos modelos propostos na literatura para representação deste equipamento em regime permanente, é realizada uma abordagem prática para aplicação e simulação no software ANAREDE utilizando os modelos de equipamentos disponíveis.

Utilizando um modelo simplificado para o UPFC, são realizadas análises da inserção deste dispositivo FACTS no sistema de distribuição de alta tensão e avaliação de aplicação, considerando os critérios de planejamento da expansão e operação, influência da geração distribuída, além dos aspectos regulatórios que devem ser observados pelas distribuidoras.

\subsection{Estrutura da Dissertação}

O restante da Dissertação está estruturada da seguinte forma:

No capítulo 3, é apresentado o histórico de evolução dos dispositivos FACTS e revisão da literatura relacionada ao UPFC, com a comparação deste equipamento com o transformador defasador. Também é apresentado o conceito do IPFC (Interline Power Flow Controller).

Na sequência, são apresentados os principais modelos para o UPFC em regime permanente, equipamentos em operação e estimativa de custos para os dispositivos FACTS.

O capítulo 4 apresenta a avaliação dos modelos em regime permanente do UPFC para simulações em um software de fluxo de potência comercial. Com base no modelo de transformador ideal e reatância shunt, é realizado o desenvolvimento do modelo com a representação do transformador ideal, a impedância do 
transformador série e o compensador estático. A partir do modelo desenvolvido e sua facilidade para obtenção dos parâmetros necessários ao cálculo dos valores do modelo de injeção de potências, são apresentados os resultados das simulações comparativas entre estes modelos.

No capítulo 5, é apresentada uma avaliação de aplicação do UPFC no sistema de distribuição de alta tensão e comparação com a alternativa de um novo ponto de conexão deste sistema à Rede Básica.

O capítulo 6 apresenta as conclusões e propostas de trabalhos futuros. 


\section{DISPOSITIVOS FACTS: REVISÃO DA LITERATURA}

A seguir são apresentados os principais aspectos referentes à literatura publicada com relação ao tema em análise. É apresentada a evolução dos dispositivos FACTS, com destaque para o princípio de funcionamento do UPFC e comparação com o transformador defasador que também realiza a função de controle do fluxo de potência ativa. São apresentados os modelos para o UPFC em regime permanente com seus respectivos parâmetros. Também são listados os UPFC em operação no mundo e estimativa de custos associados aos dispositivos FACTS.

\subsection{Evolução dos dispositivos FACTS}

Após o surgimento do conceito de FACTS (HINGORANI, 1988), o desenvolvimento dos dispositivos semicondutores de potência possibilitou a evolução destes equipamentos que permitem controlar os principais parâmetros do sistema elétrico, podendo ser classificados em quatro gerações (HINGORANI; GYUGYI, 2000), conforme a tabela 1.

Tabela 1- Gerações de dispositivos FACTS

\begin{tabular}{|c|c|}
\hline Fase & Dispositivos FACTS \\
\hline \multirow{1}{1^{\underline{a}}}{} & $\begin{array}{c}\text { TCR: Thyristor Controlled Reactor } \\
\text { (Reator Controlado por Tiristores) }\end{array}$ \\
Geração & $\begin{array}{c}\text { TSC: Thyristor Switched Capacitor } \\
\text { (Capacitores Chaveados por Tiristores) } \\
\text { SC: Series Capacitor (Capacitor série) }\end{array}$ \\
\hline
\end{tabular}




\begin{tabular}{|c|c|}
\hline$\stackrel{2^{\underline{a}}}{\text { Geração }}$ & $\begin{array}{c}\text { SVC: Static Var Compensator } \\
\text { (Compensador Estático de Reativos) } \\
\text { TCSC: Thyristor Controlled Series Capacitor } \\
\text { (Capacitores Série Controlados por Tiristores) } \\
\text { TCVR: Thyristor Controlled Voltage Regulator } \\
\text { (Reguladores de Tensão Controlados por Tiristores) } \\
\text { TCPAR: Thyristor Controlled Phase Angle Regulator } \\
\text { (Reguladores de Ângulo de Fase Controlados por Tiristores) }\end{array}$ \\
\hline $\begin{array}{c}3 .^{\mathrm{a}} \\
\text { Geração }\end{array}$ & $\begin{array}{l}\text { STATCOM: Static Synchronous Compensator (Compensador } \\
\text { Síncrono Estático) } \\
\text { SSSC: Static Synchronous Series Compensator } \\
\text { (Compensador Série Síncrono Estático) }\end{array}$ \\
\hline $\begin{array}{c}4 .^{\underline{a}} \\
\text { Geração }\end{array}$ & $\begin{array}{l}\text { UPFC : Unified Power Flow Controller } \\
\text { IPFC: Interline Power Flow Controller }\end{array}$ \\
\hline
\end{tabular}

Fonte: (PEREIRA, 2008, p.23).

- TCR: Thyristor Controlled Reactor (Reator Controlado por Tiristores)

Neste equipamento, a ação controlada dos tiristores permite a variação linear da indutância de zero até a reatância total do indutor.

- TSC: Thyristor Switched Capacitor (Capacitores Chaveados por Tiristores) No TSC, os tiristores controlam a variação linear da capacitância de zero até o valor total.

- Capacitores série:

Os capacitores série, utilizados para reduzir a reatância de transferência das linhas de transmissão, também são considerados dispositivos FACTS. A figura 2 apresenta a instalação de um capacitor série. 
Figura 2 - Capacitor Série

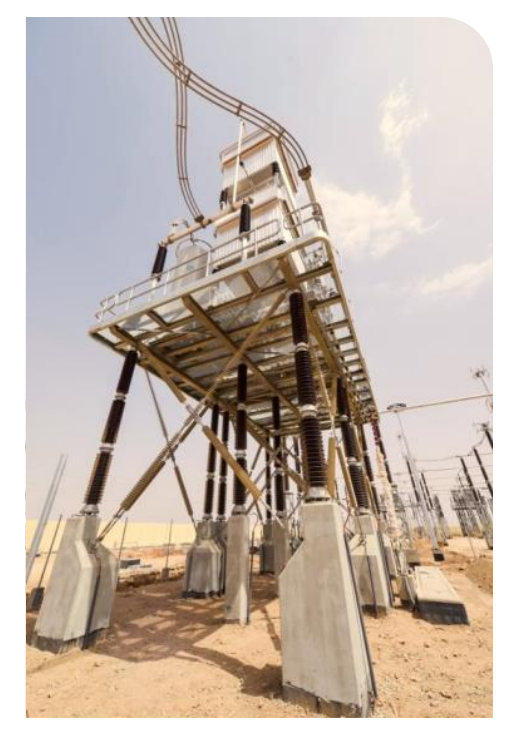

Fonte: (Alstom).

- SVC: Static Var Compensator (Compensador Estático de Reativos)

A associação do TSC com o TCR compõe o SVC. Atualmente é o dispositivo FACTS mais utilizado para solucionar problemas de controle dinâmico de tensão. A precisão e rápida resposta permitem aos SVCs terem alto desempenho em regime permanente e para controle de transitórios de tensão, comparados com a compensação shunt convencional. SVCs também são utilizados para amortecer oscilações de potência e aumentar a estabilidade transitória, otimizando o controle de potência reativa. A figura 3 apresenta os diagramas esquemáticos do TCR, TSC e SCV.

Figura 3 - Diagramas do TCR, TSC e SVC


Fonte: (PAL; REHTANZ; ZHANG, 2006, p.12). 
A figura 4 apresenta as instalações de um SVC.

Figura 4 - SVC

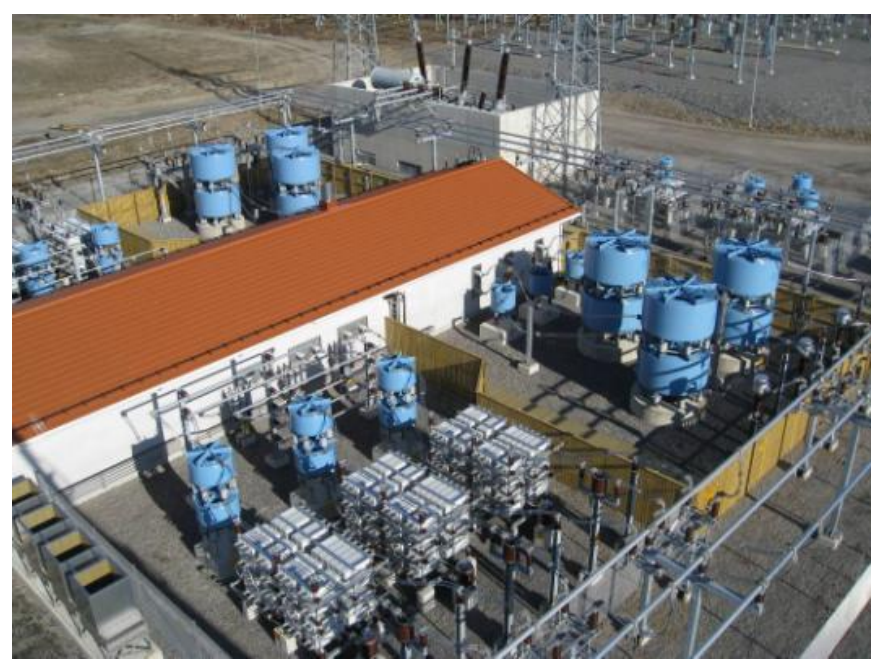

Fonte: (Alstom).

- STATCOM: Static Synchronous Compensator (Compensador Síncrono Estático)

São SVCs baseados em IGBTs (Insulated Gate Bipolar Transistor) do tipo fonte de tensão. Comparado com o SVC convencional eles não exigem grandes componentes indutivos e capacitivos para fornecer energia reativa para os sistemas de transmissão. A figura 5 apresenta o diagrama esquemático do STATCOM.

Figura 5 - Diagrama do STATCOM

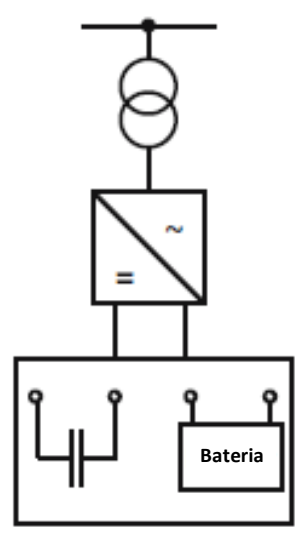

Fonte: (PAL; REHTANZ; ZHANG, 2006, p.13). 
A figura 6 apresenta as instalações de um STATCOM.

Figura 6 - Statcom

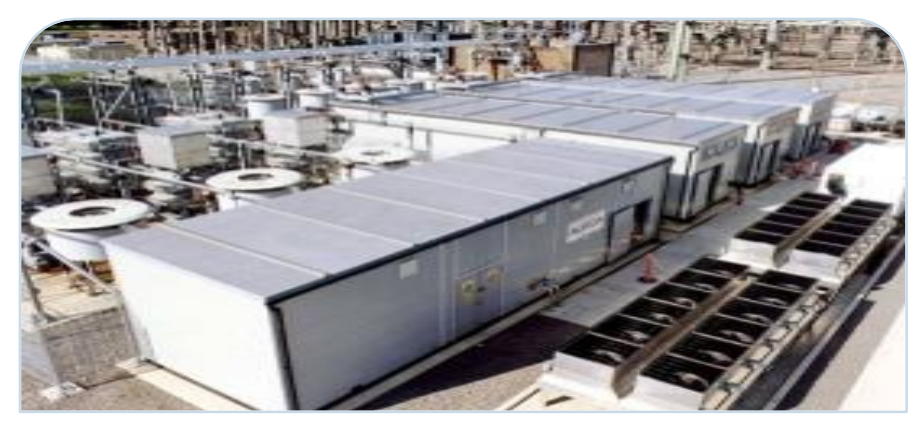

Fonte: (Alstom).

- TCSC: Thyristor Controlled Series Capacitor

São uma extensão dos capacitores série convencionais através da adição de um reator controlado por tiristores. A variação da reatância através do chaveamento dos tiristores, em paralelo com o capacitor série, permite a contínua e rápida variação da compensação série. Os principais benefícios dos TCSCs são o aumento na capacidade de transferência de potência, controle do fluxo de potência na linha, amortecimento das oscilações de potência e amortecimento das ressonâncias subsíncronas. A figura 7 apresenta o diagrama esquemático do TCSC.

Figura 7 - Diagrama do TCSC

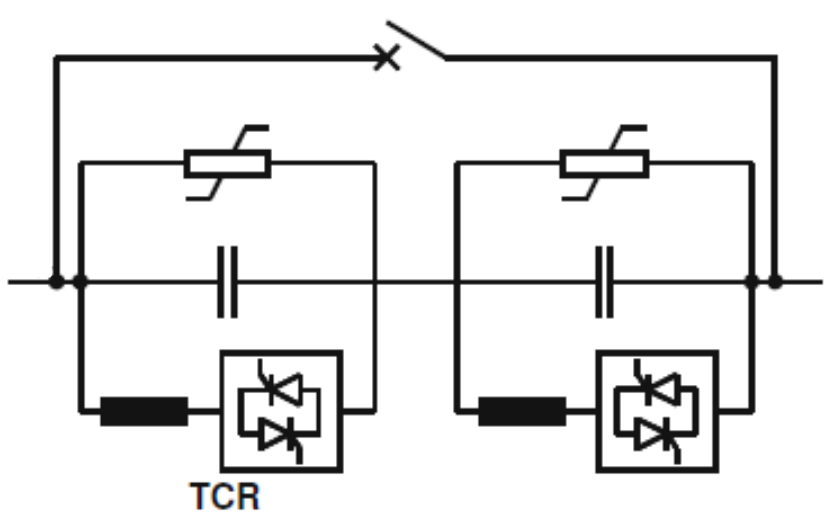

Fonte: (PAL; REHTANZ; ZHANG, 2006, p.17). 
- TCVR: Thyristor Controlled Voltage Regulator

O regulador de tensão controlado a tiristores pode realizar a variação da tensão controlada de modo contínuo. Pode ser implementado através de um transformador convencional com um comutador de tap controlado a tiristores ou através de um conversor AC-AC também controlado a tiristores.

- TCPAR :Thyristor Controlled Phase Angle Regulator

O regulador de ângulo de fase controlado a tiristores, assim como o transformador defasador convencional, realiza o controle do ângulo da tensão controlada, porém de modo contínuo.

- SSSC: Static Synchronous Series Compensator (Compensador Série Síncrono Estático)

Corresponde à compensação série capacitiva, porém com controles baseados em IGBTs (Insulated Gate Bipolar Transistor) do tipo fonte de tensão, possibilitando a variação contínua do fluxo de potência nas linhas de transmissão.

A aplicação dos dispositivos FACTS, iniciada a partir da década de 70 , tem encontrado grande aplicação atualmente em função da evolução dos dispositivos baseados em IGBTs do tipo fonte de tensão que proporcionam o recurso de auto restabelecimento ("black start"), sendo utilizados na conexão de fontes de geração renováveis. Apresentando tamanho reduzido em relação às instalações baseadas em tiristores, esta tecnologia tem encontrado aplicação nos conversores HVDC (High Voltage Direct Current) que realizam a integração das fontes de geração eólica, solar e biomassa. A integração de geração offshore através de conversores HVDC tipo VSC (Voltage Source Converters) também corresponde a um promissor mercado destes dispositivos (PAL; REHTANZ; ZHANG, 2006), além da sua usual utilização na contribuição à estabilidade e controle de oscilações no sistema de potência (PADIYAR, 2007). 


\subsection{Unified Power Flow Controller (UPFC)}

O conceito do Unified Power Flow Controller (UPFC) foi proposto em 1992 por L. Gyugyi.

O UPFC pode controlar em tempo real e com variação instantânea o fluxo de potência ativa, o fluxo de potência reativa e a tensão, que correspondem aos parâmetros básicos do sistema elétrico. Estes parâmetros são controlados de maneira independente, possibilitando uma grande flexibilidade no controle operativo do sistema no qual este equipamento está inserido (ARNEZ; ZANETTA, 2002).

O modelo simplificado de um sistema com duas máquinas apresentado na figura 8 com os respectivos fasores de tensão e gráficos de potência, pode ser utilizado para demonstrar a capacidade do UPFC para controle da potência ativa e reativa (GYUGYI, 1992; CIGRÉ TASK FORCE, 2000).

Figura 8 - Sistema simplificado com duas máquinas: (a) Sistema de duas máquinas; (b) fasores de tensão; (c) potência ativa e reativa x ângulo; (d) potência reativa x potência ativa.

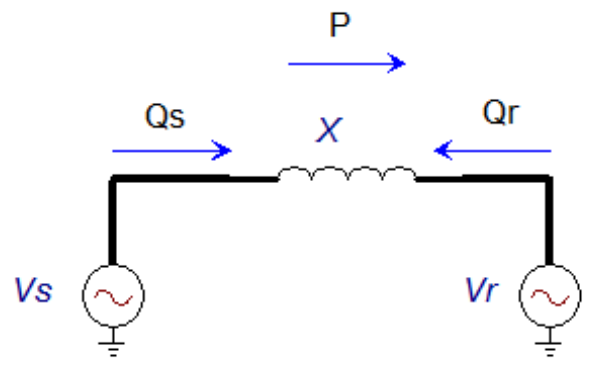

(a)

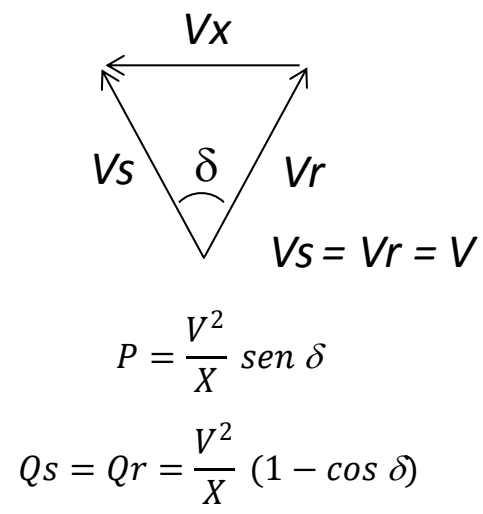

(c)



(b)

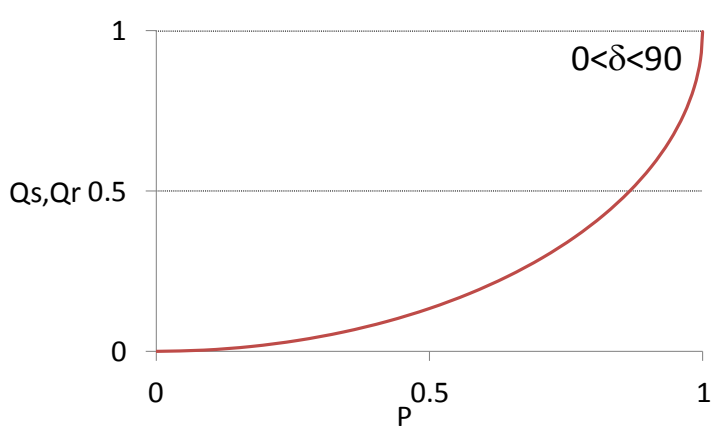

(d)

Fonte: (CIGRÉ TASK FORCE 14.27, 2000, p.22). 
O modelo simplificado mostra os limites de transmissão de potência ativa e reativa do sistema em função da variação do módulo das tensões $V_{s}$ e $V_{r}$, e do ângulo $\delta$, além da relação entre a transmissão de potência ativa e reativa.

Considerando agora a inclusão no sistema de uma fonte $V_{p q}$ cujo módulo da tensão varia de 0 a 0,5 pu e o ângulo $\rho$ de $0^{\circ}$ a $360^{\circ}$, apresentado na figura 9 :

Figura 9 - Sistema de duas máquinas com a fonte Vpq representando o UPFC

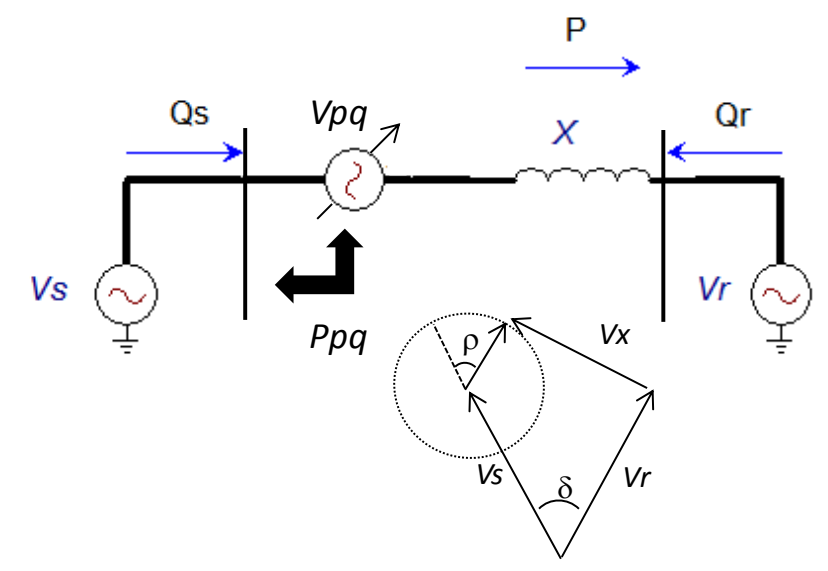

Fonte: (CIGRÉ TASK FORCE 14.27, 2000, p.23).

Nestas condições, a tensão aplicada no terminal da linha corresponde a $V_{s}+V_{p q}$, ou seja, variações no módulo e ângulo da tensão $V_{p q}$ alteram as potências ativa e reativa transmitidas pela linha representada através da impedância $X$.

Os gráficos da figura 10 mostram as regiões de controle do UPFC, representado pela fonte $V_{p q}$ com variação do módulo e ângulo da tensão série aplicada ao sistema. 
Figura 10 - Regiões de controle do sistema com o UPFC
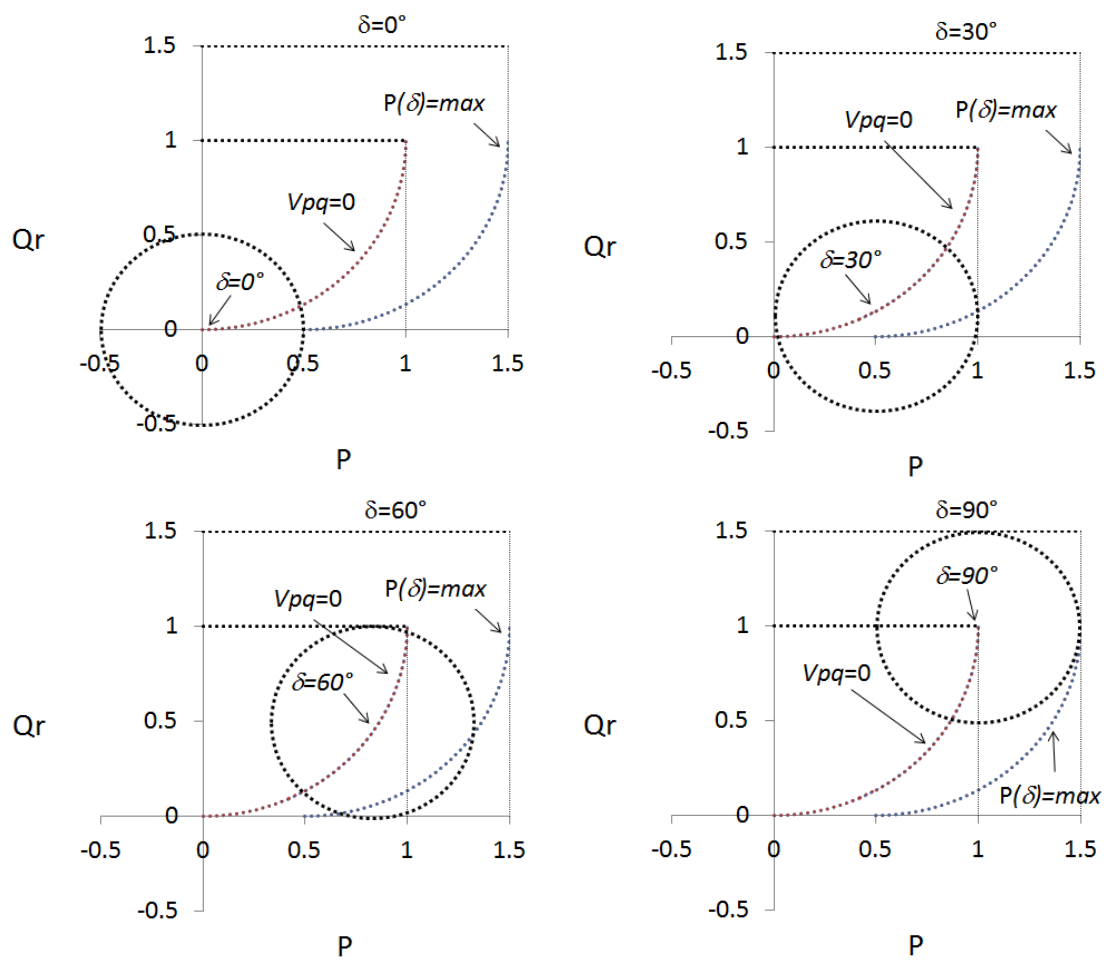

Fonte: (CIGRÉ TASK FORCE 14.27, 2000, p.24).

A área no interior dos círculos corresponde a possíveis pontos de operação do sistema para cada valor do ângulo $\delta$.

Observamos a ampliação dos possíveis pontos de operação quando comparado ao sistema sem a inserção da fonte de tensão $V_{p q}$, que corresponde às linhas pontilhadas nos gráficos.

Em 1992, quando da apresentação do conceito do UPFC (GYUGYI, 1992), também foi apresentada sua implementação através de dois conversores tipo fonte de tensão, acoplados através de um link CC (back-to-back). Estes conversores estariam conectados ao sistema através de dois transformadores, um em série e outro em derivação.

O método mais comumente utilizado para controle da tensão gerada pelos inversores é a técnica de modulação em largura de pulso.

O diagrama da figura 11 mostra a representação simplificada do UPFC com os conversores shunt e série conectados ao sistema através dos respectivos transformadores de acoplamento. 
Figura 11 - Diagrama esquemático do UPFC

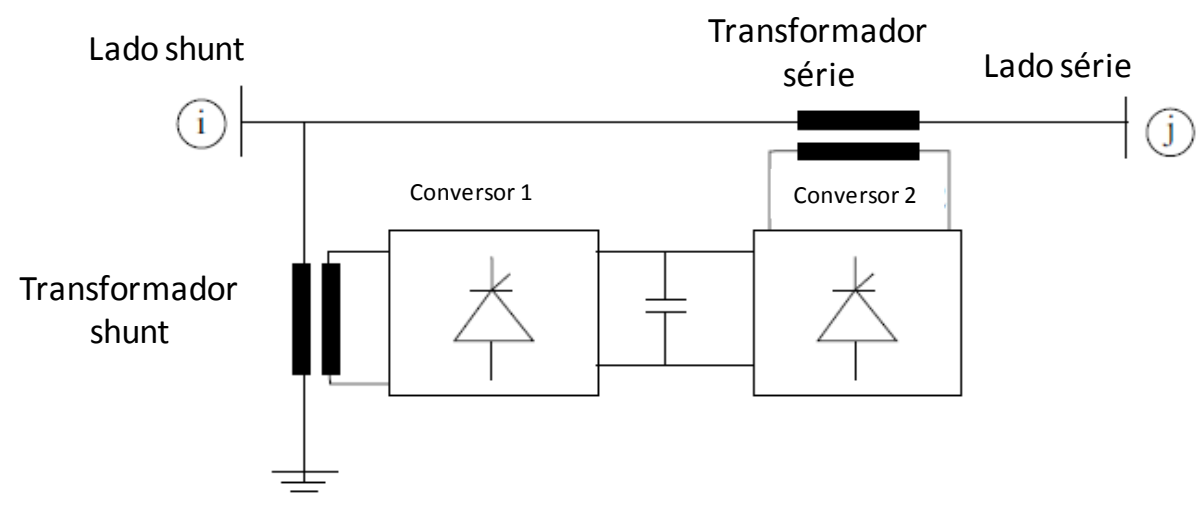

Fonte: (SADIKOVIC, 2003, p.2).

O ramo série do UPFC é responsável pelo controle do fluxo de potência ativa e reativa através da variação do módulo de ângulo da tensão gerada pelo conversor série e inserida no sistema através do transformador série. A potência ativa necessária para este conversor é fornecida pelo conversor shunt através do link CC, sendo absorvida pelo ramo shunt do UPFC.

Deste modo, com exceção das perdas nos transformadores de acoplamento e nos conversores, a potência ativa no ramo shunt é igual à potência ativa no ramo série do UPFC, sendo esta a principal relação entre as grandezas envolvidas neste equipamento FACTS.

O ramo shunt, além de fornecer a potência ativa ao conversor série, mantendo constante a tensão CC no capacitor de acoplamento, também absorve ou gera potência reativa, efetuando o controle de tensão na barra i de conexão do UPFC.

A operação do ramo shunt corresponde à característica de operação do STATCOM (SADIKOVIC, 2003).

\subsection{UPFC e Transformador Defasador}

Para ilustrar a operação do UPFC é apresentada a comparação deste dispositivo com o transformador defasador, equipamento utilizado no sistema elétrico para controle de fluxo de potência. 
Comparando a atuação do transformador defasador ao UPFC, observamos que o primeiro não possui a capacidade de elevar a máxima potência transmitida por determinada linha de transmissão ou realizar o controle independente entre os fluxos de potências ativa e reativa. O transformador defasador realiza a variação do fluxo de potência ativa, baseado nos ângulos entre as barras de entrada e saída, com a inserção de uma defasagem angular $\delta$ '.

Através do sistema de duas máquinas apresentado na figura 12 e respectivos gráficos de potência ativa e reativa para determinado ângulo $\delta$ de defasagem entre as tensões de entrada e saída, apresentados na figura 13, pode-se observar a diferença entre o intervalo e a região de controle do transformador defasador e do UPFC (CIGRÉ TASK FORCE, 2000).

Figura 12 -Sistema de duas máquinas com inserção de transformador defasador

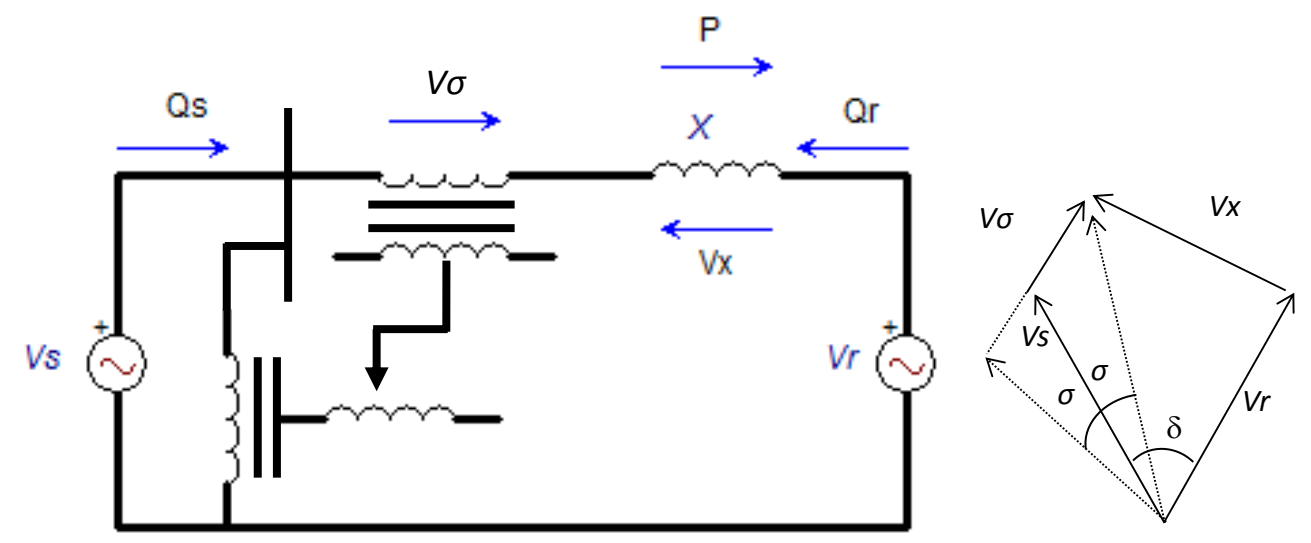

Fonte: (CIGRÉ TASK FORCE 14.27, 2000, p.18). 
Figura 13 -Regiões de controle do sistema para o transformador defasador e o UPFC
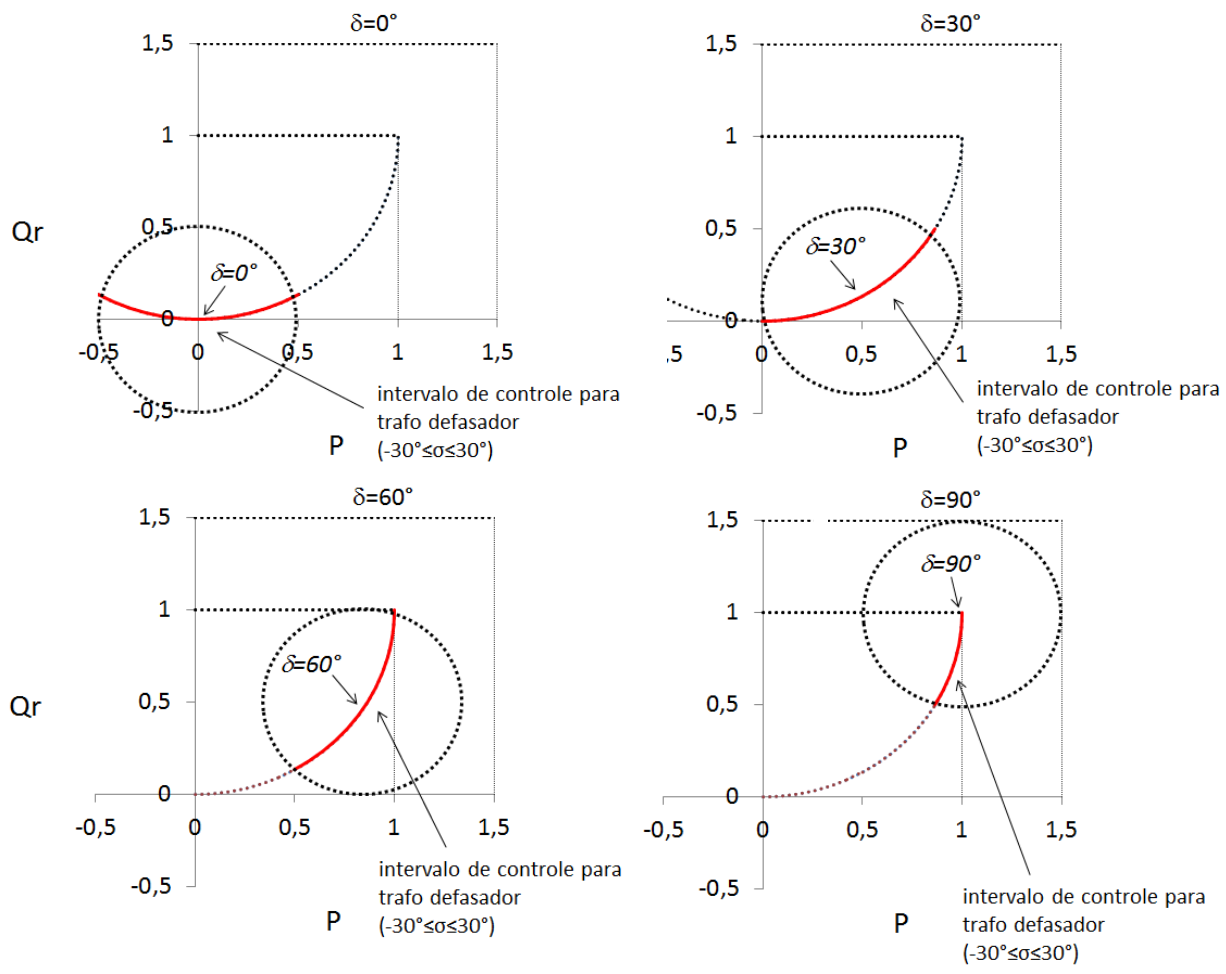

Fonte: (CIGRÉ TASK FORCE 14.27, 2000, p.19).

Na figura 13, a região de controle do transformador defasador corresponde à linha destacada em vermelho, enquanto a região de controle do UPFC corresponde à área interna ao círculo pontilhado.

\subsection{Interline Power Flow Controller (IPFC)}

O conceito do Interline Power Flow Controller (IPFC) foi proposto em 1999 por L. Gyugyi.

O objetivo do IPFC é o controle do fluxo de potência ativa e reativa para diferentes linhas de transmissão. Este equipamento FACTS é composto por conversores CC-AC responsáveis pelo controle de fluxo para cada linha, correspondendo a uma série de SSSCs (Static Synchronous Series Compensator). Os conversores são conectados através de um link CC que permite a transferência de potência, possibilitando a compensação série de potência ativa. A figura 14 
apresenta um diagrama esquemático do IPFC para compensação de múltiplas linhas de transmissão.

Figura 14 -Configuração do IPFC para compensação de 'n' linhas de transmissão

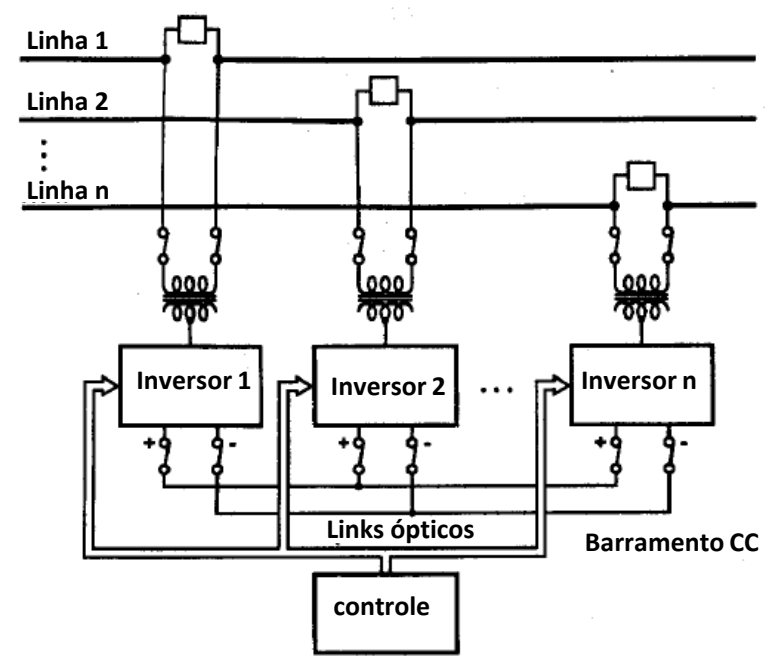

Fonte: (GYUGYI, SEN, SCHAUDER, 1999, p.1116).

O IPFC pode ser representado em regime permanente através de fontes de tensão em série com a impedância do transformador de acoplamento, assim como na representação apresentada por Noroozian (1997) para o UPFC. A figura 15 apresenta o modelo do tipo fonte de tensão para representação do IPFC.

Figura 15 -Modelo tipo fonte de tensão para o IPFC

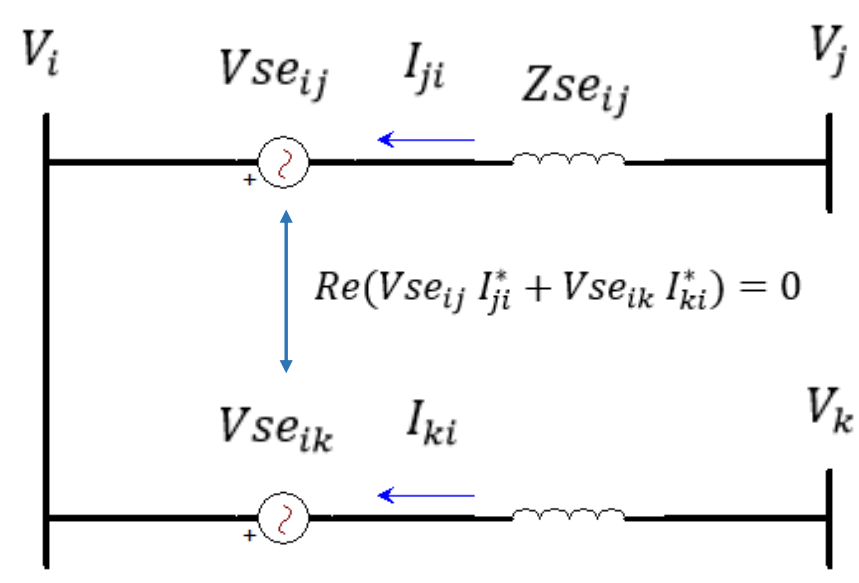

Fonte: (BABU et al, 2010, p.649). 


\subsection{Modelos do UPFC em regime permanente}

Em função do potencial de controle do UPFC sobre os parâmetros básicos do sistema elétrico, passaram a ser desenvolvidos modelos para sua representação em regime permanente, dinâmico, transitório e de controle, para simulação do impacto e resposta do UPFC quando inserido em grandes sistemas.

A seguir são apresentados alguns dos principais modelos desenvolvidos para representação do UPFC em regime permanente.

\subsubsection{Modelo com fonte de tensão síncrona}

Conforme representação de Gyugyi (1994) e citado por Acha e Fuerte-Esquivel (1997), desconsiderando as impedâncias dos transformadores de acoplamento, o UPFC pode ser modelado como uma fonte de tensão síncrona em série com a linha de transmissão. Este modelo é apresentado na figura 16.

Figura 16 - Modelo do UPFC como fonte de tensão inserida na linha de transmissão

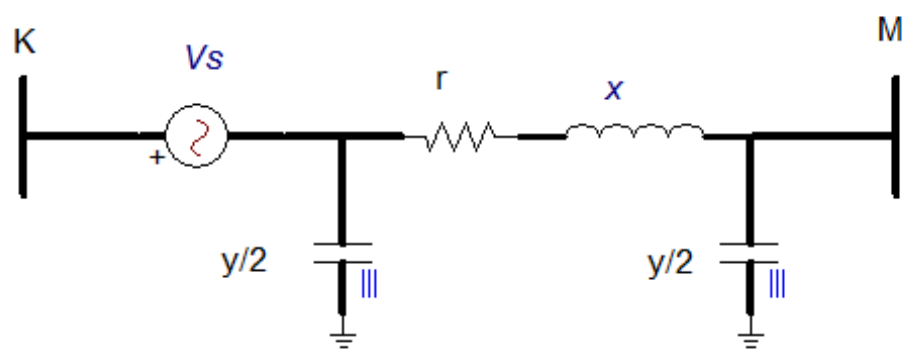

Fonte: (ACHA; FUERTE-ESQUIVEL, 1997, p.440).

Esta fonte em série com a linha de transmissão aplica uma tensão variável em módulo e ângulo. A variação destes parâmetros realiza o controle do fluxo de potência ativa e reativa na linha.

Entretanto, esta representação considera o conversor shunt operando com fator de potência unitário, sem contribuição de potência reativa, característica de um dos modos de operação do UPFC. 


\subsubsection{Modelo com barra de carga e gerador (PQ+PV)}

Em 1996, foi apresentado por Nabavi-Niaki e Iravani um dos primeiros modelos para simulação do UPFC em regime permanente e dinâmico.

Como já citado anteriormente, desprezando as perdas do UPFC, o equipamento não absorve ou gera potência para o sistema ao qual está conectado, conforme figura 17.

Figura 17 - Representação unifilar do UPFC

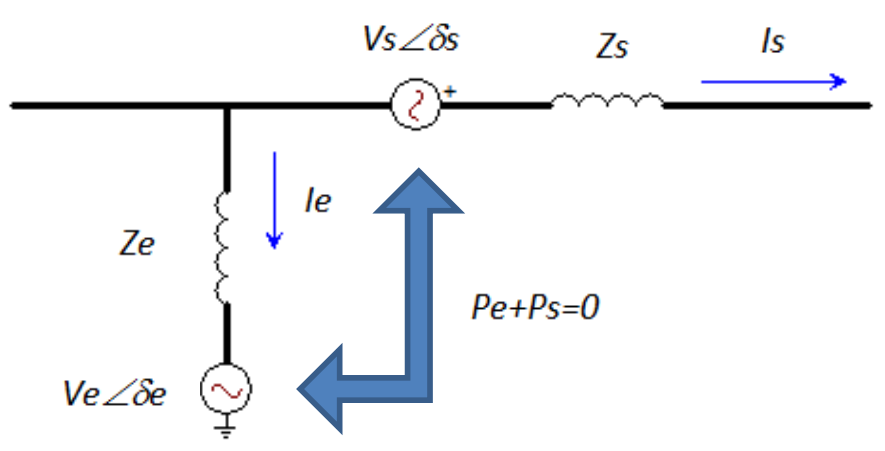

Fonte: (IRAVANI; NABAVI-NIAKI, 1996, p.1939).

Considerando que o UPFC opera no controle de tensão, fluxo de potência ativa e reativa de seu ponto de conexão, é proposto o modelo da figura 18 para os estudos em regime permanente:

Figura 18 - Modelo de UPFC (PQ-PV) proposto por Nabavi-Niaki e Iravani

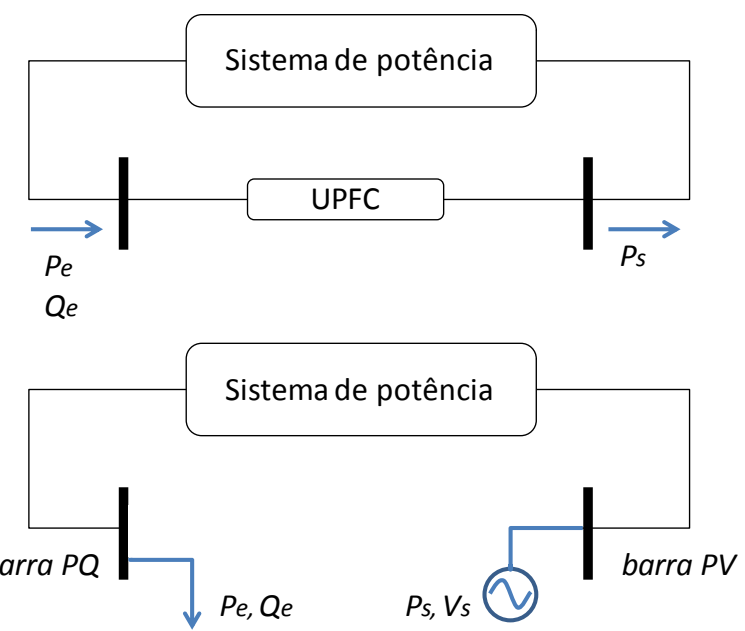

Fonte: (IRAVANI; NABAVI-NIAKI, 1996, p.1939). 
O modelo considera como barra de entrada do UPFC uma barra de carga do tipo $\mathrm{PQ}$, com carga de potência ativa $P e$ e potência reativa $Q e$, que corresponde à potência na linha controlada pelo UPFC. A barra de saída é adotada como sendo uma barra de geração do tipo PV, com injeção de potência ativa $P s$ e tensão $V s$.

Adotando a potência de carga $P e$ igual à potência de injeção $P s$, é mantida a relação de potências do UPFC ideal.

Este modelo, devido a sua simplicidade, apresenta restrições (ACHA, E.; FUERTE-ESQUIVEL, 1997), pois é válido somente nos casos em que o UPFC opera simultaneamente no controle de tensão, potência ativa e reativa. Caso o equipamento não esteja operando no controle de uma destas variáveis, o modelo passa a não ser válido. Também observa-se que este modelo desconecta as barras de entrada e saída do UPFC, podendo representar a separação de sistemas interligados.

\subsubsection{Modelo de injeção de potências (PIM - Power Injection Model)}

Em 1997, foi apresentado por Noroozian o modelo de injeção de potências para representação do UPFC em regime permanente.

Inicialmente, é considerado um conversor série conectado entre as barras $i$ e $j$,



Figura 19 - Representação do conversor série

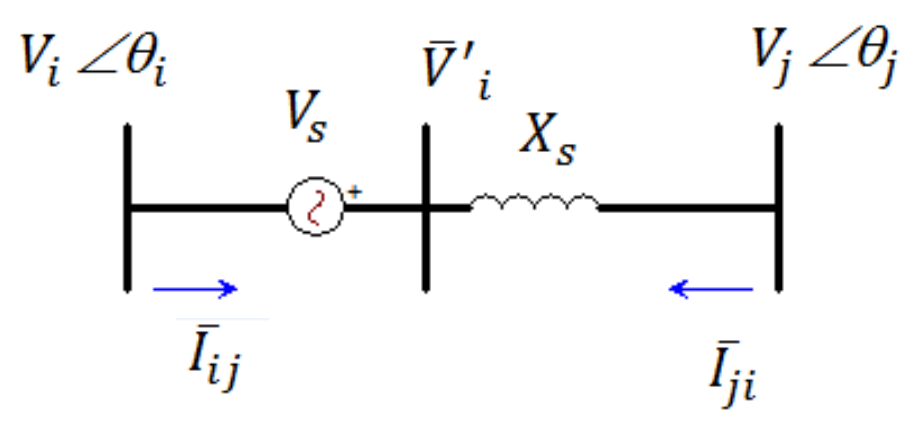

Fonte: (NOROOZIAN et al., 1997, p.1630). 
A fonte $V_{s}$ controla o ângulo e magnitude da tensão $\bar{V}_{i}^{\prime}$ :

$$
\bar{V}_{s}=r \bar{V}_{i} e^{j \gamma}
$$

Onde $r$ corresponde à variação de módulo da tensão série, com $0<r<r_{\max }$ e $\gamma$ representa a variação de ângulo com $0<\gamma<2 \pi$.

Substituindo a fonte de tensão $\bar{V}_{S}$ por uma fonte de corrente $\bar{I}_{S}$ em paralelo com a reatância $X$ s, temos a representação da figura 20:

Figura 20 - Substituição da fonte de tensão pela fonte de corrente

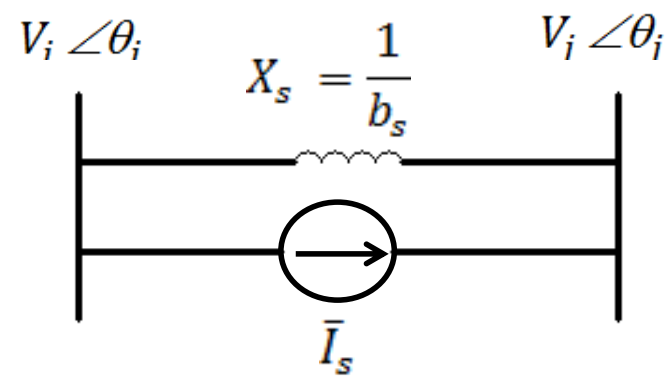

Fonte: (NOROOZIAN et al., 1997, p.1630).

$$
\bar{I}_{s}=-j \frac{\bar{V}_{s}}{\bar{X}_{S}}
$$

As potências nas barras $i$ e $j$ em função da fonte de corrente $\bar{I}_{S}$ são dadas por:

$$
\begin{gathered}
\bar{S}_{i s}=\bar{V}_{i}\left(-\bar{I}_{s}\right)^{*} \\
\bar{S}_{j s}=\bar{V}_{j}\left(\bar{I}_{s}\right)^{*}
\end{gathered}
$$

Substituindo $\bar{I}_{S}$, temos:

$$
\bar{S}_{i s}=\bar{V}_{i}\left[j \frac{1}{X s} r \bar{V}_{i} e^{j \eta}\right]^{*}=-\frac{1}{X s} r V_{i}^{2} \operatorname{sen} \gamma-\frac{1}{X s} r V_{i}^{2} \cos \gamma
$$


Considerando:

$$
\theta_{i j}=\theta_{i}-\theta_{j}
$$

Temos:

$$
S_{j s}=\bar{V}_{j}\left[-j \frac{1}{X S} r \bar{V}_{i} e^{j \gamma}\right]^{*}=\frac{1}{X S} r V_{i} V_{j} \operatorname{sen}\left(\theta_{i j}+\gamma\right)+j b_{s} r V_{i} V_{j} \cos \left(\theta_{i j}+\gamma\right)
$$

O conversor série pode ser representado pelo modelo da figura 21:

Figura 21 - Modelo de injeção de potências para o conversor série

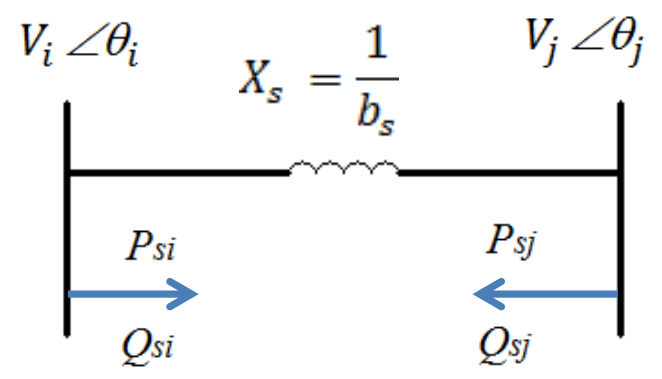

Fonte: (NOROOZIAN et al., 1997, p.1631).

Considerando que a potência ativa absorvida pelo conversor shunt é transferida ao conversor série através do link CC, temos:

$$
\begin{gathered}
P_{c o n v 1}=P_{c o n v 2} \\
S_{c o n v 2}=\bar{V}_{s}\left(\bar{I}_{i j}\right)^{*}=r e^{j \gamma} \bar{V}_{i}\left(\frac{\bar{V}_{i^{\prime}}-\bar{V}_{j^{\prime}}}{j x s}\right)^{*}
\end{gathered}
$$

As potências ativa e reativa fornecidas ao conversor série são dadas por:

$$
\begin{gathered}
P_{\text {conv } 2}=r \frac{1}{X s} V_{i} V_{j} \operatorname{sen}\left(\theta_{i}-\theta_{j}+\gamma\right)-r \frac{1}{X_{S}} V_{i}^{2} \operatorname{sen} \gamma \\
Q_{\text {conv } 2}=-r \frac{1}{X_{S}} V_{i} V_{j} \cos \left(\theta_{i}-\theta_{j}+\gamma\right)+r \frac{1}{X_{s}} V_{i}^{2} \cos \gamma+r^{2} b_{s} V_{i}^{2}
\end{gathered}
$$


Deste modo, o modelo de injeção de potências do UPFC é dado por:

$$
\begin{gathered}
P_{s i}=-P_{s j}=r \frac{1}{X S} V_{i} V_{j} \operatorname{sen}\left(\theta_{i}-\theta_{j}+\gamma\right) \\
Q_{s i}=r \frac{1}{X_{s}} V_{i}^{2} \cos \gamma \\
Q_{s j}=-r \frac{1}{X_{s}} V_{i} V_{j} \cos \left(\theta_{i}-\theta_{j}+\gamma\right)
\end{gathered}
$$

A figura 22 apresenta o modelo de injeção de potências do UPFC entre as barras $i$ e $j$ :

Figura 22 - Modelo de injeção de potências (PIM) do UPFC

$$
\begin{gathered}
V_{i} \angle \theta_{i} \quad X_{s}=\frac{1}{b_{s}} \quad V_{j} \angle \theta_{j} \\
P_{s i}=r \frac{1}{X s} V_{i} V_{j} \operatorname{sen}\left(\theta_{i j}+\gamma\right) \quad P_{s j}=-r \frac{1}{X s} V_{i} V_{j} \operatorname{sen}\left(\theta_{j i}+\gamma\right) \\
Q_{s i}=r \frac{1}{X_{s}} V_{i}{ }^{2} \cos \gamma \quad Q_{s j}=-r \frac{1}{X_{s}} V_{i} V_{j} \cos \left(\theta_{i j}+\gamma\right)
\end{gathered}
$$

Fonte: (NOROOZIAN et al., 1997, p.1631).

\subsubsection{Modelo de admitância shunt}

Um novo modelo derivado do modelo de injeção de potências foi apresentado em L'abbate et al. (2002), com a representação do UPFC através de admitâncias shunt e impedância série. A proposta deste modelo é apresentada através da representação do quadripolo equivalente da figura 23. 
Figura 23 - Modelo do UPFC através de admitâncias shunt

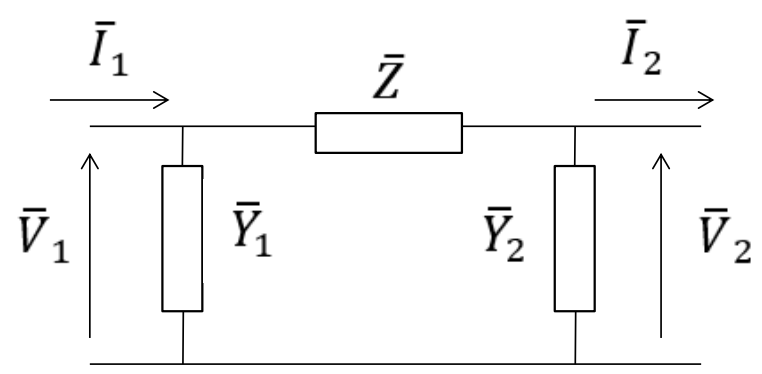

Fonte: (L'ABBATE et al., 2002).

Considerando a representação por quadripolos do modelo da Figura 23, temos sua representação na forma matricial:

$$
\left[\begin{array}{c}
\bar{V}_{2} \\
\bar{I}_{2}
\end{array}\right]=\left[\begin{array}{cc}
1+\bar{Z} \bar{Y}_{2} & \bar{Z} \\
\left(\bar{Y}_{1}+\bar{Y}_{2}+\bar{Y}_{1} \bar{Y}_{2} \bar{Z}\right) & 1+\bar{Z} \bar{Y}_{1}
\end{array}\right]\left[\begin{array}{c}
\bar{V}_{1} \\
\bar{I}_{1}
\end{array}\right]
$$

Sendo conhecidas as tensões e correntes na entrada e saída do UPFC, e $\bar{Z}$, que corresponde à reatância do transformador série, temos:

$$
\begin{gathered}
\bar{Y}_{2}=\frac{\bar{V}_{2}-\bar{V}_{1}-\bar{Z} \bar{I}_{1}}{\bar{V}_{1} \bar{Z}} \\
\bar{Y}_{1}=\frac{\bar{I}_{2}-\bar{V}_{1} \bar{Y}_{2}-\bar{I}_{1}}{\bar{V}_{1}+\bar{V}_{1} \bar{Y}_{2} \bar{Z}+\bar{I}_{1} \bar{Z}}
\end{gathered}
$$

Sendo possível definir os parâmetros do modelo de admitâncias shunt e impedância série.

\subsubsection{Modelo de transformador ideal e reatância shunt}

No trabalho Modeling of Power Electronics Equipment (FACTS) in Load Flow and Stability Programs (CIGRÉ, 1999), foi considerado como modelo aproximado do UPFC um transformador defasador com relação complexa representando o ramo série e uma barra do tipo PV como representação do ramo shunt, realizando o 
controle de tensão que pode ser efetuado pelo UPFC. Este modelo é apresentado na figura 24.

Figura 24 - Modelo do UPFC com transformador defasador e barra PV

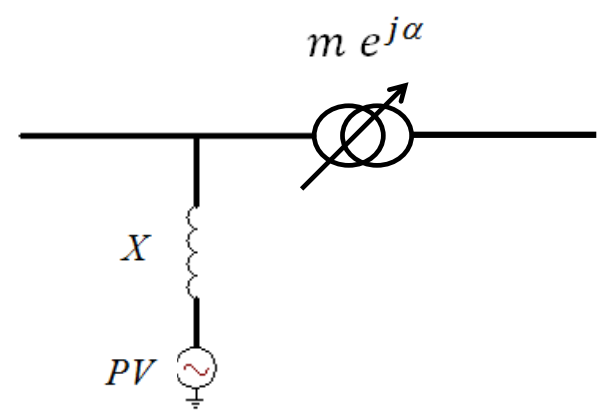

Fonte: (CIGRÈ TASK FORCE 38.01.08, 1999, p.75).

No modelo apresentado, o transformador ideal não gera ou absorve reativos, sendo esta uma das alternativas para operação do UPFC. Deste modo, para representação deste modo de controle, é citada a possibilidade de inclusão de um reator ou capacitor série.

O modelo com representação do ramo série do UPFC através do transformador defasador foi apresentado novamente em (AN; CONDREN; GEDRA, 2007), porém com a representação do ramo shunt através de uma reatância variável, conforme figura 25.

Figura 25 - Modelo do UPFC com transformador defasador e reatância variável

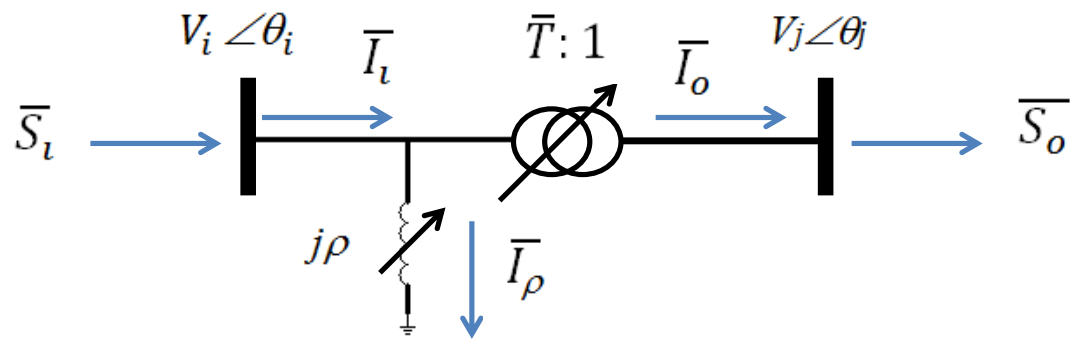

Fonte: (AN; CONDREN; GEDRA, 2007, p.70). 
Neste modelo, temos:

$T$ é a relação de transformação (real)

$\phi$ é a defasagem angular do transformador

$\rho$ é a susceptância shunt

A relação do transformador defasador ideal pode ser escrita:

$$
\bar{T}=T e^{j \phi}
$$

Como o transformador não gera ou absorve potência ativa ou reativa, e o ramo shunt gera ou absorve potência reativa, temos:

$$
\begin{gathered}
\bar{V}_{l}=\bar{V}_{o} T \angle \phi \\
\bar{I}_{l}=j \bar{T} \rho \bar{V}_{o}+\frac{1}{\bar{T}^{*}} \bar{I}_{o}
\end{gathered}
$$

Considerando a representação por quadripolos do modelo da Figura 17, temos na forma matricial:

$$
\left[\begin{array}{l}
\bar{V}_{l} \\
\bar{I}_{l}
\end{array}\right]=\left[\begin{array}{cc}
1 & 0 \\
j \rho & 1
\end{array}\right]\left[\begin{array}{cc}
\bar{T} & 0 \\
0 & 1 / \bar{T}^{*}
\end{array}\right]\left[\begin{array}{l}
\bar{V}_{o} \\
\bar{I}_{o}
\end{array}\right]
$$

Com a representação do quadripolo correspondente ao ramo shunt e transformador ideal.

$$
\left[\begin{array}{l}
\bar{V}_{l} \\
\bar{I}_{l}
\end{array}\right]=\left[\begin{array}{cc}
\bar{T} & 0 \\
j \rho \bar{T} & 1 / \bar{T}^{*}
\end{array}\right]\left[\begin{array}{l}
\bar{V}_{o} \\
\bar{I}_{o}
\end{array}\right]
$$

A potência na entrada do UPFC é dada por:

$$
\begin{gathered}
\bar{S}_{l}=\bar{V}_{l} \bar{I}_{l}^{*}=\bar{V}_{o} \bar{T}\left[j \bar{T} \rho \bar{V}_{o}+\frac{1}{\bar{T}^{*}} \bar{I}_{o}\right]^{*} \Rightarrow \\
\Rightarrow \bar{S}_{l}=\bar{V}_{o} \bar{I}_{o}^{*}-j\left|\bar{T}^{2}\right|\left|\bar{V}_{o}^{2}\right| \rho \Rightarrow
\end{gathered}
$$




$$
\Rightarrow \overline{S_{l}}=\overline{S_{o}}-j\left|\bar{T}^{2}\right|\left|{\overline{V_{o}}}^{2}\right| \rho
$$

Deste modo, a relação de potências na entrada e saída do UPFC é dada por:

$$
\begin{gathered}
P i=P o \\
Q o=Q i+\left|\bar{T}^{2}\right|\left|\bar{V}_{o}^{2}\right| \rho
\end{gathered}
$$

Ou seja, o modelo apresentado conserva potência ativa e consome ou gera potência reativa, correspondendo às relações no UPFC.

\subsection{UPFCs em operação}

O primeiro UPFC foi instalado no estado de Kentucky, nos Estados Unidos, em 1998, na subestação Inez da American Electric Power (AEP) (BIAN; J.NELSON, 1997). Este UPFC possui potência de 160 MVA e o projeto foi realizado em colaboração entre a AEP, Westighouse Electric Corporation e Electric Power Research Institute (EPRI), com a interligação entre uma nova fonte de $345 / 138 \mathrm{kV}$ à subestação de Inez, com o UPFC realizando o controle de fluxo de potência ativa, reativa e tensão para solucionar os problemas de baixos níveis de tensão e sobrecarga nas linhas de transmissão da região em condição de contingência no sistema elétrico da região. A figura 26 apresenta as instalações do UPFC de Inez. 
Figura 26 - Foto UPFC Inez

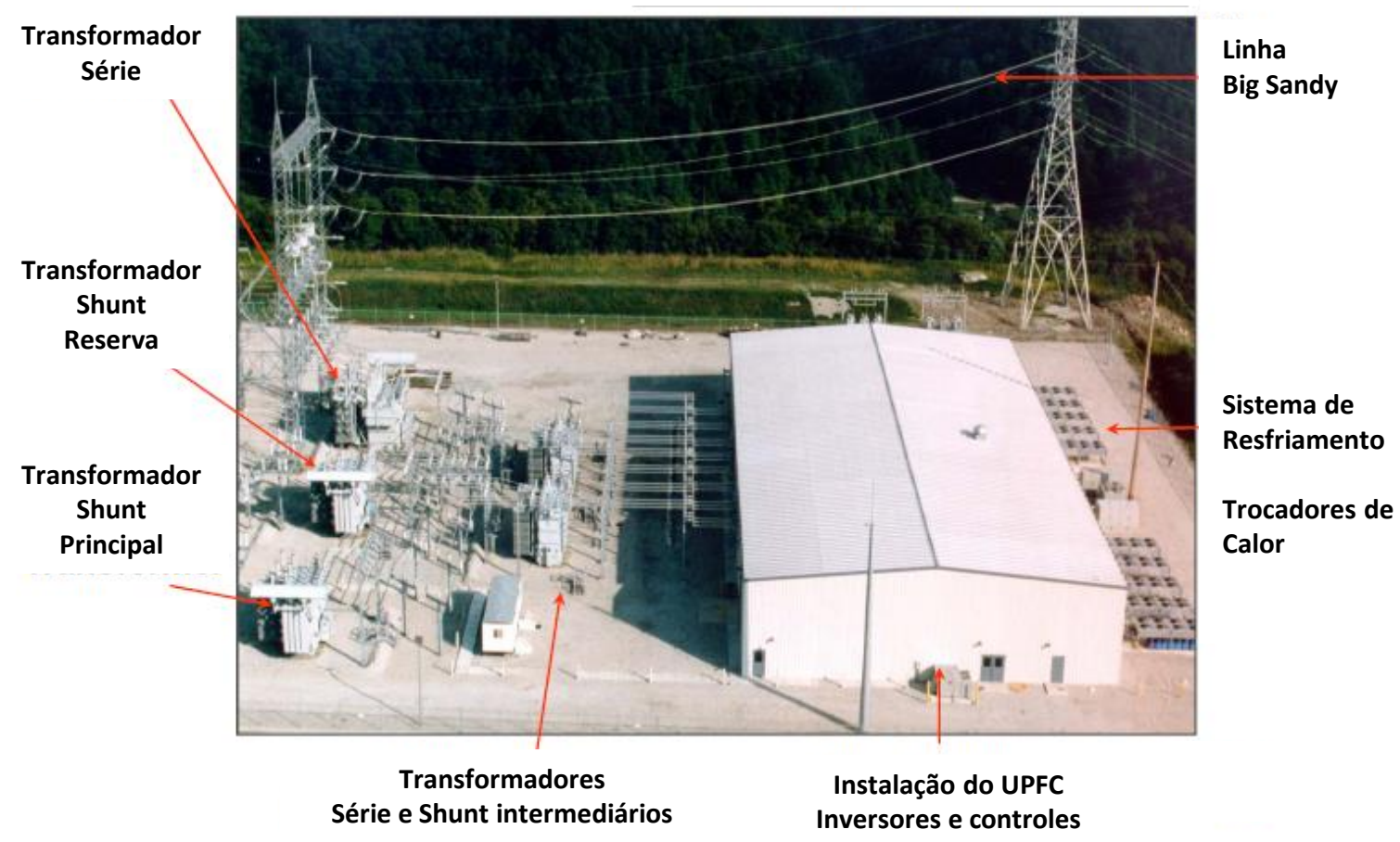

Fonte: (Satcon Technology Corporation).

A figura 27 apresenta os inversores do UPFC de Inez.

Figura 27 - Foto inversores UPFC Inez - GTO

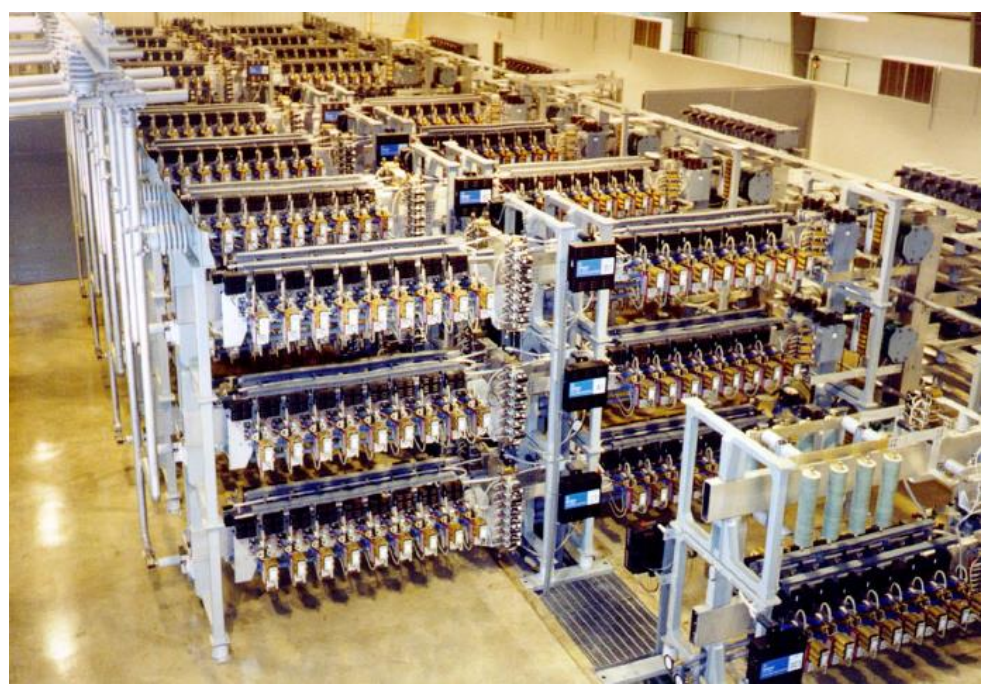

Fonte: (Satcon Technology Corporation). 
O segundo UPFC foi instalado em KangJin, na Coreia, em 2003, através de um projeto realizado pela Korean Electric Power Corporation (KEPCO), Hyosung Corporation e Siemens (B.H.CHANG et al., 2004), com o objetivo de solucionar os problemas de superação de equipamentos devido à elevação dos valores de corrente de curto-circuito, além dos problemas de estabilidade devido à larga expansão da geração. Outro aspecto considerado na proposta de aplicação do UPFC, estava associado à dificuldade de expansão do sistema de transmissão em função das questões ambientais para construção de novas instalações no sistema elétrico. Este UPFC possui potência de 80 MVA. A figura 28 apresenta o diagrama do sistema elétrico da Coréia e ponto de instalação do UPFC de KangJin.

Figura 28 - Diagrama do sistema da Coreia e ponto de instalação do UPFC



Fonte: (B.H.CHANG et al., 2004, p.2).

Em 2001, entrou em operação o Convertible Static Compensator (CSC) com potência de 100 MVA, instalado na subestação Marcy em Nova lorque, projeto da New York Power Authority (NYPA), EPRI (e Siemens (SIEMENS, 2001). O CSC, através de chaveamentos e mudança na configuração de conexão, pode operar como quatro diferentes dispositivos FACTS: STATCOM, SSSC, UPFC ou IPFC. 
A figura 29 apresenta o diagrama unifilar do CSC de Marcy com as chaves que possibilitam a mudança de configuração.

Figura 29 - Diagrama unifilar do CSC em Nova lorque

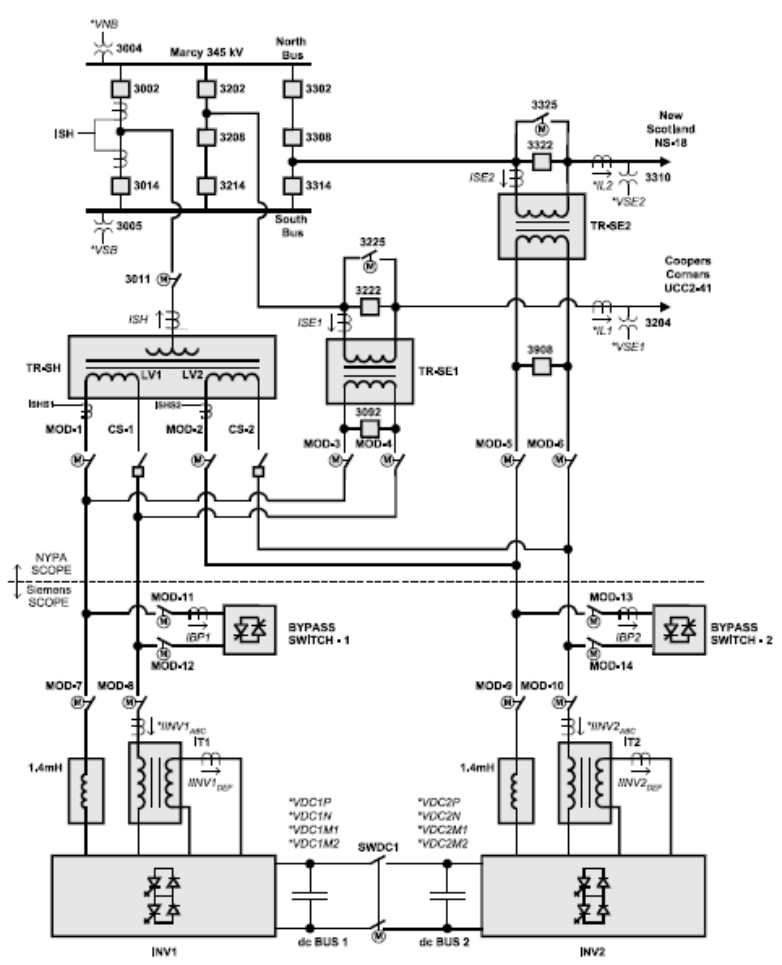

Fonte: (SIEMENS, 2001, p.2-3).

A figura 30 apresenta as instalações do CSC de Marcy.

Figura 30 - Foto CSC em Nova lorque

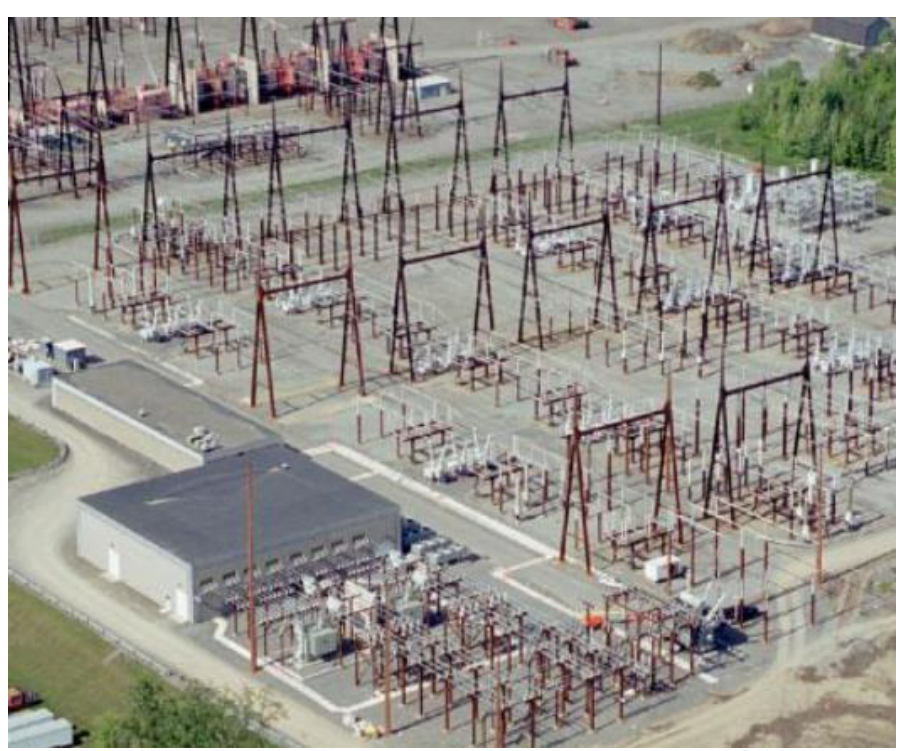

Fonte: (Worcester Polytechnic Institute). 


\subsection{Custos associados aos dispositivos FACTS}

Uma restrição à aplicação dos dispositivos FACTS nos sistemas elétricos está associada ao elevado custo apresentado por estes equipamentos quando comparados aos equipamentos convencionais.

Os custos dos dispositivos FACTS, associados à infraestrutura necessária e equipamentos para sua instalação, podem ser estimados com base nas curvas das Figuras 31 e 32, onde o limite inferior das áreas representadas corresponde aos custos dos equipamentos, e o limite superior corresponde ao custo total, somado ao custo de equipamentos o custo da infraestrutura necessária para instalação (HABUR; O'LEARY).

Figura 31 - Estimativa de custos para SVC e Statcom



Fonte: (Siemens AG Database).

Figura 32 - Estimativa de custos para Capacitor Série (FSC), TCSC e UPFC 


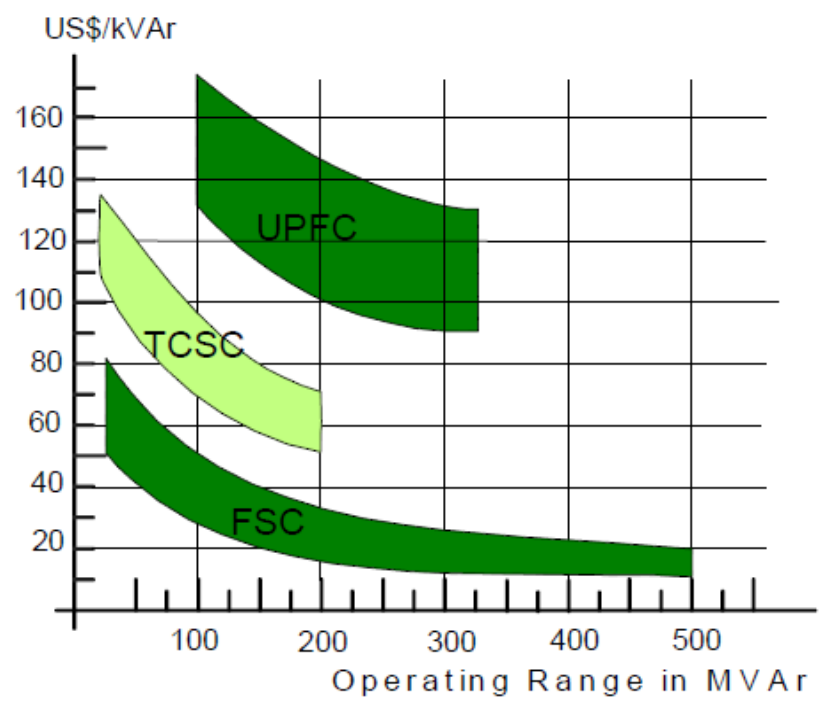

Fonte: (Siemens AG Database).

Esta estimativa de custos não considera taxas e impostos, itens específicos de cada país, ocasionando uma variação de $-10 \%$ a $+30 \%$ no investimento total.

Para o UPFC, os custos correspondentes à curva superior do gráfico podem ser calculados pela fórmula (SOOD; TIWARI, 2011):

$$
C_{U P F C}=0.0003 S_{U P F C}^{2}-0.2691 S_{U P F C}+188.22\left[\frac{\$}{k V a r}\right]
$$

Onde:

$$
S_{U P F C}=\text { range do } U P F C=Q_{\max }-Q_{\min }
$$

Os custos apresentados, apesar de estimados, dão a ordem de grandeza dos investimentos necessários para instalação de dispositivos FACTS e sua relação com a potência destes equipamentos. 


\section{ANÁLISE DE MODELOS DO UPFC PARA SIMULAÇÃO EM REGIME PERMANENTE}

Considerando os modelos propostos para representação do UPFC em regime permanente, observamos que o modelo com fonte de tensão síncrona e modelo com barra de carga e gerador, apesar de suas facilidades para inserção nas simulações do sistema elétrico a ser analisado, não consegue representar todos os modos de operação do UPFC. Estes modos correspondem ao controle de tensão, fluxo de potência ativa e fluxo de potência reativa de maneira independente.

O modelo com fonte de tensão síncrona (GYUGYI, 1994) não representa a contribuição do ramo shunt à operação do UPFC, enquanto o modelo com barra de carga e gerador (IRAVANI; NABAVI-NIAKI, 1996) não possibilita representar o UPFC com o modo de controle de tensão, potência ativa ou potência reativa desabilitados. Neste modelo ainda existe a questão associada à separação das barras de entrada e saída do UPFC, que desconecta partes do sistema em análise, podendo provocar a não convergência do caso de fluxo de potência, além de não representar a influência do sistema ao qual está conectado na operação do UPFC.

A representação do UPFC através do modelo de injeção de potências (NOROOZIAN, 1997) é a mais utilizada para inserção em algoritmos de cálculo. Este modelo exige a execução de um processo iterativo para obtenção das potências, com base nas tensões das barras de entrada $\left(\bar{V}_{i}\right)$ e saída $\left(\bar{V}_{j}\right)$ do UPFC, além da tensão na barra intermediária, conforme descrição do item 2.5.3.

O modelo de transformador ideal e reatância shunt variável apresentado em An, Condren e Gedra (2007) corresponde ao modelo que pode ser utilizado com maior facilidade em programas de simulação comerciais, pois a representação do UPFC é realizada a partir de componentes normalmente existentes nestes programas (transformador e reatância).

Deste modo, com o objetivo de avaliar a aplicação dos modelos em regime permanente do UPFC em um software de fluxo de potência comercial, foram avaliados os modelos propostos na literatura para representação deste equipamento. 


\subsection{Modelo de Transformador Defasador e Compensador Estático (PST - Phase Shifter Transformer + SVC - Static Var Compensator)}

Baseado no modelo do UPFC com representação do ramo série através do transformador defasador ideal e do ramo shunt através de uma reatância variável, foi considerada a inserção da reatância do transformador série $x$, sendo realizado o equacionamento através da representação do quadripolo correspondente:

$$
\left[\begin{array}{l}
\bar{V}_{l} \\
\bar{I}_{l}
\end{array}\right]=\left[\begin{array}{cc}
1 & 0 \\
j \rho & 1
\end{array}\right]\left[\begin{array}{cc}
\bar{T} & 0 \\
0 & 1 / \bar{T}^{*}
\end{array}\right]\left[\begin{array}{cc}
1 & j x \\
0 & 1
\end{array}\right]\left[\begin{array}{l}
\bar{V}_{o} \\
\bar{I}_{o}
\end{array}\right]
$$

A figura 33 apresenta o modelo do UPFC proposto.

Figura 33 - Modelo do UPFC com transformador defasador com a respectiva reatância, e reatância shunt variável

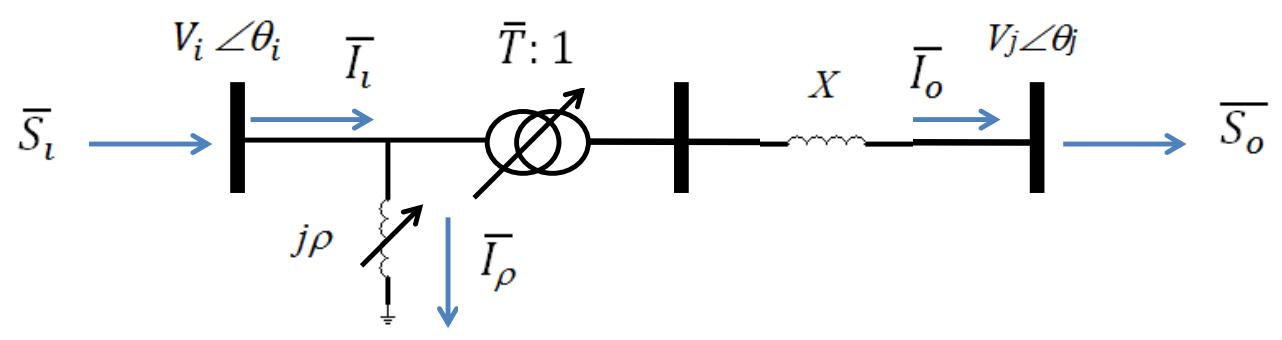

Fonte: Autor.

Desenvolvendo as equações, obtemos:

$$
\begin{gathered}
{\left[\begin{array}{l}
\bar{V}_{l} \\
\bar{I}_{l}
\end{array}\right]=\left[\begin{array}{cc}
\bar{T} & 0 \\
j \rho \bar{T} & 1 / \bar{T}^{*}
\end{array}\right]\left[\begin{array}{cc}
1 & j x \\
0 & 1
\end{array}\right]\left[\begin{array}{l}
\bar{V}_{o} \\
\bar{I}_{o}
\end{array}\right]} \\
{\left[\begin{array}{c}
\bar{V}_{l} \\
\bar{I}_{l}
\end{array}\right]=\left[\begin{array}{cc}
\bar{T} & j x \bar{T} \\
j \rho \bar{T} & -\rho x \bar{T}+(1 / \bar{T})
\end{array}\right]\left[\begin{array}{l}
\bar{V}_{o} \\
\bar{I}_{o}
\end{array}\right]} \\
\bar{V}_{l}=\bar{V}_{o} \bar{T}+j x \bar{T} \bar{I}_{o}
\end{gathered}
$$




$$
\overline{I_{l}}=j \rho \bar{T} \overline{V_{o}}+\overline{I_{o}}\left(-\rho x \bar{T}+\left(\frac{1}{\bar{T}^{*}}\right)\right)
$$

A potência na entrada do UPFC será dada por:

$$
\begin{aligned}
& \bar{S}_{l}=\bar{V}_{l} \bar{I}_{l}^{*}=\left(\overline{V_{o}} \bar{T}+j x \bar{T} \overline{I_{o}}\right)\left(j \rho \bar{T} \overline{V_{o}}-\rho x \bar{T} \overline{I_{o}}+\frac{{\overline{I_{o}}}_{\bar{T}^{*}}}{\bar{T}^{*}}\right. \\
& \Rightarrow \bar{S}_{i}=\left(\bar{V}_{o} \bar{T}+j x \bar{T} \bar{I}_{o}\right)\left(-j \rho \bar{T}^{*} \bar{V}_{o}^{*}-\rho x \bar{T}^{*} \bar{I}_{o}^{*}+\frac{\bar{I}_{o}^{*}}{\bar{T}}\right) \Rightarrow \\
& \Rightarrow \bar{S}_{i}=\bar{V}_{o} \bar{T}\left(-j \rho \bar{T}^{*} \bar{V}_{o}^{*}\right)+\bar{V}_{o} \bar{T}\left(-\rho x \bar{T}^{*} \bar{I}_{o}{ }^{*}\right)+\bar{V}_{o} \bar{T}\left(\frac{\bar{I}_{o}^{*}}{\bar{T}}\right)+ \\
& j x \bar{T} \overline{I_{o}}\left(-j \rho \bar{T}^{*} \bar{V}_{o}^{*}\right)+j x \bar{T} \overline{I_{o}}\left(-\rho x \bar{T}^{*}{\overline{I_{o}}}^{*}\right)+j x \bar{T} \overline{I_{o}}\left(\frac{\bar{I}_{o}^{*}}{\bar{T}}\right) \Rightarrow \\
& \Rightarrow \bar{S}_{i}=\bar{V}_{o}{\overline{I_{o}}}^{*}+\rho x|\bar{T}|^{2}\left(\bar{V}_{o}^{*} \bar{I}_{o}-\bar{V}_{o}{\overline{I_{o}}}^{*}\right) \\
& +j\left(-\rho\left|\overline{V_{o}}\right|^{2}|\bar{T}|^{2}-\left(\rho x^{2}|\bar{T}|^{2}\left|\bar{I}_{o}\right|^{2}\right)+\left(x\left|\overline{I_{o}}\right|^{2}\right)\right)
\end{aligned}
$$

Observamos que o modelo conserva potência ativa e consome ou gera potência reativa, conforme relações do UPFC.

A representação deste modelo do UPFC em um programa de fluxo de potência comercial pode ser realizada através da utilização de um transformador com defasagem angular (PST) em série com uma reatância representando o ramo série, e um compensador estático de reativos (SVC) conectado à barra de entrada do UPFC.

A inserção da impedância entre o transformador e a barra de saída, possibilita também obter, a partir dos resultados do cálculo de fluxo de potência, todos os parâmetros necessários para o cálculo das potências do modelo de injeção de potências.

A reatância $x$, corresponde à reatância vista pelos terminais do transformador série, cujo valor é dado por (AHMADNIA et al., 2012):

$$
x=x_{k} r_{\max }^{2}\left(\frac{S_{b}}{S_{s}}\right)
$$

Onde:

$x_{k}=$ reatância do transformador série (na potência nominal do conversor série) 
$r_{\max }=$ máximo valor do módulo da tensão série (conforme modelo de injeção de potências)

$S_{b}=$ base de potência

$S_{s}=$ potência nominal do conversor série

\subsection{Simulações utilizando os modelos de UPFC em regime permanente}

O programa de Análise de Redes Elétricas (ANAREDE) compõe o pacote de programas do CEPEL (Centro de Pesquisas de Energia Elétrica). Este pacote corresponde aos programas utilizados para estudos e análises no Sistema Interligado Nacional (SIN), sendo adotado pelos diversos agentes do setor elétrico brasileiro (geradores, transmissoras e distribuidoras).

O programa ANAREDE possui diversos modelos de equipamentos, tais como geradores, transformadores, linhas de transmissão, barramentos, cargas, etc.

Dentre os dispositivos FACTS, o programa possui modelos para compensadores estáticos (SVC - Static Var Compensator), compensadores série controláveis (SSSC) e representação de HVDC através de retificadores e inversores.

Considerando as funcionalidades do programa ANAREDE, o modelo com barra de carga e gerador (PQ+PV) (IRAVANI; NABAVI-NIAKI, 1996) (que representa 0 UPFC através de uma barra de carga do tipo $P Q$ na entrada e a barra de saída como sendo uma barra de geração do tipo PV) e o modelo de injeção de potências (PIM) (NOROOZIAN et al., 1997) (representando o UPFC através da injeção de potências ativa e reativa nas barras de entrada e saída, conectadas através da reatância do transformador série) correspondem a representações simplificadas, facilmente inseridas nas simulações. Entretanto, o modelo de injeção de potências apresenta dificuldades para representação direta, que corresponde ao ajuste desejado nos casos de simulação, sendo necessário um processo iterativo para cálculo dos valores que representem o ponto de operação desejado.

Considerando o modelo do UPFC representado através de um transformador com defasagem angular (PST) em série com uma reatância representando o ramo série e um compensador estático de reativos (SVC) conectado à barra de entrada do UPFC, observamos a facilidade de representação deste modelo no programa 
ANAREDE, devido à existência do modelo para transformador defasador e seus respectivos controles. O modelo de transformador defasador no ANAREDE permite definir o controle por corrente ou potência, com variação automática de fase para o valor do parâmetro especificado, ou fixação do ângulo de defasagem.

O programa possui também um modelo para o compensador estático de reativos (SVC) com sua característica de controle que permite definir a tensão da barra controlada, com controle por potência reativa ou corrente e respectiva inclinação da curva de resposta.

Deste modo, o modelo simplificado do UPFC pode ser representado através da utilização dos componentes já existentes, conforme diagrama da figura 34.

Figura 34 - Modelo do UPFC com transformador defasador, impedância série e SVC (PST+SVC)

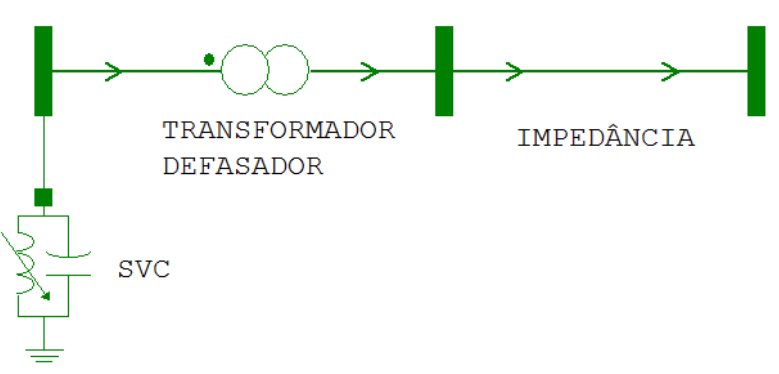

Fonte: Autor.

Os modelos de injeção de potências (PIM) (NOROOZIAN, 1997) e com barra de carga e gerador (PQ+PV) (IRAVANI; NABAVI-NIAKI, 1996), também podem ser facilmente representados, conforme figuras 35 e 36 , considerando as restrições descritas anteriormente.

Figura 35 - Modelo de injeção de potências (PIM) do UPFC

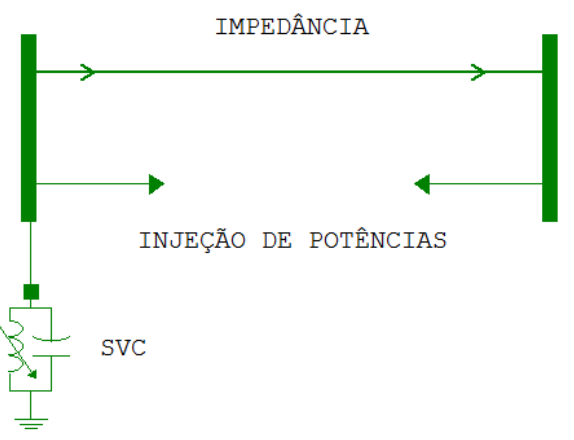

Fonte: Autor. 
As barra podem ser definidas como tipo PQ com especificação das potências ativa e reativa, ou do tipo PV com definição também da tensão na barra.

Figura 36 - Modelo com barra de carga e gerador (PQ+PV) do UPFC

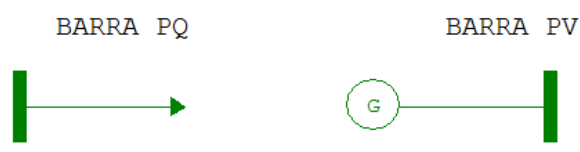

Fonte: Autor.

Utilizando a base de dados de fluxo de potência do Sistema Interligado Nacional, disponível no formato do programa ANAREDE, foram realizadas simulações para representação do UPFC, utilizando o modelo (PST+SVC) e o modelo (PIM).

Inicialmente, foram realizadas simulações com o modelo (PST+SVC), com ajuste de tensão e fluxo de potências na linha de transmissão em análise, utilizando os controles de transformador defasador e SVC disponíveis no ANAREDE, sem a necessidade de um processo iterativo para obtenção das potências representadas nas barras de entrada e saída, caso fosse utilizado o modelo de injeção de potências (PIM).

A partir dos resultados obtidos com o modelo (PST+SVC), foram calculados os parâmetros para o modelo de injeção de potências (PIM), conforme equações apresentadas no item 2.5.3.

O modelo (PST+SVC) foi então substituído pelo modelo (PIM) sendo realizado o cálculo de fluxo de potência para comparação de resultados com a utilização destes dois modelos.

Foi simulada a inserção do UPFC em diversos pontos de um sistema de $138 \mathrm{kV}$, caracterizado pela presença de geração distribuída a biomassa, que corresponde às UTEs (Usinas Termelétricas) e hidráulica, correspondendo às PCHs (Pequenas Centrais Hidrelétricas). Este sistema realiza a conexão entre diferentes pontos de fronteira com a Rede Básica do Sistema Interligado Nacional.

Abaixo são apresentados dois casos de simulação e repectivos resultados de tensões e fluxos de potência nas barras de entrada e saída do UPFC (com inclusão da barra intermediária no caso do modelo PST+SVC). 
A figura 37 corresponde ao diagrama unifilar simplificado do sistema de $138 \mathrm{kV}$ analisado, com a inserção do UPFC no quarto circuito das linhas que interligam a subestação 1 à subestação 2. Esta interligação é composta de outros três circuitos. Conectada à subestação 1, temos uma usina hidrelétrica (UHE), cuja geração é transmitida ao sistema através das linhas entre a subestação 4 e as subestações 5 e 14.

Figura 37 - Caso 1: Diagrama unifilar simplificado do sistema de 138 kV com inserção do UPFC entre as subestações 4 e 5

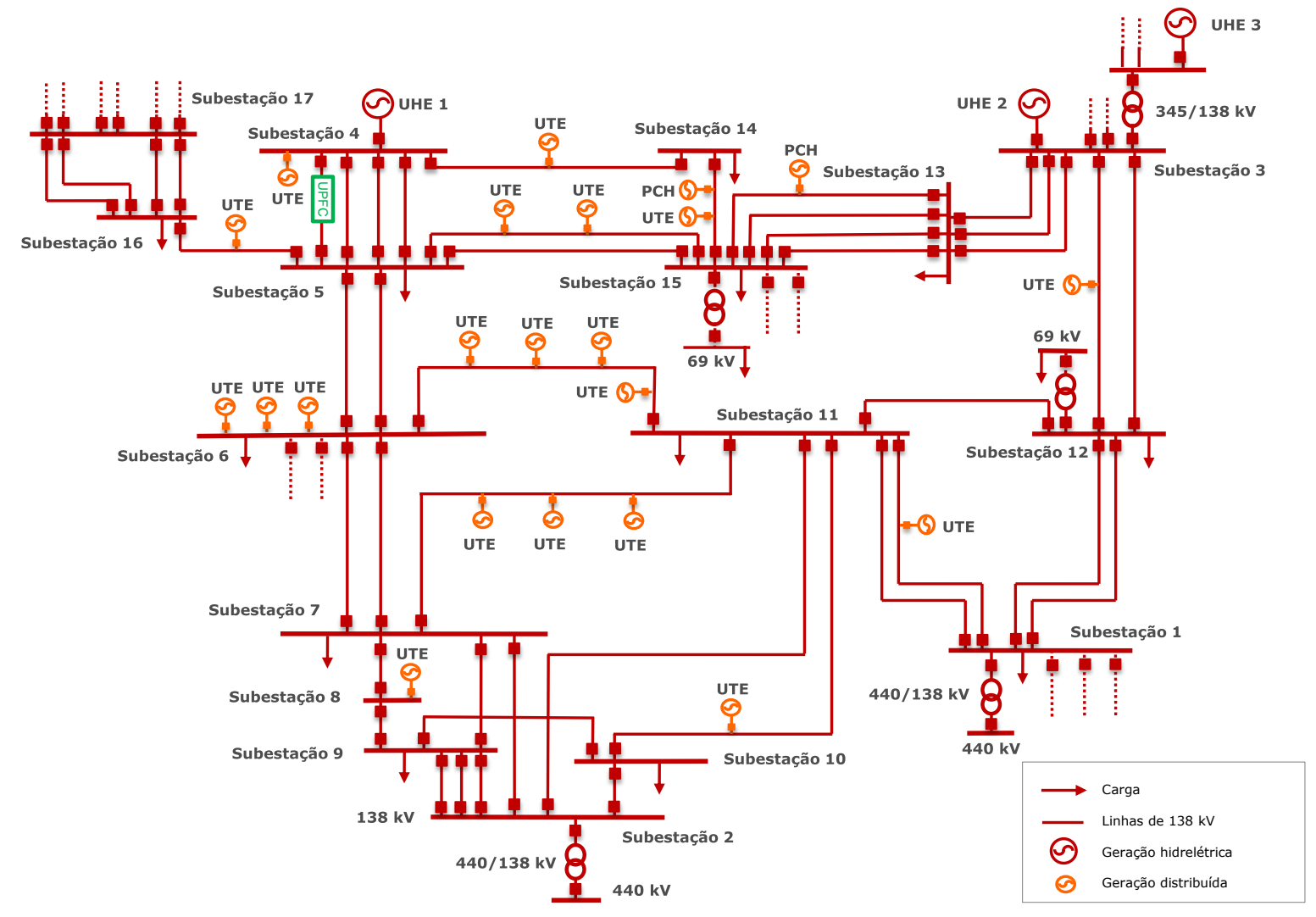

Fonte: Autor.

A tabela 2 apresenta os resultados de tensão nas barras de entrada e saída do UPFC localizado em um dos circuitos que interligam as subestações 4 e 5 , além dos fluxos de potência ativa e reativa para os dois modelos considerados. Foi adotada, para as potências, a representação utilizada no ANAREDE, com sinal positivo para potências saindo da barra e sinal negativo para potências entrando na barra em análise. Também são apresentados para cada modelo, o número de iterações para convergência do caso de fluxo de potência após a inclusão do modelo do UPFC no sistema. 
Tabela 2 - Caso 1: Resultados de simulação dos modelos de UPFC no ANAREDE com inserção do UPFC entre as subestações 4 e 5

\begin{tabular}{|c|c|c|c|c|c|c|c|}
\hline & qtde. de iterações & barra & tensão [pu] & ângulo [graus] & fluxo ativo [MW] & fluxo reativo [Mvar] & SVC (Mvar) \\
\hline \multirow{3}{*}{ Modelo (PST+SVC) } & \multirow{3}{*}{26} & entrada & 1.049 & -34.1 & -142.0 & 111.1 & 87.6 \\
\hline & & intermediária & 0.954 & -24.1 & -142.0 & 23.5 & - \\
\hline & & saída & 0.959 & -25.9 & 142.0 & -28.4 & - \\
\hline \multirow{3}{*}{ Modelo (PIM) } & \multirow{3}{*}{26} & entrada & 1.049 & -34.0 & -141.7 & 110.9 & 57.2 \\
\hline & & intermediária & - & - & - & - & - \\
\hline & & saída & 0.960 & -25.9 & 142.6 & -28.0 & - \\
\hline
\end{tabular}

A figura 38 apresenta o diagrama de simulação no ANAREDE com o caso $1 \mathrm{e}$ resultados utilizando os modelos (PST+SVC) e (PIM).

Figura 38 - Caso 1: Diagrama de simulação com os modelos analisados

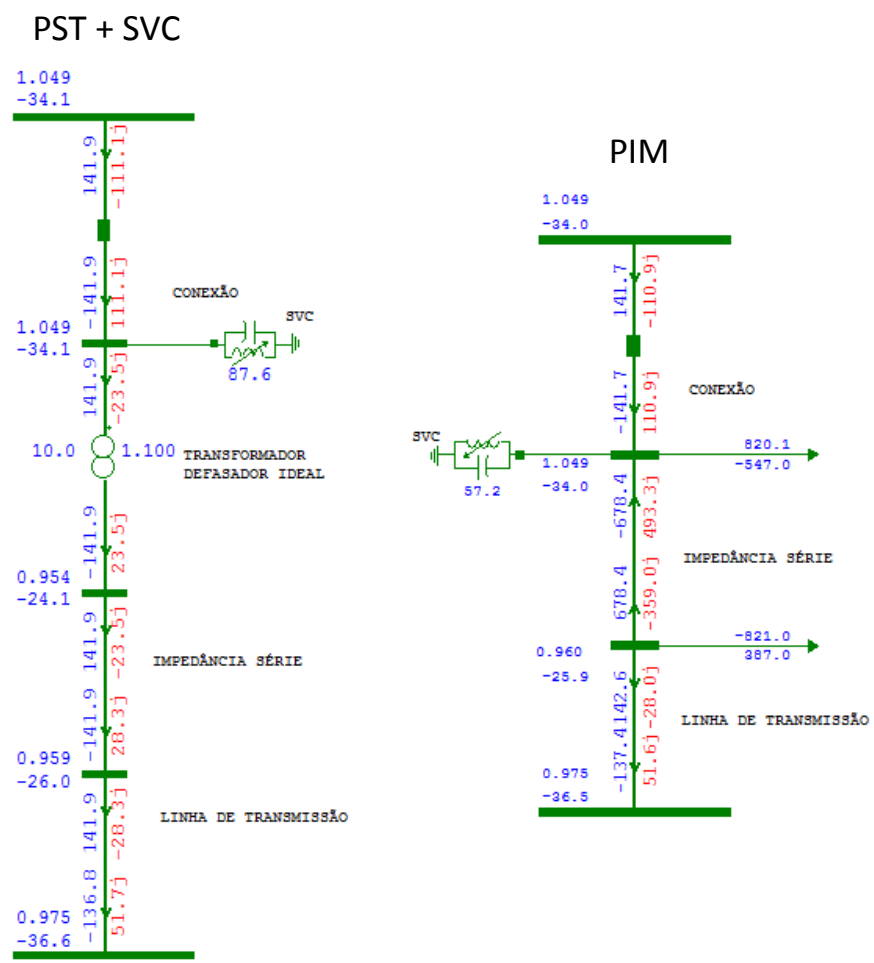

Fonte: Autor.

A figura 39 apresenta o diagrama unifilar simplificado do sistema de $138 \mathrm{kV}$, agora com a inserção do UPFC na linha que interliga as subestações 9 e 11. 
Figura 39 - Caso 2: Diagrama unifilar simplificado do sistema de 138 kV com a inserção do UPFC entre as subestações 9 e 11

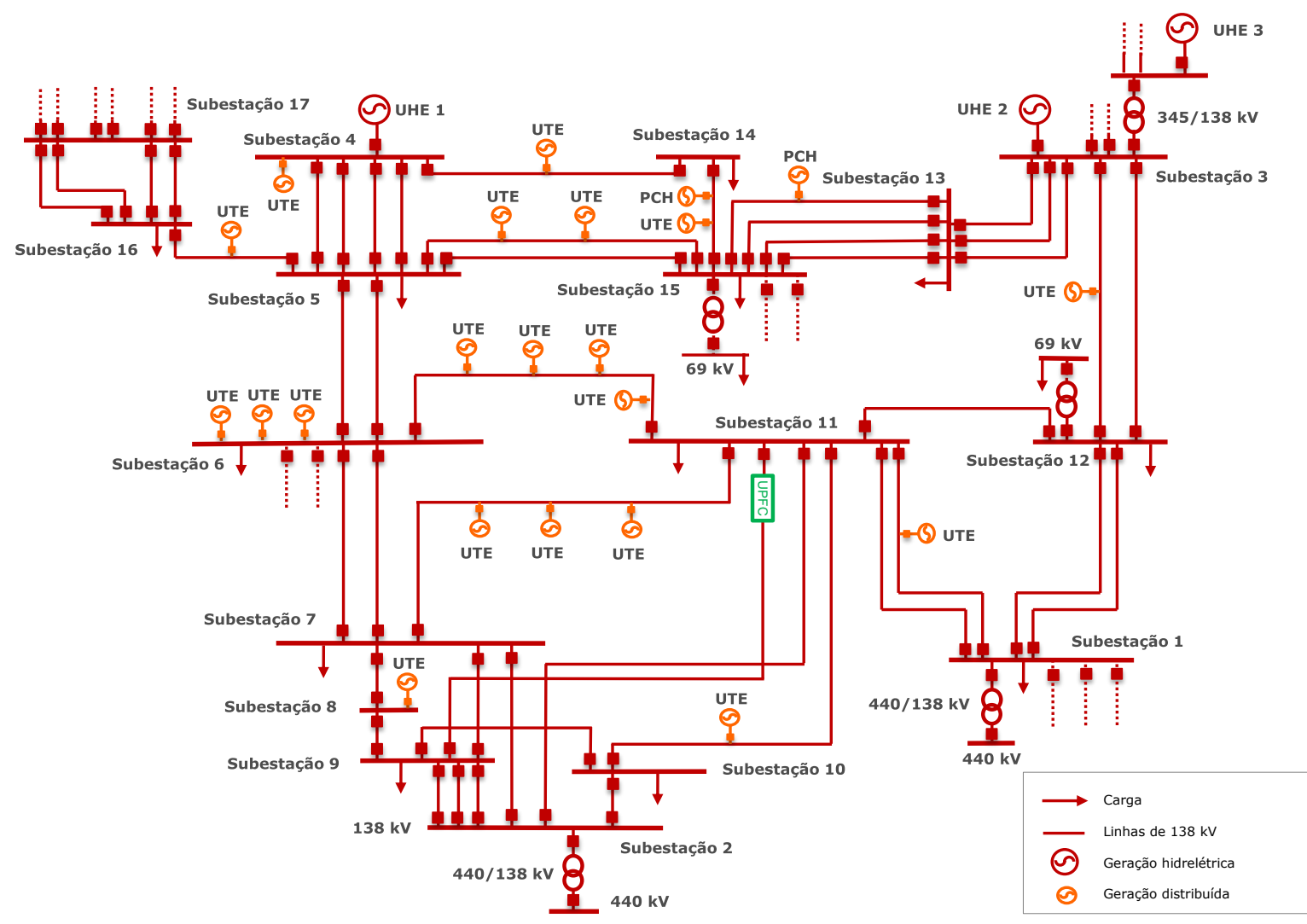

Fonte: Autor.

Os resultados considerando os dois modelos de UPFC são apresentados na tabela 3.

Tabela 3 - Caso 2: Resultados de simulação dos modelos de UPFC no ANAREDE com inserção do UPFC entre as subestações 4 e 5

\begin{tabular}{|c|c|c|c|c|c|c|c|}
\cline { 2 - 8 } & qtde. de iterações & barra & tensão [pu] & angulo [graus] & fluxo ativo [MW] & fluxo reativo [MW] & SVC (Mvar) \\
\hline \multirow{3}{*}{ Modelo (PST+SVC) } & \multirow{3}{*}{22} & entrada & 1.011 & -14.2 & -30.0 & -20.5 & -29.0 \\
\cline { 3 - 9 } & & intermediária & 1.011 & -11.0 & -30.0 & 8.5 & - \\
\cline { 3 - 9 } & & saída & 1.013 & -11.4 & 30.0 & -8.7 & - \\
\hline \multirow{3}{*}{ Modelo (PIM) } & \multirow{2}{*}{18} & entrada & 1.011 & -14.3 & -30.0 & -20.5 & -30.5 \\
\cline { 3 - 9 } & & intermediária & - & - & - & - & - \\
\cline { 3 - 9 } & & saída & 1.013 & -11.4 & 29.7 & -8.8 & - \\
\hline
\end{tabular}

No caso 2, foi observado maior número de iterações para convergência do fluxo de potência utilizando o modelo (PST+SVC), em função da necessidade de inserção do modelo inicialmente sem ativação dos controles do transformador defasador e posterior ajuste (com ativação dos controles) para convergência do caso simulado.

A figura 40 apresenta o diagrama de simulação no ANAREDE com o caso 2 e resultados utilizando os modelos analisados. 
Figura 40 - Caso 2: Diagrama de simulação com os modelos analisados

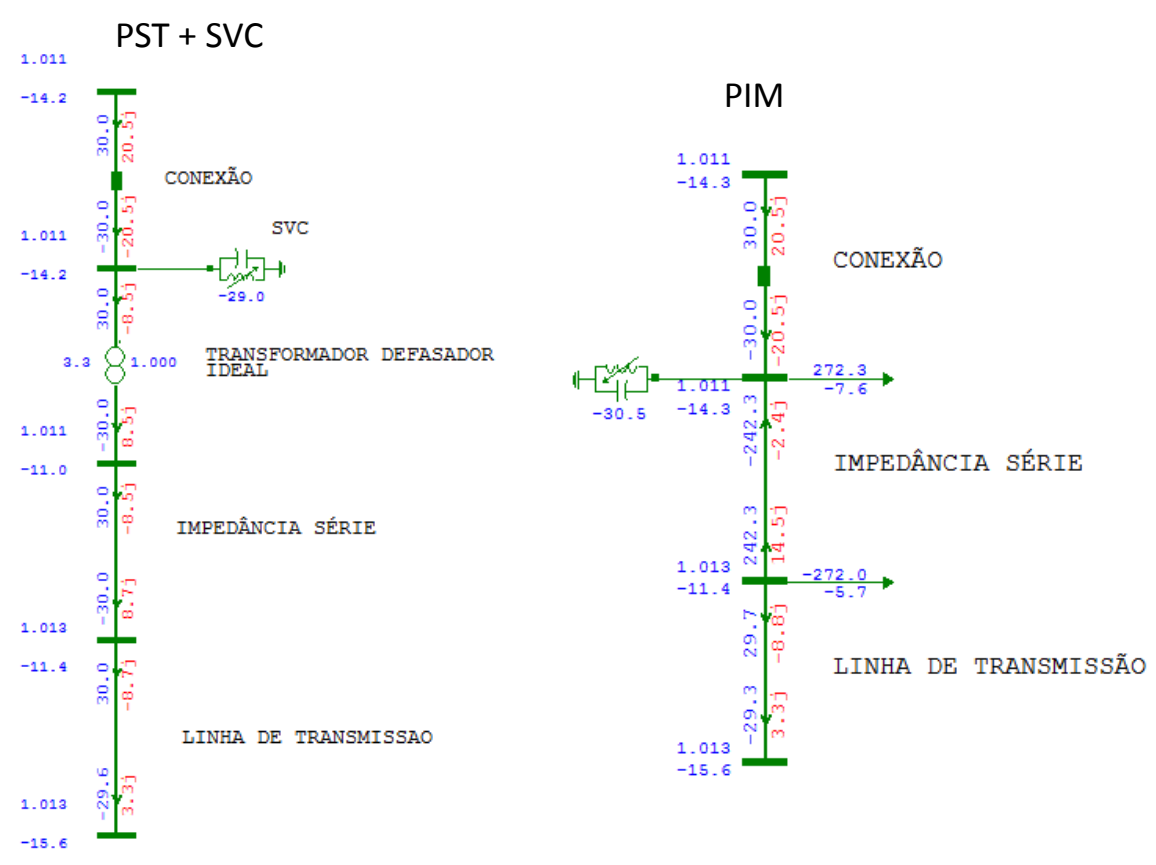

Fonte: Autor.

As simulações de fluxo de potência demonstraram a facilidade de aplicação do modelo utilizando o transformador defasador em série com sua respectiva impedância e compensador estático conectado na barra de entrada (PST+SVC), ao invés do modelo de injeção de potências (PIM), que apesar de possuir maior aplicação em algoritmos de cálculo de fluxo de potência, exigiria a execução de um processo iterativo para obtenção das potências representadas nas barras de entrada e saída do UPFC.

A aplicação do modelo (PST+SVC) utilizando a biblioteca de componentes existentes na maioria dos programas de cálculo de fluxo de potência comerciais apresenta facilidade para representação e análise simplificada do UPFC no sistema elétrico, além de permitir o cálculo dos parâmetros para utilização do modelo (PIM) equivalente, a partir dos resultados obtidos.

As diferenças apresentadas nos resultados de fluxo de potência das simulações, correspondem à limitação existente no programa para inserção dos algarismos decimais, além da tolerância de convergência do caso simulado.

Foi observada a necessidade para aplicação do modelo (PST+SVC) em determinados pontos, de execução inicialmente sem a ativação dos controles do transformador defasador para convergência do caso. 


\section{ANÁLISE DE APLICAÇÃO DO UPFC NO SISTEMA DE DISTRIBUIÇÃO DE ALTA TENSÃO}

A análise de aplicação do UPFC foi realizada utilizando um sistema de distribuição de alta tensão que faz a conexão entre diferentes pontos de fronteira com a Rede Básica e possui uma grande quantidade de usinas a biomassa conectadas.

Neste sistema, o fluxo de potência varia de acordo com as condições operativas da Rede Básica e períodos de safra e entressafra das usinas a biomassa, que associados aos patamares de carga (pesada, média e leve), resultam em cenários bastante distintos.

Nestas condições, foi avaliada alternativa de expansão do sistema com a aplicação do UPFC, que possibilita o controle do fluxo de potência, atendendo aos limites de carregamento de linhas, transformadores e tensões nos barramentos em condição normal de operação ou durante contingências no sistema, nos diversos cenários possíveis.

Também foi analisada a influência desta aplicação no controle de fluxo de potência nas fronteiras.

Inicialmente são apresentadas as características do sistema e restrições previstas considerando sua atual configuração (sistema sem obras).

Utilizando o modelo (PST+SVC) para o UPFC, é realizada a avaliação de alternativa de expansão do sistema de $138 \mathrm{kV}$ com aplicação deste equipamento FACTS.

Esta alternativa é então comparada com a alternativa de conexão ao sistema de $500 \mathrm{kV}$, consolidada pelos estudos de planejamento da expansão do sistema elétrico para a região.

\subsection{Sistema de distribuição interligado com influência de geração distribuída}

O sistema de distribuição de alta tensão apresentado na figura 41 através de seu diagrama unifilar simplificado, é composto por linhas de $138 \mathrm{kV}$ que interligam os sistemas de 440 kV e 345 kV através das subestações transformadoras 1 e 2, de 
440/138 kV, e subestação 3, de 345/138 kV. As linhas possuem predominantemente estruturas em torres metálicas para circuito duplo possuindo um ou dois circuitos lançados, em condutores CAA 336 Linnet com capacidade de 144 MVA ou condutores CAA 477 Hawk com capacidade de 179 MVA. Em condição de emergência (contingência simples), de acordo com as características construtivas e temperatura de projeto de cada linha, é admitido carregamento de até $15 \%$ acima do limite nominal por um período de 4 horas.

Neste sistema de $138 \mathrm{kV}$ estão conectadas também duas usinas hidrelétricas nas subestações 3 e 4 com potência instalada de 328 MW e 166 MW respectivamente.

Essa região tem como principal característica a presença de um grande parque gerador térmico, movido por usinas de biomassa a partir de bagaço de cana.

O diagrama da figura 41 apresenta o unifilar simplificado do sistema com as distâncias aproximadas entre as principais subestações da região, correspondendo ao comprimento das linhas de $138 \mathrm{kV}$ que interligam estas subestações, e potências de geração das usinas a biomassa (UTEs) e pequenas centrais hidrelétricas (PCHs).

Figura 41 - Diagrama unifilar simplificado com as distâncias entre as principais subestações em km e geração distribuída em MW

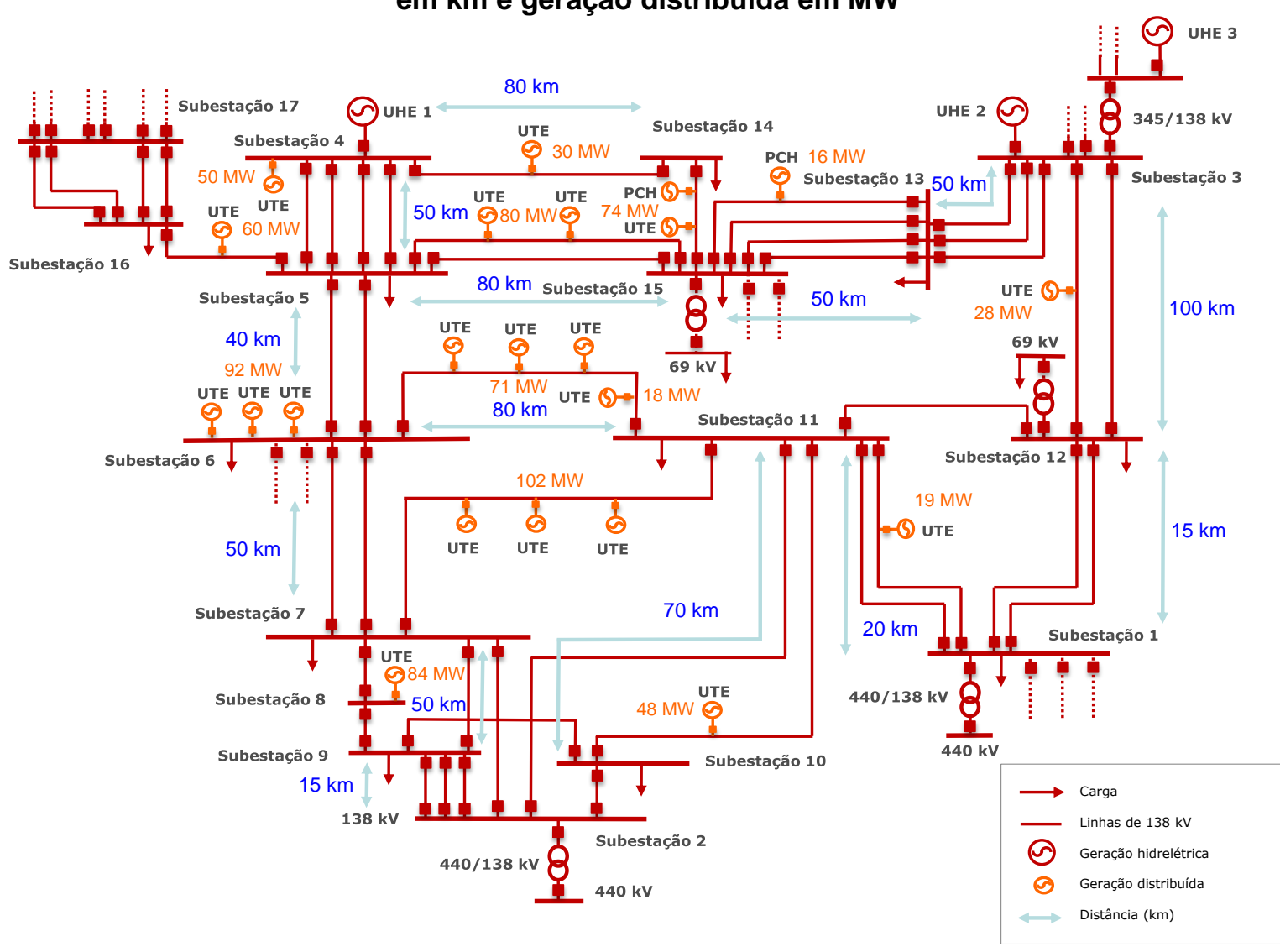

Fonte: Autor. 
A maior parte dessas usinas está conectada no sistema de $138 \mathrm{kV}$ da distribuidora, causando impacto no desempenho desse sistema e gerando dois cenários bastante distintos. O período de safra, que corresponde aos meses de Abril a Novembro de cada ano, quando ocorre a produção de açúcar e etanol, e geração de energia elétrica associada ao processo produtivo. No período de dezembro a março, ocorre parada da produção e consequentemente não há geração de energia elétrica. Deste modo, os patamares correspondentes às demandas de carga pesada, média e leve, associados aos períodos de safra e entressafra, geram seis diferentes cenários. Estes cenários estão também associados aos períodos seco e úmido que correspondem aos despachos de geração e influenciam os intercâmbios na Rede Básica, estando representados nos casos de fluxo de potência utilizados para os estudos de planejamento da expansão do sistema de transmissão e distribuição de alta tensão.

Na região avaliada, a geração das usinas a biomassa totalizam aproximadamente 1,2 GW, montante equivalente a $50 \%$ da carga total do sistema.

Este montante de geração distribuída faz com que o sistema elétrico na região apresente características e desempenhos bastante distintos nos períodos de safra e entressafra.

No período da safra, as usinas de biomassa injetam no sistema grandes montantes de energia. Essa injeção de potência ativa, principalmente no patamar de carga leve, faz com que o excedente de geração seja transferido para a Rede Básica do Sistema Interligado Nacional (SIN) através dos transformadores de fronteira.

No período da entressafra, não há geração das usinas a biomassa, mantendo as cargas associadas ao processo produtivo destas usinas, solicitando do sistema ao qual estão conectadas as demandas de potência ativa e reativa.

Para demonstrar o efeito da geração distribuída, são apresentados na figura 42 , os montantes de fluxo de potência ativa nas transformações de fronteira deste sistema com a Rede Básica nos períodos de safra e entressafra no ano de 2016.

Observamos que, no período de entressafra, a somatória das potências nos transformadores de fronteira com a Rede Básica corresponde ao montante de carga da distribuidora. 
Entretanto, no período de safra, este valor é significativamente menor em função do atendimento de parte da carga pela geração distribuída (usinas a biomassa e $\mathrm{PCHs}$ ) conectadas no sistema da distribuidora.

Figura 42 - Gráfico do fluxo de potência nas fronteiras x carga da área

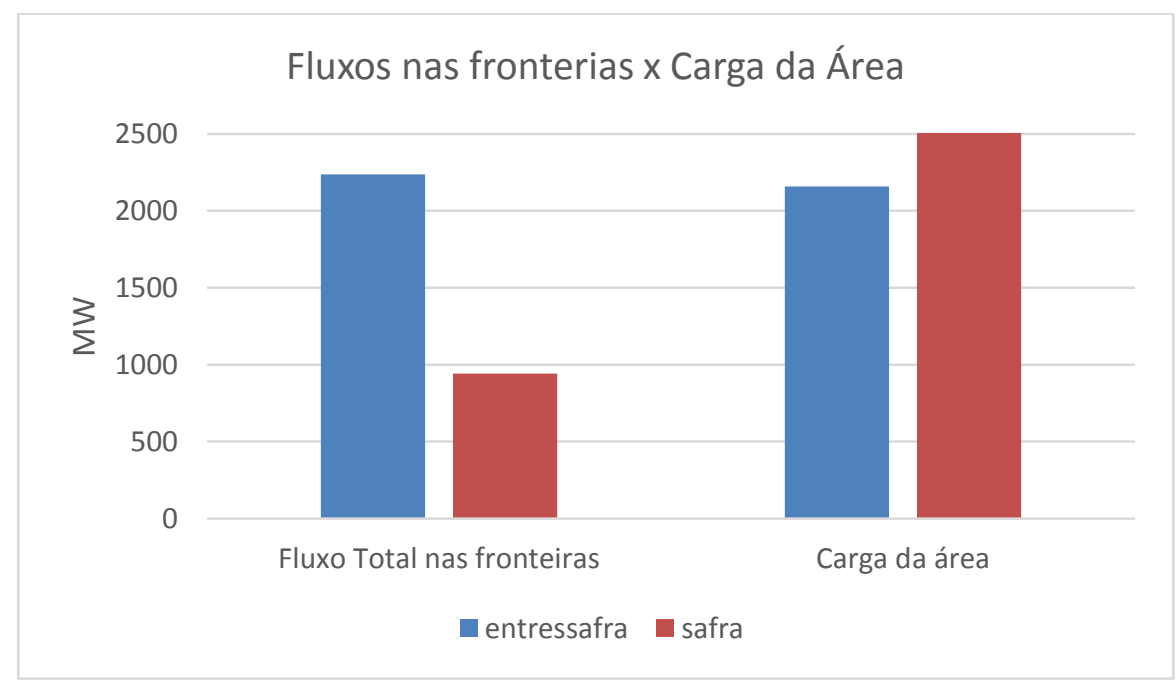

Fonte: Autor.

Nestas condições, a indicação da necessidade de obras de reforços e ampliações pode ser dividida em dois conjuntos distintos. O primeiro conjunto corresponde às obras necessárias para atendimento ao crescimento da carga existente e conexão de novas cargas, em função das condições do sistema no período de entressafra das usinas a biomassa. O segundo conjunto está associado às obras necessárias devido à geração conectada no sistema da distribuidora (usinas hidrelétricas, usinas a biomassa e PCHs) e exportada no período de safra.

A seguir são apresentadas as condições simuladas para este sistema considerando a atual configuração e projeção de demanda e geração no ano horizonte de 2024. São apresentados os cenários de carga média no período de entressafra (máxima demanda e sem a presença da geração a biomassa) e carga leve no período de safra (mínima demanda e presença da geração a biomassa) que correspondem aos cenários críticos com relação aos carregamentos nas linhas e níveis de tensão nos barramentos do sistema em análise.

Os resultados apresentados contemplam também as condições de contingência, com desligamento de um circuito das linhas de interligação entre as subestações. 


\subsubsection{Sistema atual: carga média - período de entressafra}

As figuras de 43 a 45 apresentam os fluxos de potência ativa nas linhas de interligação com as barras de fronteira com as fontes do sistema, carregamento percentual em relação à capacidade nominal das linhas que apresentam indicação de sobrecarga e níveis de tensão nos barramentos das subestações com tensões próximas ao limite mínimo admitido, no patamar de carga média e período de entressafra das usinas a biomassa. Os valores de fluxo de potência correspondem à somatória da potência em todos os circuitos das linhas que interligam as subestações, com indicação do sentido do fluxo de potência através das setas. O carregamento percentual apresentado corresponde ao maior carregamento dos circuitos das linhas em relação à sua capacidade nominal e emergência nestas condições. A figura 43 apresenta o fluxo de potência ativa total nas linhas de interligação com as barras de fronteira com as fontes do sistema.

Figura 43 - Fluxo de potência ativa (MW) - carga média - período de entressafra

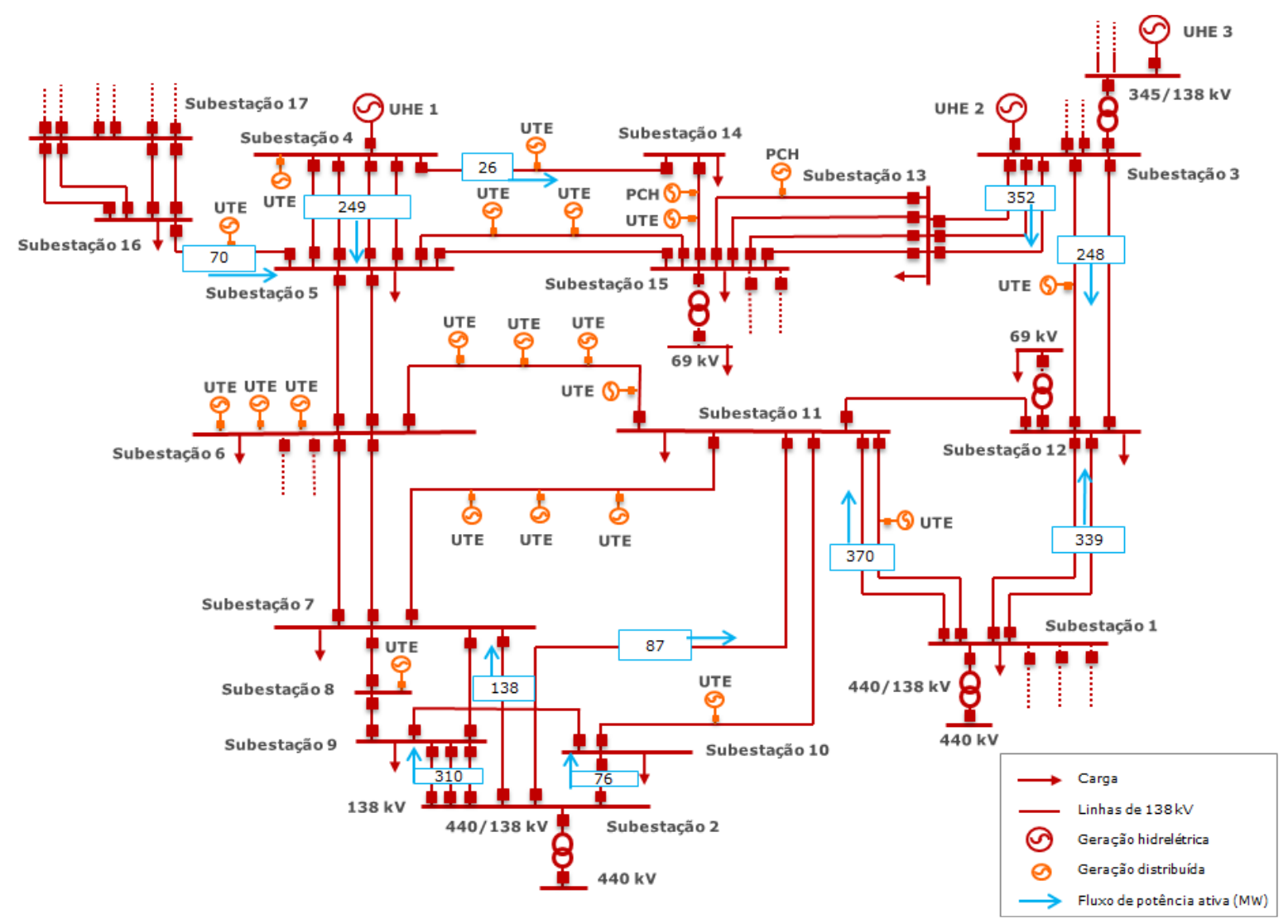

Fonte: Autor. 
Neste cenário de carga média (que apresenta valores de demanda superiores aos patamares de carga pesada e leve) e período de entressafra (sem a presença da geração distribuída associada às usinas a biomassa), pode-se observar que a carga da área é atendida através das transformações de fronteira com a Rede Básica, instaladas nas subestações 1, 2 e 3, além da usina hidrelétrica conectada na subestação 4.

A figura 44 apresenta o máximo carregamento percentual em relação à capacidade nominal das linhas que apresentam indicação de sobrecarga.

Figura 44 - Carregamento das linhas de 138 kV (\%) - carga média - período de entressafra



Fonte: Autor.

Existe indicação de sobrecarga em condição normal (sem contingência no sistema) nas linhas de interligação entre as subestações 3 e 13, 2 e $7 . \mathrm{Na}$ contingência de um circuito das linhas de interligação entre as subestações 1 e 11, há indicação de carregamento acima do limite em emergência no circuito remanescente.

A figura 45 apresenta os valores de tensão em pu nos barramentos de $138 \mathrm{kV}$ com previsão de valores próximos ao limite mínimo admissível. 
Figura 45 -Tensão nos barramentos (pu) - carga média - período de entressafra



Fonte: Autor.

São previstos níveis de tensão no limite inferior admissível nas subestações 6, 7, 11 e 14, localizadas em pontos mais distantes das subestações fontes do sistema.

Em resumo, as simulações apresentaram para o ano horizonte avaliado, baixos níveis de tensão em subestações distantes das fontes do sistema e elevados carregamentos nas linhas provenientes destas subestações fontes.

\subsubsection{Sistema atual: carga leve - período de safra}

As figuras de 46 a 48 apresentam os resultados das simulações no patamar de carga leve e período de safra das usinas a biomassa.

A figura 46 apresenta o fluxo de potência ativa total nas linhas de interligação com as barras de fronteira com as fontes do sistema. 
Figura 46 - Fluxo de potência ativa (MW) - carga leve - safra

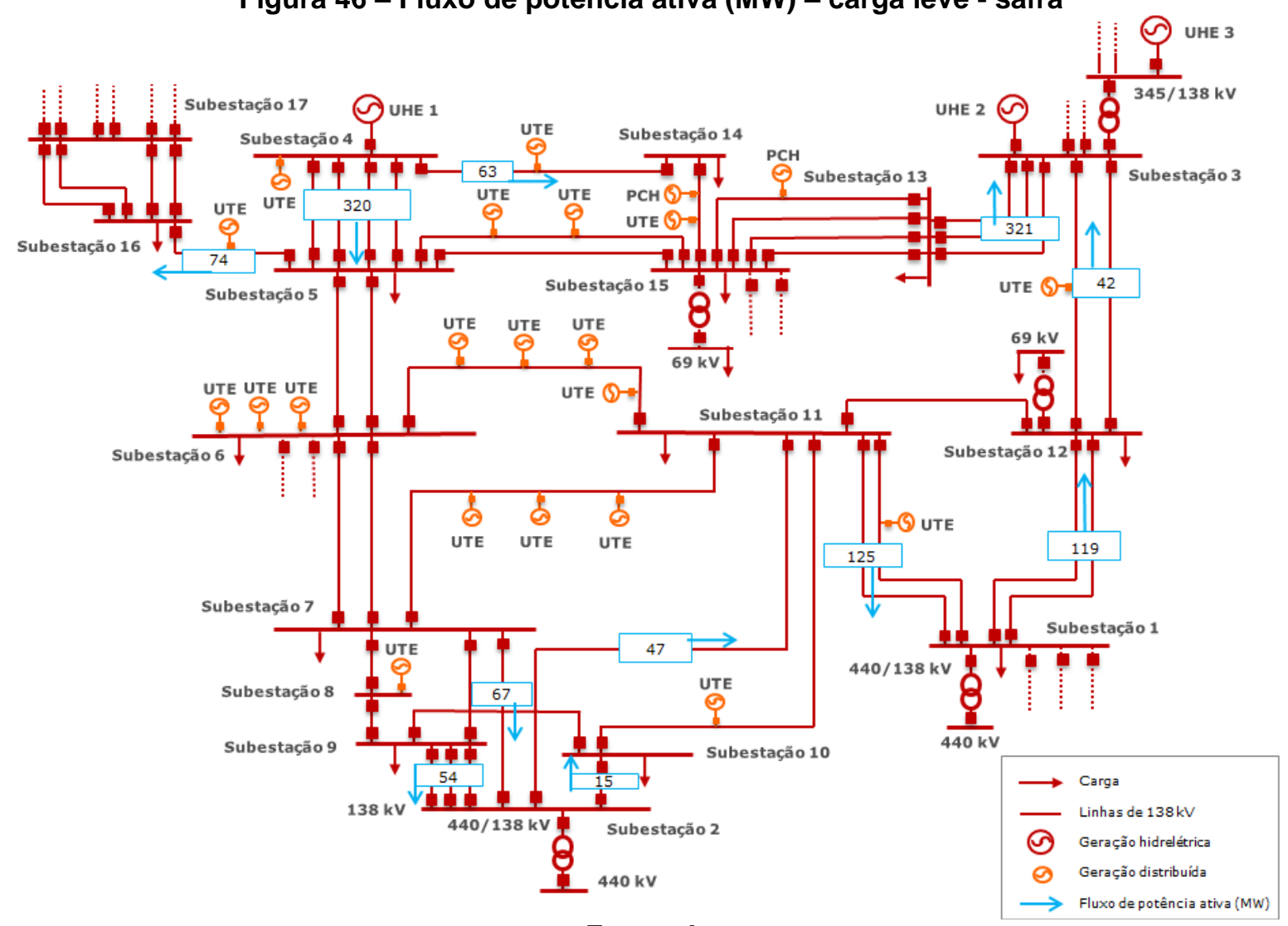

Fonte: Autor.

Neste cenário de carga leve (que apresenta valores de demanda inferiores aos patamares de carga média e pesada) e período de safra (com a presença da geração distribuída associada às usinas a biomassa), a carga da área é atendida pela usina hidrelétrica conectada na subestação 4, além da geração distribuída conectada no sistema de $138 \mathrm{kV}$.

Observa-se a inversão do fluxo de potência nas transformações de fronteira com a Rede Básica das subestações 1 e 3, além da redução no carregamento da transformação existente na subestação 2.

A figura 47 apresenta o máximo carregamento percentual em relação à capacidade nominal das linhas que apresentam indicação de sobrecarga. 
Figura 47 - Carregamento das linhas de 138 kV (\%) - carga leve - período de safra

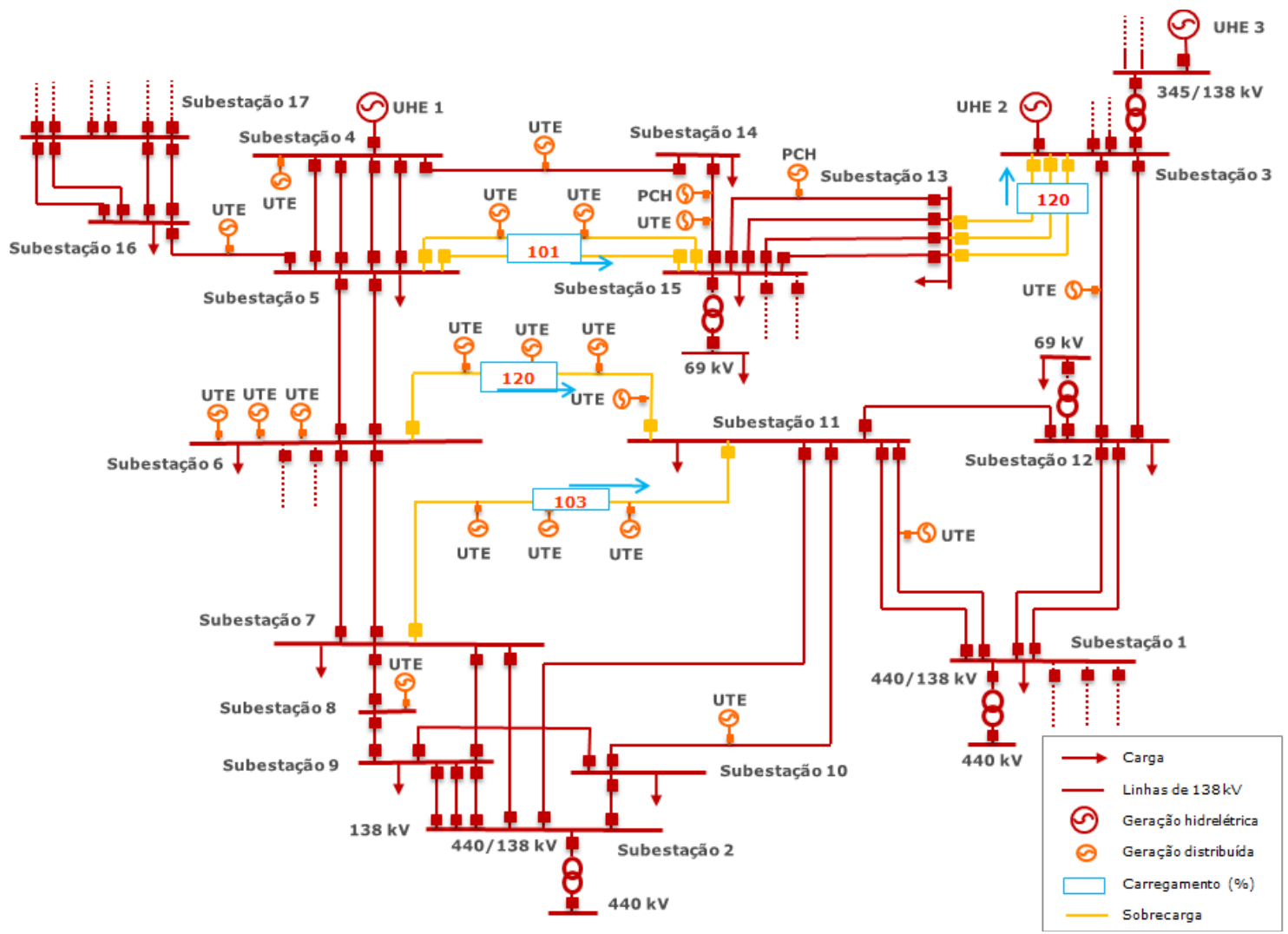

Fonte: Autor.

Existe indicação de sobrecarga em condição normal (sem contingência no sistema) nas linhas de interligação entre as subestações 5 e 15, 3 e 13, 6 e 11, 7 e 11.

São previstos níveis de tensão dentro dos limites em todo o sistema, considerando o desligamento dos bancos de capacitores existentes.

No patamar de carga leve e período de safra, são esperados elevados níveis de tensão e carregamentos nas linhas que interligam as usinas a biomassa aos principais centros de carga, em função do fluxo da geração distribuída.

\subsubsection{Sistema atual: restrições previstas}

Com base nas análises apresentadas anteriormente, considerando a atual configuração do sistema e diversos patamares de carga e geração, foram listadas as linhas com previsão de restrição de carregamento em condição normal e 
contingência em um dos circuitos existentes, além dos barramentos com indicação de tensão abaixo do limite inferior admissível.

A figura 48 indica em laranja as linhas com previsão de restrição de carregamento e barramentos de subestações com níveis de tensão próximos ou abaixo do limite inferior.

Figura 48 - Indicação dos pontos com restrição de tensão e carregamento - em azul

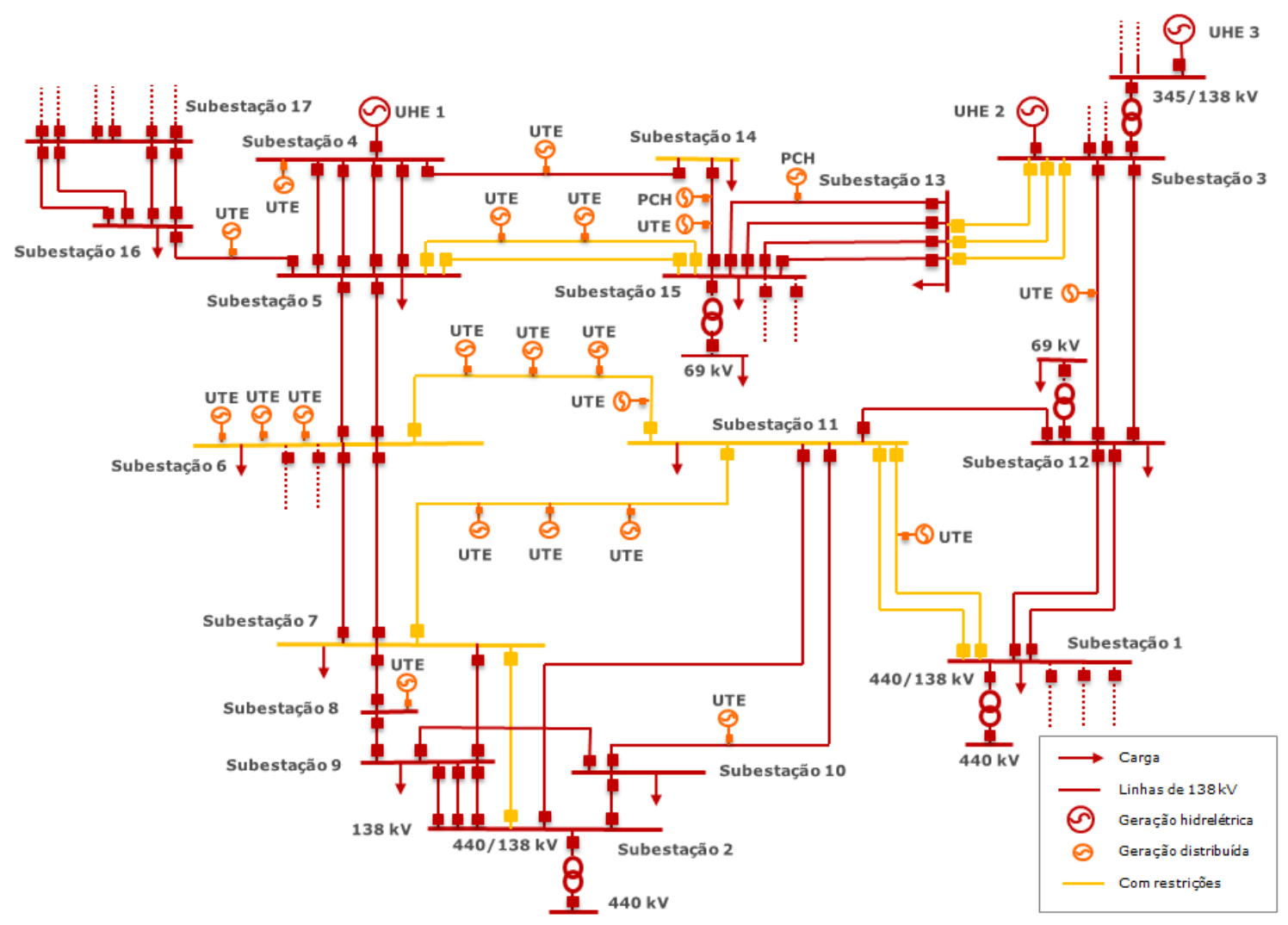

Fonte: Autor.

Observamos a previsão de restrição em diversos pontos do sistema, indicando a necessidade de obras de ampliações e reforços para atendimento à projeção de demanda e geração esperada no horizonte de estudo.

\subsection{Análise de aplicação do UPFC no sistema de distribuição de alta tensão}

Considerando as restrições de tensão e carregamento previstas, foram avaliadas alternativas de expansão para o sistema apresentado. 
Com base nas obras previstas para a região, cuja alternativa é composta por uma nova conexão ao sistema de $500 \mathrm{kV}$, foi avaliada um alternativa contemplando a aplicação do UPFC, que realiza o controle ativo dos parâmetros do sistema elétrico, para expansão e melhor aproveitamento do sistema existente, realizando o direcionamento do fluxo de potência associado à geração distribuída e possibilitando também o controle da potência nas fronteiras entre os sistemas de transmissão e distribuição.

A alternativa de aplicação do UPFC avaliada foi composta por um UPFC controlando o fluxo de potência e níveis de tensão em uma nova linha de $138 \mathrm{kV}$ interligando a subestação 9 a uma nova subestação em seccionamento da linha de interligação entre as subestações 6 e 11, reconstruída para adequação aos fluxos de potência previstos. Compõe também esta alternativa uma nova conexão ao sistema de $345 \mathrm{kV}$ através de um transformador defasador conectado à subestação 4 que realiza o controle do fluxo de potência ativa neste ponto.

A figura 49 apresenta em azul as obras referentes à alternativa avaliada.

Figura 49 - Diagrama unifilar simplificado da região com a alternativa avaliada

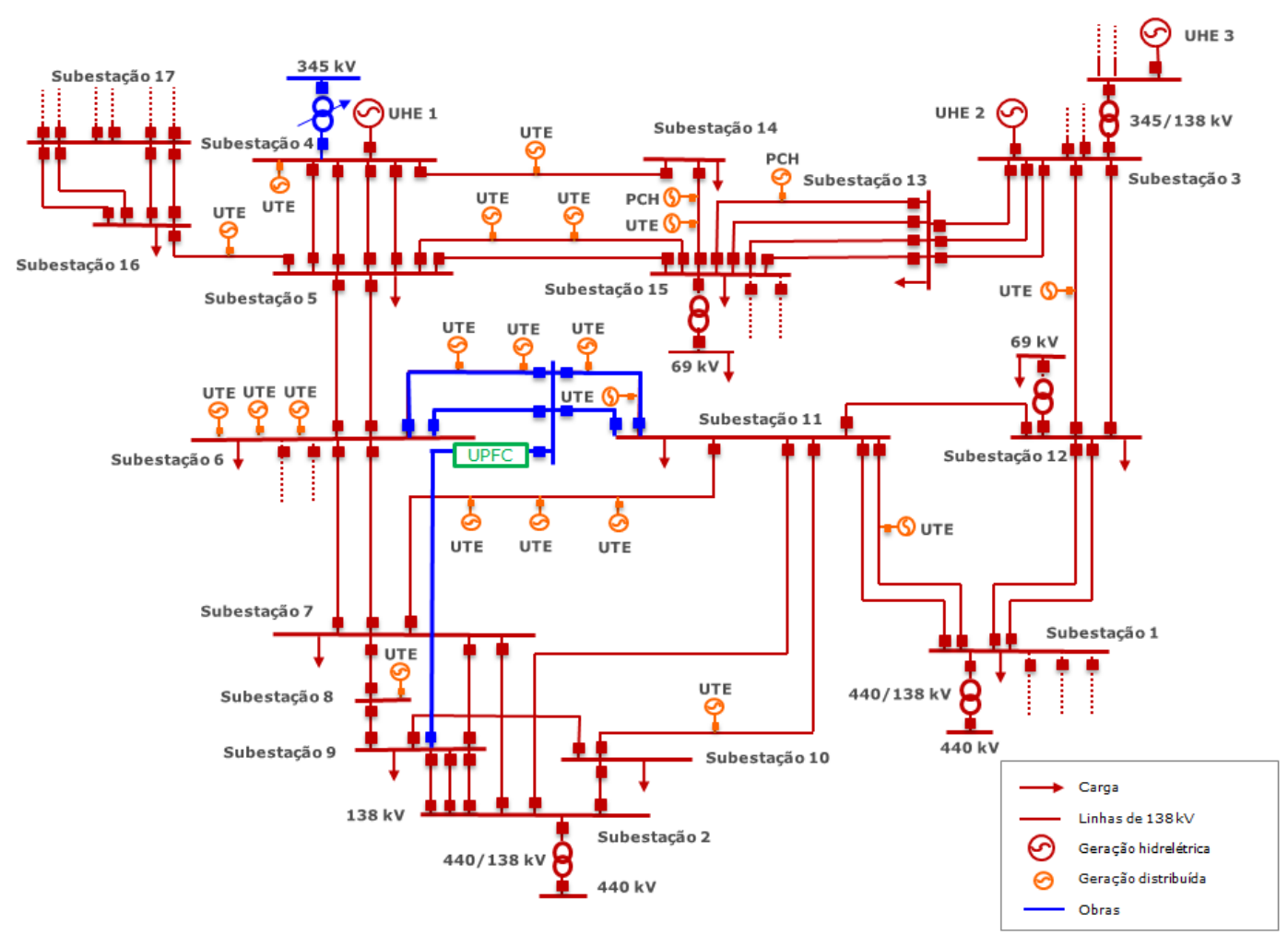

Fonte: Autor. 
Abaixo são listadas as obras propostas desta alternativa:

- conexão ao sistema de $345 \mathrm{kV}$ através da subestação 4, com instalação de um transformador defasador para controle do fluxo de potência ativa;

- reconstrução e duplicação da linha que interliga as subestações 6 e 11 com aumento da capacidade nominal.

- construção de uma nova subestação em seccionamento da linha de interligação entre as subestações 6 e 11 para conexão da nova linha de interligação com a subestação 9;

- construção de uma nova linha de $138 \mathrm{kV}$ em circuito simples, condutores CAA 795 Drake com capacidade nominal de 249 MVA e aproximadamente $100 \mathrm{~km}$ de extensão, interligando a nova subestação com a subestação 9;

- instalação do UPFC com potência de 100 MVA na nova subestação para controle do fluxo de potência e níveis de tensão na linha de interligação entre a nova subestação e a subestação 9;

O objetivo da transformação defasadora na subestação 4, é realizar o controle de fluxo de potência entre os sistemas de $345 \mathrm{kV}$ e $138 \mathrm{kV}$.

No período de safra, o transformador defasador foi ajustado para manter o fluxo de potência ativa no sentido do sistema de $138 \mathrm{kV}$ para o sistema de $345 \mathrm{kV}$, proporcionando um caminho para escoamento da geração existente no sistema de $138 \mathrm{kV}$, incluindo a geração da usina hidrelétrica conectada à subestação 4, reduzindo o carregamento do sistema de $138 \mathrm{kV}$ neste período.

No período de entressafra, o transformador defasador foi ajustado para manter $\mathrm{o}$ fluxo de potência ativa no sentido do sistema de $345 \mathrm{kV}$ para o sistema de $138 \mathrm{kV}$, operando como uma nova fonte para suprimento da carga na região.

Apesar do controle de fluxo de potência ativa proporcionado pelo transformador defasador, deve-se salientar que este equipamento possui tempo de resposta para alterações nas condições do sistema (que corresponde à resposta do equipamento ao comando para mudança no fluxo de potência ativa) superior aos tempos de resposta dos dispositivos de proteção. Deste modo, o tempo de resposta não atende a condições de contingências no sistema que resultem em carregamentos acima dos limites admissíveis nas linhas e demais equipamentos, sendo necessária atuação instantânea para controle de carregamento.

A nova subestação proposta em seccionamento da linha que interliga as subestações 6 e 11, associada ao UPFC e linha de interligação com a subestação 9, 
representa uma nova fonte localizada no ponto central do sistema em análise. Através do UPFC, é possível realizar o controle de tensão, injeção ou absorção de potência ativa e reativa neste ponto do sistema utilizando a potência disponível da transformação 440/138 kV existente na subestação 2.

A construção da linha de interligação entre a nova subestação e a subestação 9 , sem aplicação do UPFC, não proporcionaria benefícios ao sistema, pois sem o UPFC foi obtido fluxo máximo de $24 \mathrm{MW}$ no sentido da subestação 9 para a nova subestação no período de entressafra, e $22 \mathrm{MW}$ no sentido inverso no período de safra, além de não ser observada melhoria nos níveis de tensão dos barramentos do sistema.

O desempenho desta alternativa para os cenários de safra e entressafra nos patamares de carga pesada, média e leve foi realizado utilizando para representação do UPFC o modelo de transformador defasador em série com sua impedância e compensador estático conectado à barra de entrada.

Foram verificadas as condições para atender aos critérios de tensão e carregamento em condições de operação normal e contingência através do controle dos parâmetros do sistema realizado pelo transformador defasador e UPFC, utilizando o programa ANAREDE e a base de dados do sistema interligado nacional.

No período de safra, o UPFC foi ajustado para controle do fluxo de potência ativa no sentido da subestação 9 para a nova subestação, mantendo a tensão na barra da nova subestação em 1,00 pu. Nos patamares de carga pesada e média, foi ajustado para 70 MW o fluxo de potência na linha controlada pelo UPFC, e no patamar de carga leve o fluxo de potência na linha foi reduzido para $0 \mathrm{MW}$. O transformador defasador foi ajustado para controle de fluxo de potência ativa de $130 \mathrm{MW}$ no sentido do sistema de $345 \mathrm{kV}$ para o sistema de $138 \mathrm{kV}$ em todos os patamares de carga.

No período de entressafra, foi ajustado o fluxo de potência ativa na linha controlada pelo UPFC no sentido da nova subestação para a subestação 9, mantendo a tensão na barra da nova subestação em 1,00 pu.

Nos patamares de carga pesada e média foi ajustado para $0 \mathrm{MW}$ o fluxo de potência na linha controlada pelo UPFC e no patamar de carga leve o fluxo de potência nesta linha foi elevado para $30 \mathrm{MW}$. O transformador defasador foi ajustado para controle de fluxo de potência ativa de $200 \mathrm{MW}$ no sentido do sistema de $138 \mathrm{kV}$ para o sistema de $345 \mathrm{kV}$ em todos os patamares de carga. 
Com base nestes ajustes, a seguir são apresentadas as condições simuladas para o sistema no ano de 2024, considerando a alternativa de aplicação do UPFC avaliada.

\subsubsection{Alternativa com UPFC: carga média - período de entressafra}

As figuras de 50 a 52 apresentam para o sistema sem obras, os fluxos de potência ativa nas linhas de interligação com as barras fontes do sistema, 0 carregamento percentual em relação à capacidade nominal nas linhas que apresentaram indicação de sobrecarga, e níveis de tensão nos barramentos das subestações com indicação de tensões próximas ao limite mínimo admitido, no patamar de carga média e período de entressafra das usinas a biomassa.

Os valores de fluxo de potência correspondem à somatória da potência em todos os circuitos das linhas que interligam as subestações, com indicação do sentido do fluxo de potência através das setas. O carregamento percentual apresentado corresponde ao maior carregamento dos circuitos das linhas em relação à sua capacidade nominal e emergência nestas condições.

A figura 50 apresenta o fluxo de potência ativa nas linhas de interligação com as barras fontes do sistema. 
Figura 50 - Alternativa com UPFC - Fluxo de potência ativa (MW) - carga média - período de entressafra

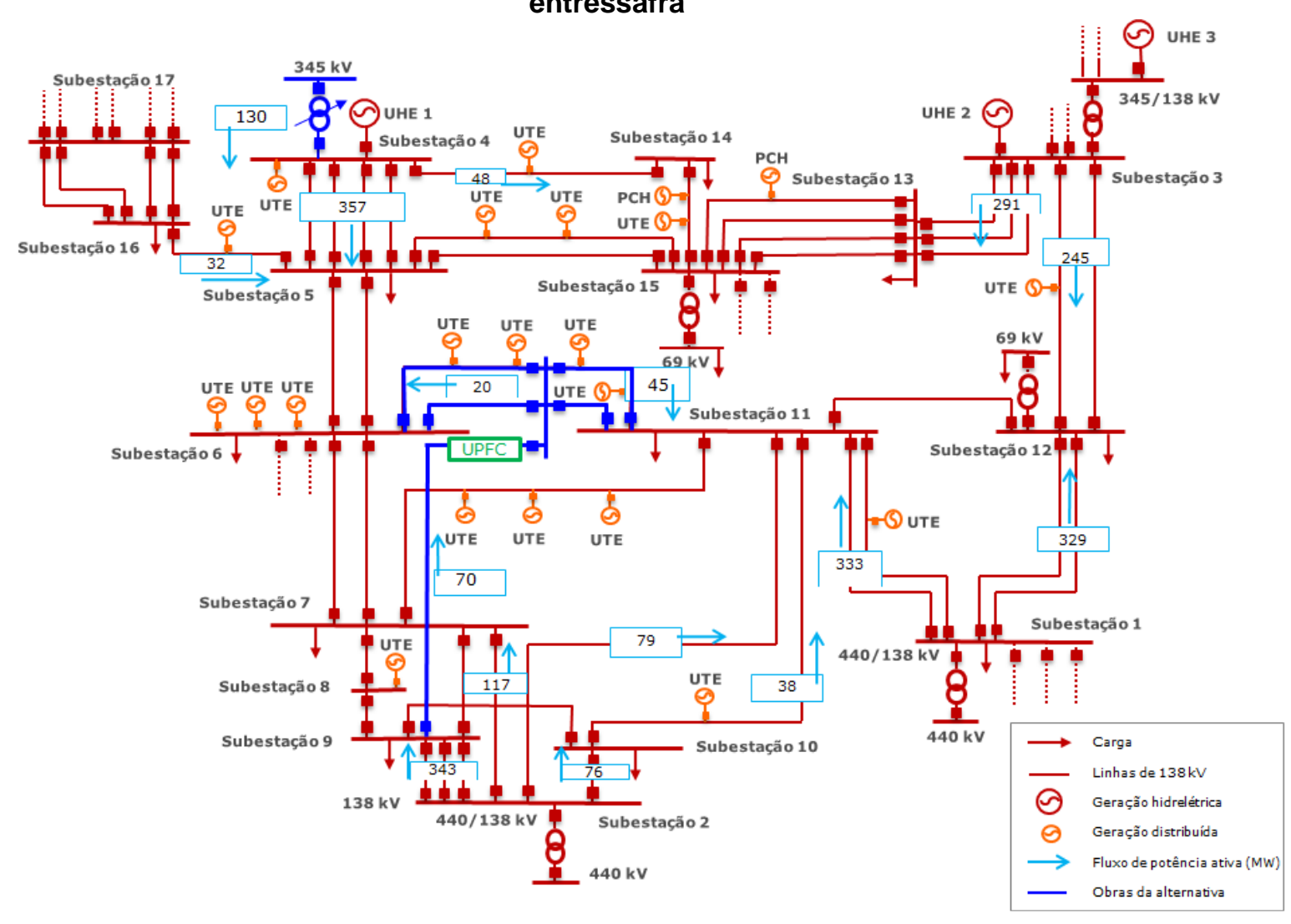

Fonte: Autor.

Neste cenário de carga média e período de entressafra, a carga da área é atendida através das transformações de fronteira com a Rede Básica, que correspondem às subestações 1, 2, 3 e 4, além das usinas hidrelétricas conectadas nas subestações 3 e 4.

A nova subestação, através da potência injetada na linha controlada pelo UPFC, simula a inserção de uma nova fonte no ponto central do sistema com aproveitamento da potência disponível na transformação de 440/138 kV da subestação 2, reduzindo o carregamento das linhas de interligação com as fontes do sistema e melhoria do perfil de tensão na região. O controle de tensão neste novo ponto é realizado com injeção de potência reativa através do ramo shunt do UPFC.

A figura 51 mostra para as linhas que apresentaram sobrecarga no sistema sem obras, o máximo carregamento percentual em relação à capacidade nominal, considerando a alternativa de aplicação do UPFC. 
Figura 51 - Alternativa com UPFC - carregamento das linhas de 138 kV (\%) - carga média período de entressafra

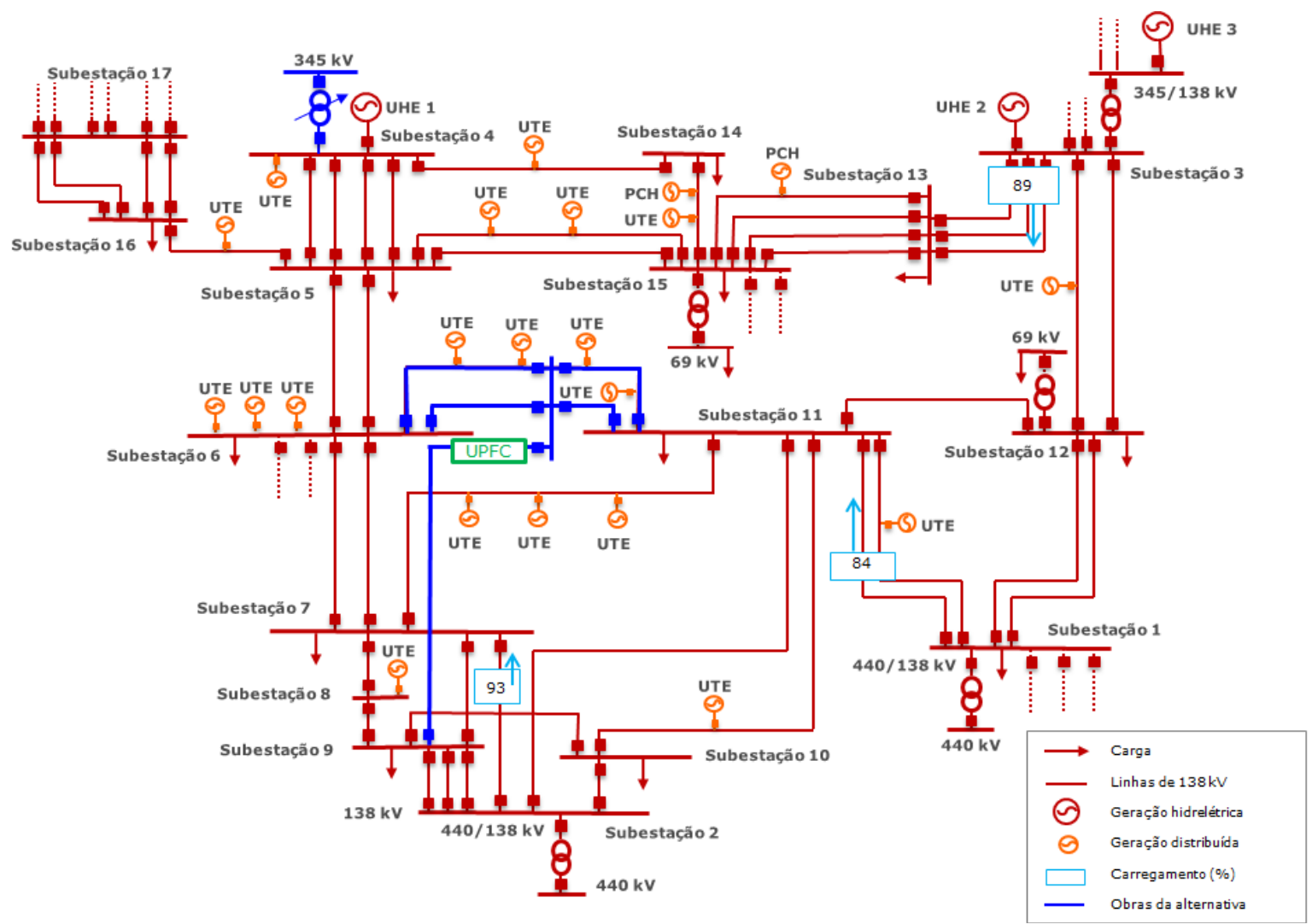

Fonte: Autor.

A figura 52 apresenta os valores de tensão em pu nos barramentos de $138 \mathrm{kV}$ que apresentaram indicação de tensão no limite inferior para o sistema sem obras. 
Figura 52 - Alternativa com UPFC - tensão nos barramentos (pu) - carga média - período de entressafra

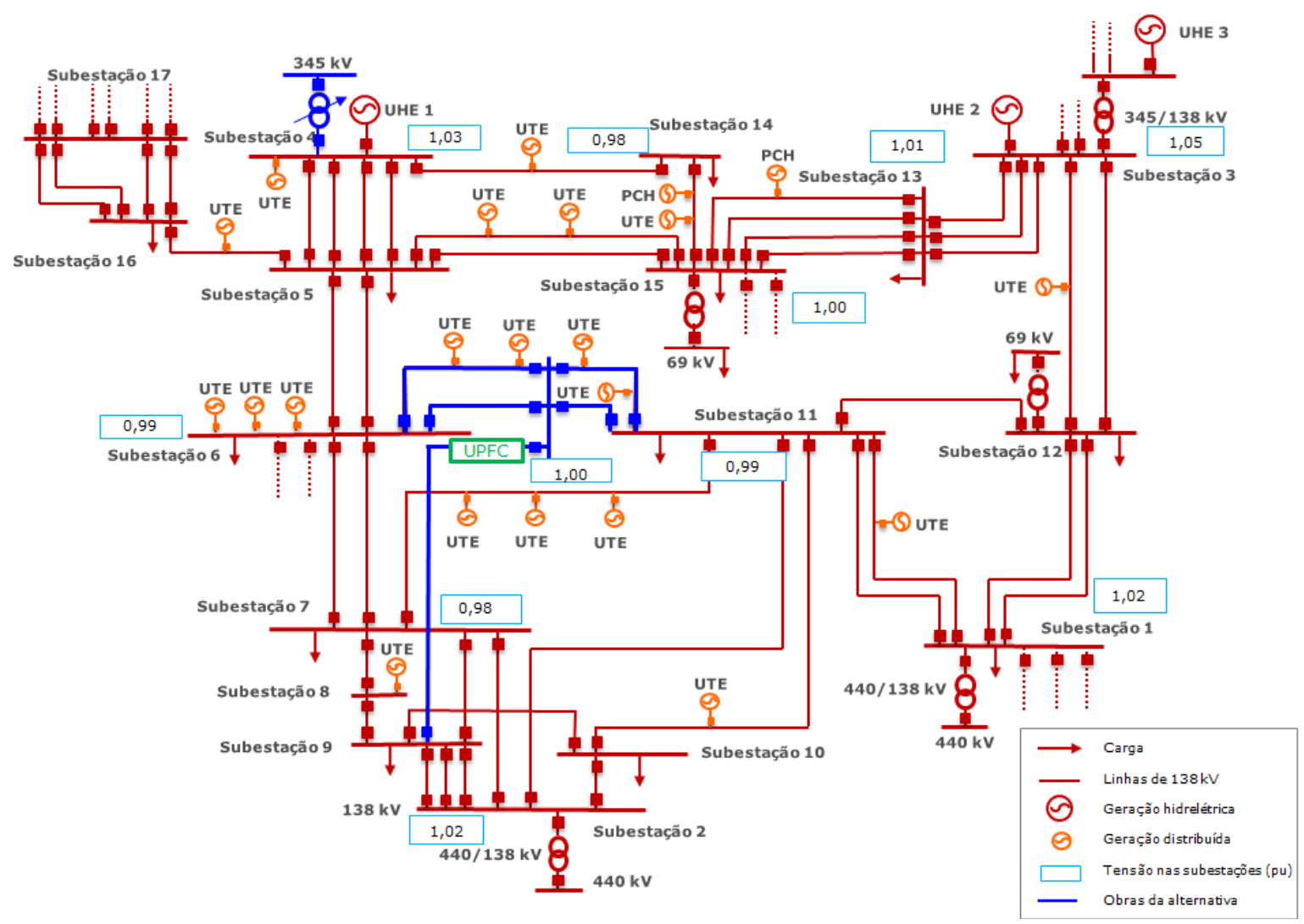

Fonte: Autor.

Pode ser observada a eliminação das restrições referentes ao carregamento das linhas e nível de tensão nos barramentos com a inclusão das obras da alternativa de aplicação do UPFC.

\subsubsection{Alternativa com UPFC: carga leve - período de safra}

As figuras 53 e 54 apresentam os resultados das simulações no patamar de carga leve e período de safra das usinas a biomassa.

A figura 53 apresenta o fluxo de potência ativa nas linhas de interligação com as barras fontes do sistema. 
Figura 53 - Alternativa com UPFC - fluxo de potência ativa (MW) - carga leve - período de safra

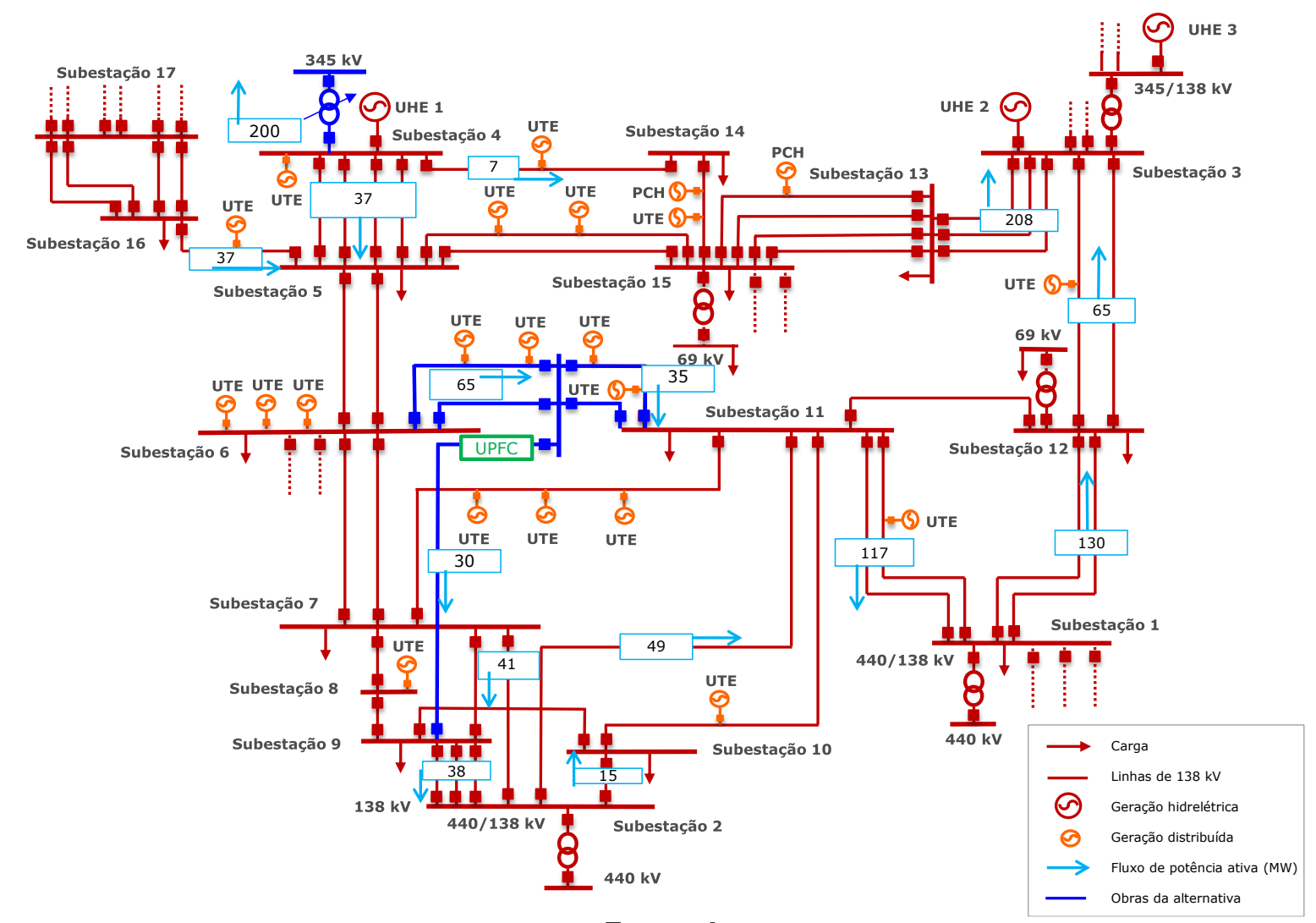

Fonte: Autor.

Neste cenário de carga leve e período de safra, a carga da área é atendida por parte da geração da usina hidrelétrica conectada na subestação 4, pela transformação de fronteira com a Rede Básica da subestação 2, além da geração distribuída conectada no sistema de $138 \mathrm{kV}$.

O transformador defasador realiza a inversão do fluxo de potência ativa do sistema de $138 \mathrm{kV}$ para o sistema de $345 \mathrm{kV}$ e o UPFC realiza o controle do fluxo de potência no sentido da nova subestação para a subestação 9, com transferência de parte da geração distribuída para a região da subestação 9, distante 100 km da nova subestação.

Observa-se a inversão do fluxo de potência nas transformações de fronteira com a Rede Básica das subestações 1 e 3 em função do excedente de geração no sistema de $138 \mathrm{kV}$.

A figura 54 apresenta para as linhas que apresentaram sobrecarga no sistema sem obras, o máximo carregamento percentual em relação à capacidade nominal, considerando a alternativa de aplicação do UPFC. 
Figura 54 - Alternativa com UPFC - carregamento das linhas de 138 kV (\%) - carga leve período de safra

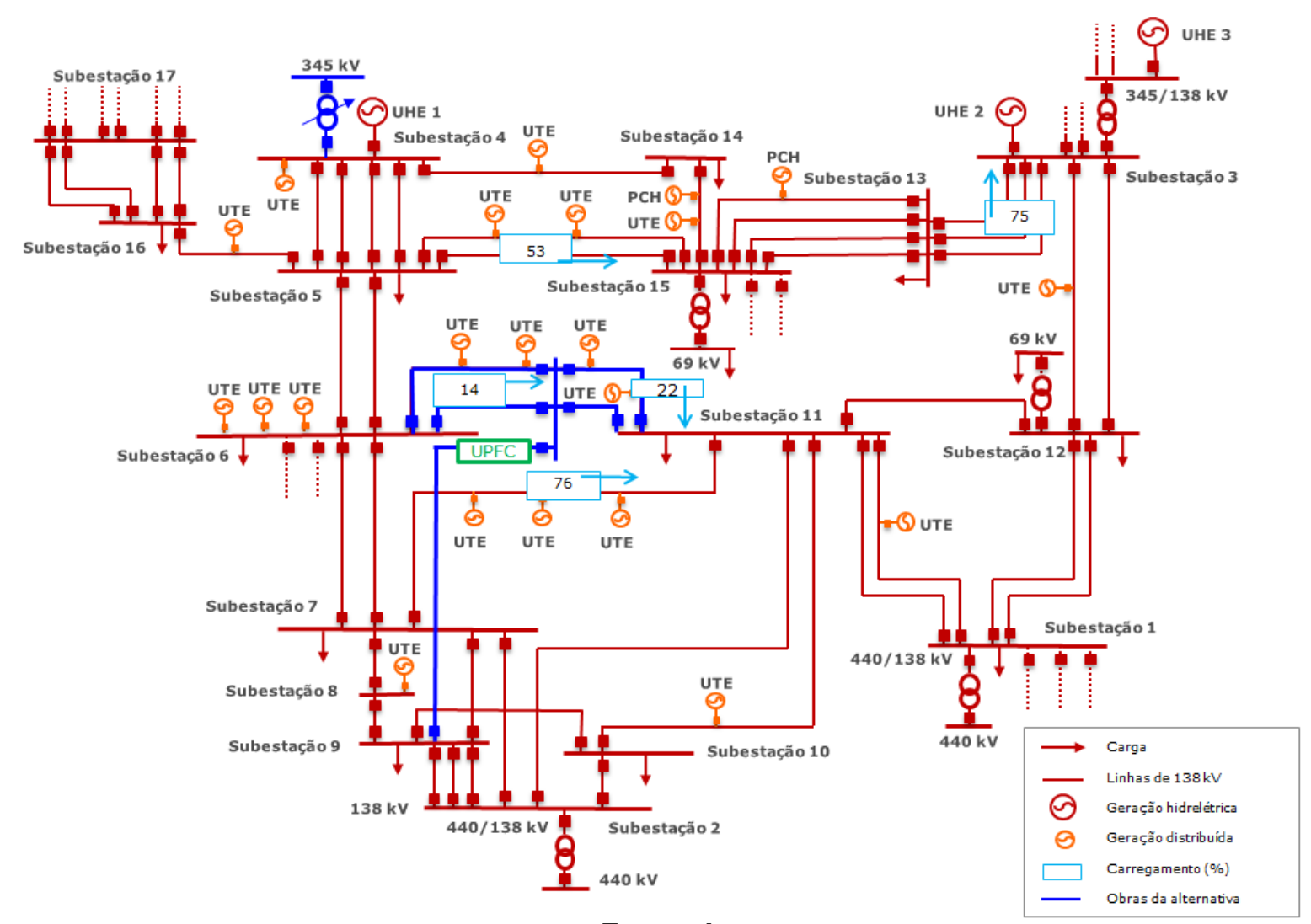

Fonte: Autor.

\subsubsection{Alternativa com UPFC: avaliação e operação em contingência}

Considerando a alternativa de aplicação do UPFC e obras associadas, foram verificados carregamentos nas linhas existentes e níveis de tensão na região dentro dos limites admissíveis, nos períodos de safra e entressafra das usinas a biomassa, com eliminação das restrições observadas no sistema sem obras.

Salienta-se que foram adotados valores de fluxo de potência na linha de interligação entre a nova subestação e a subestação 9, controlada pelo UPFC, com o objetivo de manter os carregamentos nas linhas e níveis de tensão nas barras dentro dos limites admissíveis, mas também minimizando as perdas no sistema, incluindo a perda na linha controlada.

Em caso de sobrecargas em contingência, também existe a possibilidade de controle de carregamento no sistema através da atuação do UPFC, pois em condição de contingência no sistema, o UPFC permite a mudança instantânea dos parâmetros controlados (potência ativa, reativa e nível de tensão). 
A figura 55 apresenta para o sistema em análise a condição de desligamento de um circuito da linha de interligação entre as subestações 5 e $6 \mathrm{com}$ indicação do fluxo de potência de 70 MW controlado pelo UPFC. É apresentado o carregamento percentual do circuito remanescente considerando sua capacidade de emergência.

Figura 55 - Alternativa com UPFC - carregamento da linha de 138 kV em contingência (\%) controle UPFC $70 \mathrm{MW}$

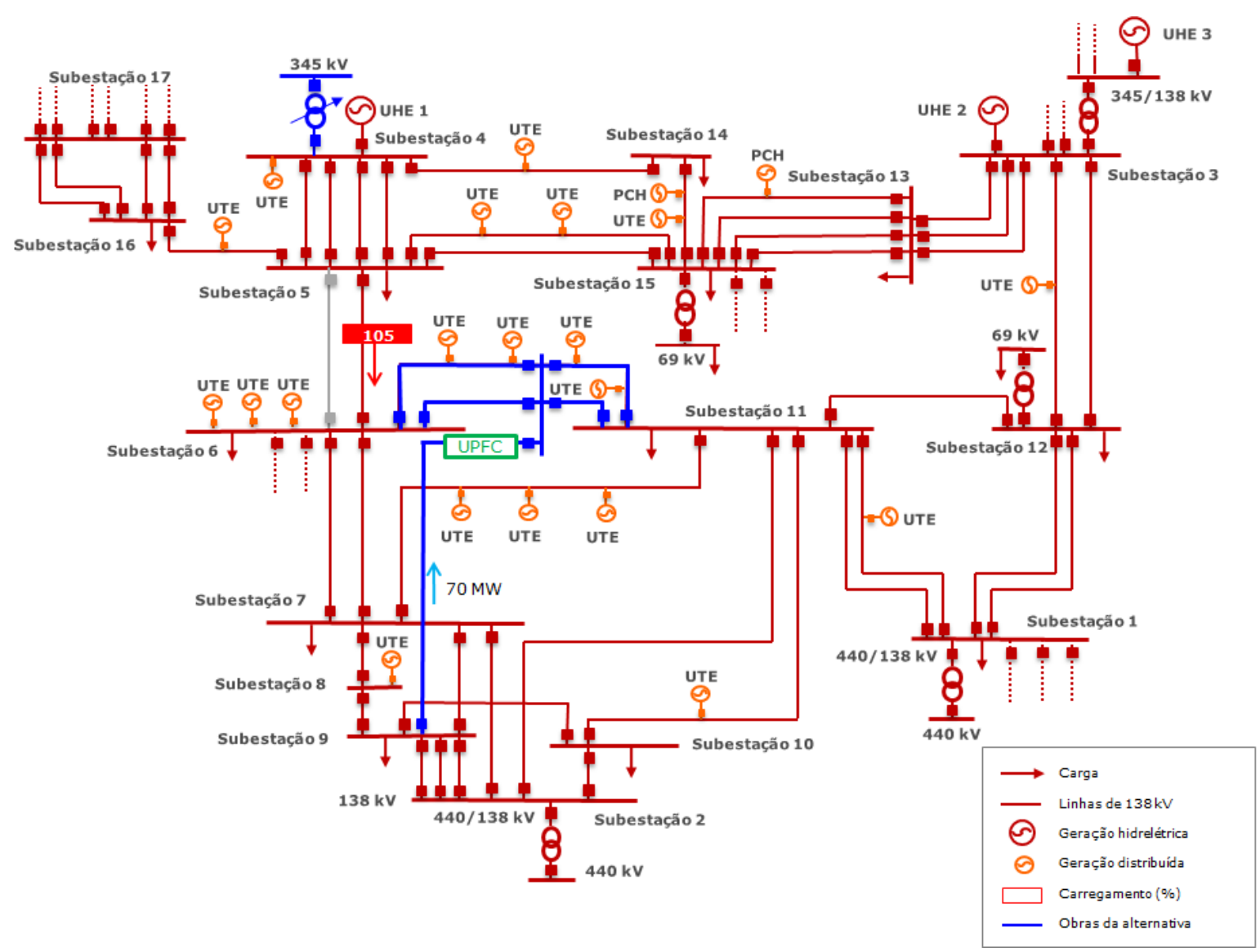

Fonte: Autor.

Nesta condição é verificado carregamento no circuito remanescente da linha de interligação entre as subestações 5 e 6 superior à sua capacidade em emergência. A redução do carregamento neste circuito é realizada através da elevação do fluxo de potência controlado pelo UPFC entre a subestação 9 e a nova subestação, para $150 \mathrm{MW}$.

A figura 56 apresenta o carregamento percentual do circuito considerando sua capacidade de emergência após elevação do fluxo controlado pelo UPFC. 
Figura 56 - Alternativa com UPFC - carregamento da linha de 138 kV em contingência (\%) controle UPFC $150 \mathrm{MW}$

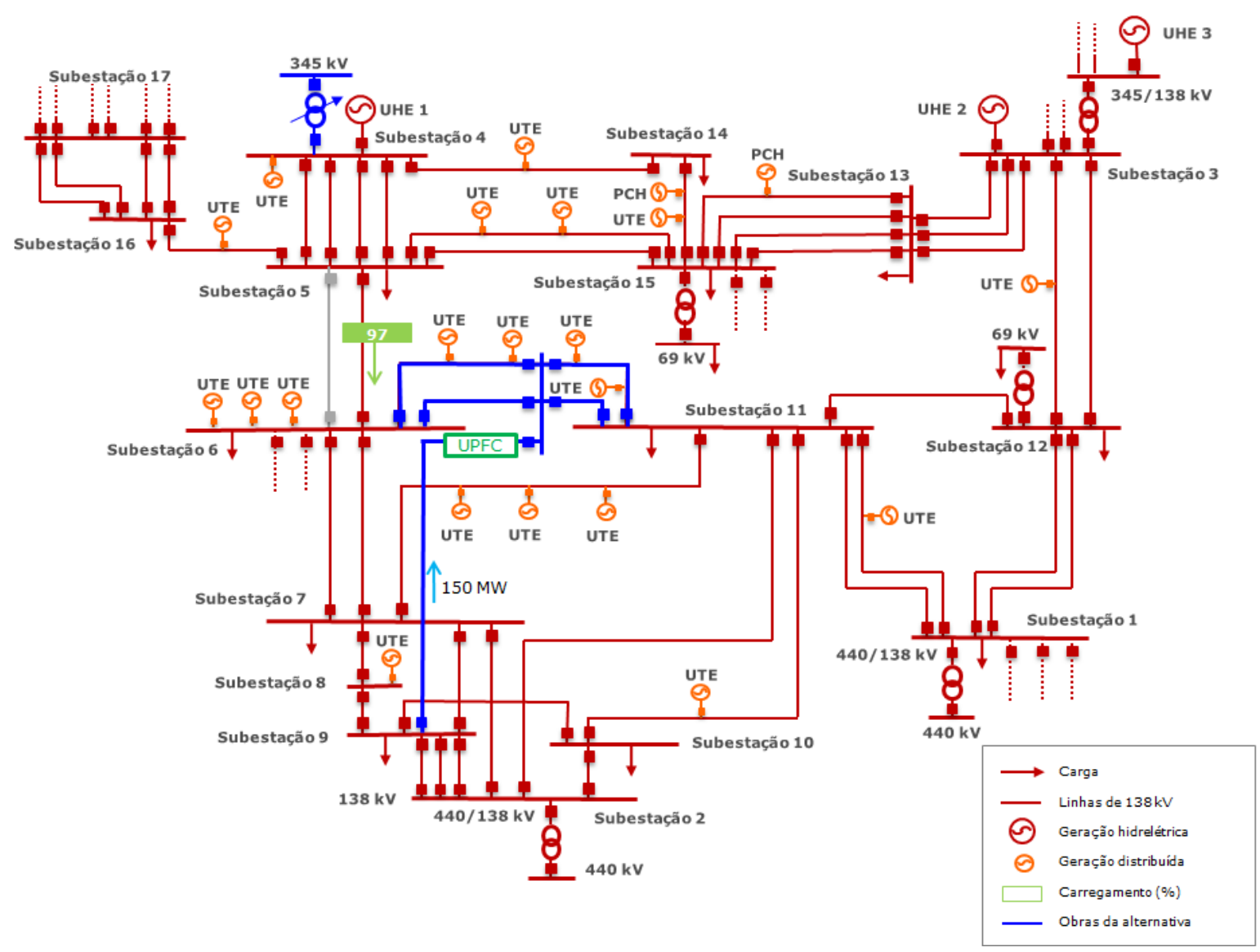

Fonte: Autor.

No caso do sistema em análise, outro ganho associado à aplicação do UPFC corresponde ao controle de fluxo de potência nas fronteiras do sistema de distribuição com a rede de transmissão de acordo com a demanda contratada em cada ponto de fronteira. A ultrapassagem destes valores representam penalizações à distribuidora e pagamento de multas da ordem de milhões de reais.

A figura 57 apresenta a variação do fluxo de potência nas fronteiras para uma variação no ajuste do fluxo de potência na linha controlada pelo UPFC de $0 \mathrm{MW}$ para $150 \mathrm{MW}$ no sentido da subestação 9 para a nova subestação. Pode ser observada a elevação do fluxo a partir da transformação 440/138 kV da subestação 1 e correspondente redução na transformação 440/138 kV da subestação 2. Esta variação instantânea no fluxo de potência controlado pelo UPFC permitiria o controle de demanda nestes pontos em tempo real. 
Figura 57 - Gráfico de variação do fluxo de potência nas fronteiras em função do ajuste do UPFC

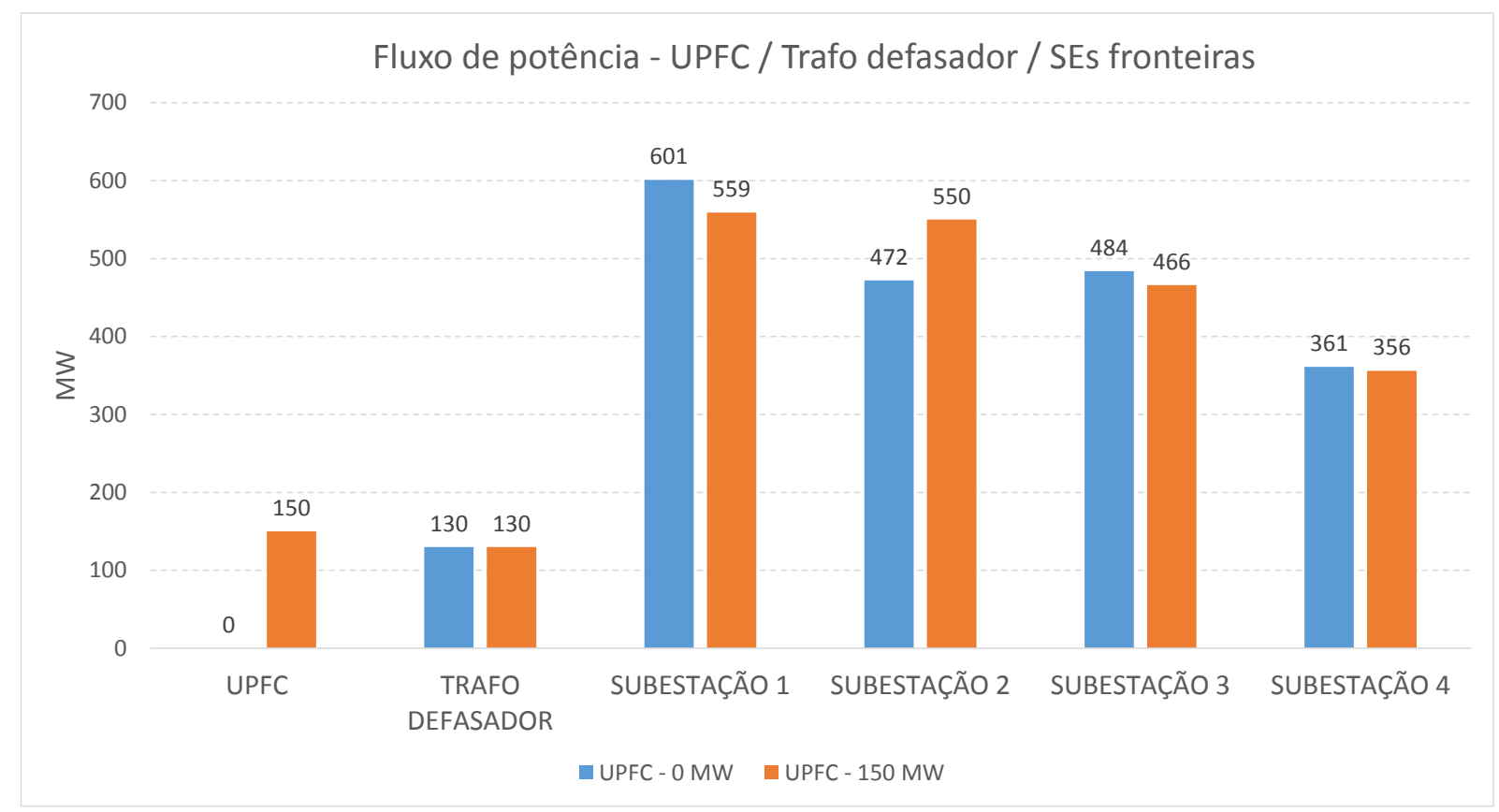

Fonte: Autor.

\subsection{Alternativa de conexão ao sistema de $500 \mathrm{kV}$}

A seguir, é apresentada para comparação com a alternativa de aplicação do UPFC, a alternativa de reforços e ampliações para o sistema em análise consolidada pelos estudos de planejamento da expansão do sistema elétrico para a região (ANEEL, 2016).

Esta alternativa é composta por uma conexão ao sistema de $500 \mathrm{kV}$ através de uma nova subestação na linha de interligação entre as subestações 6 e 11, reconstruída e duplicada para adequação aos fluxos de potência previstos. Compõe também esta alternativa uma nova linha de interligação entre a nova subestação e a subestação 15, além de nova conexão ao sistema de $345 \mathrm{kV}$ através de um transformador defasador conectado à subestação 4 que realiza o controle do fluxo de potência ativa neste ponto.

Com exceção da nova conexão ao sistema de 500 kV e linha de interligação entre a nova subestação e a subestação 15 , as demais obras são comuns entre esta alternativa e a alternativa de aplicação do UPFC apresentada. 
A figura 58 apresenta a alternativa com conexão ao sistema de $500 \mathrm{kV}$ e demais obras associadas.

Figura 58 - Diagrama unifilar simplificado da região com a alternativa de conexão com o sistema de $500 \mathrm{kV}$

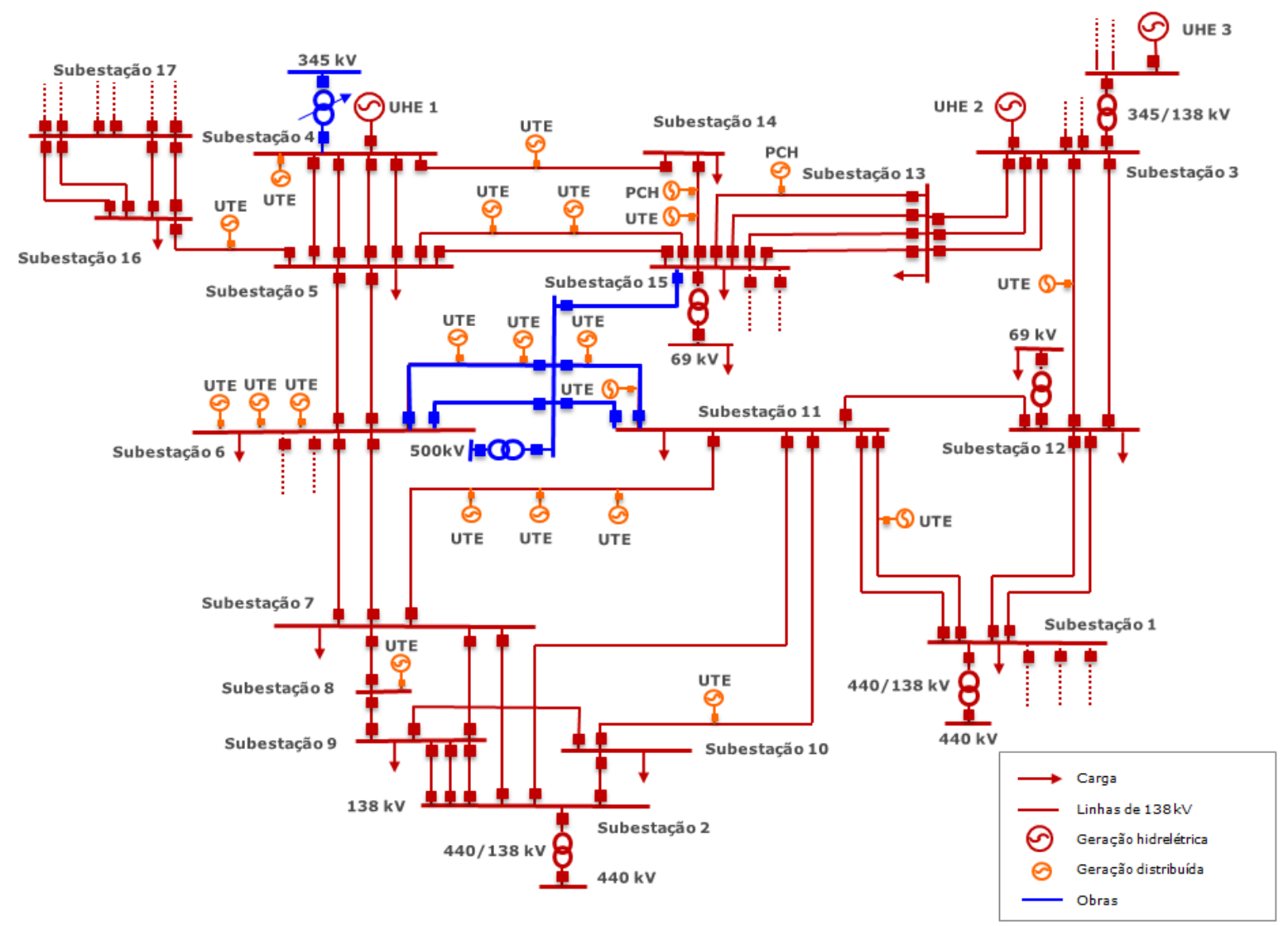

Fonte: Autor.

Abaixo são listadas as obras desta alternativa:

- conexão ao sistema de 500 kV através da nova subestação, com instalação de dois transformadores de 400 MVA, em seccionamento da linha de interligação entre as subestações 6 e 11;

- reconstrução e duplicação da linha que interliga as subestações 6 e 11 para conexão da nova subestação;

- construção de uma linha de 138 kV em circuito duplo, condutores CAA 477 Hawk com capacidade nominal de 125 MVA e aproximadamente 50 km de extensão, interligando a nova subestação com a subestação 15;

- conexão ao sistema de 345 kV através da subestação 4, com instalação de um transformador defasador para controle do fluxo de potência ativa; 
A seguir são apresentadas as condições simuladas para o sistema no ano de 2024, considerando a alternativa de conexão ao sistema de $500 \mathrm{kV}$ e demais obras associadas.

\subsubsection{Alternativa $500 \mathrm{kV}$ : carga média - período de entressafra}

As figuras de 59 a 61 apresentam os fluxos de potência ativa nas linhas de interligação com as barras de fronteiras com as fontes do sistema, carregamento percentual em relação à capacidade nominal das linhas que apresentaram indicação de sobrecarga e níveis de tensão nos barramentos das subestações com tensões próximas ao limite mínimo admitido para o sistema sem obras, no patamar de carga média e período de entressafra das usinas a biomassa.

A figura 59 apresenta o fluxo de potência ativa nas linhas de interligação com as barras fontes do sistema.

Figura 59 - Alternativa $500 \mathrm{kV}$ - fluxo de potência ativa (MW)

Patamar de carga média - período de entressafra

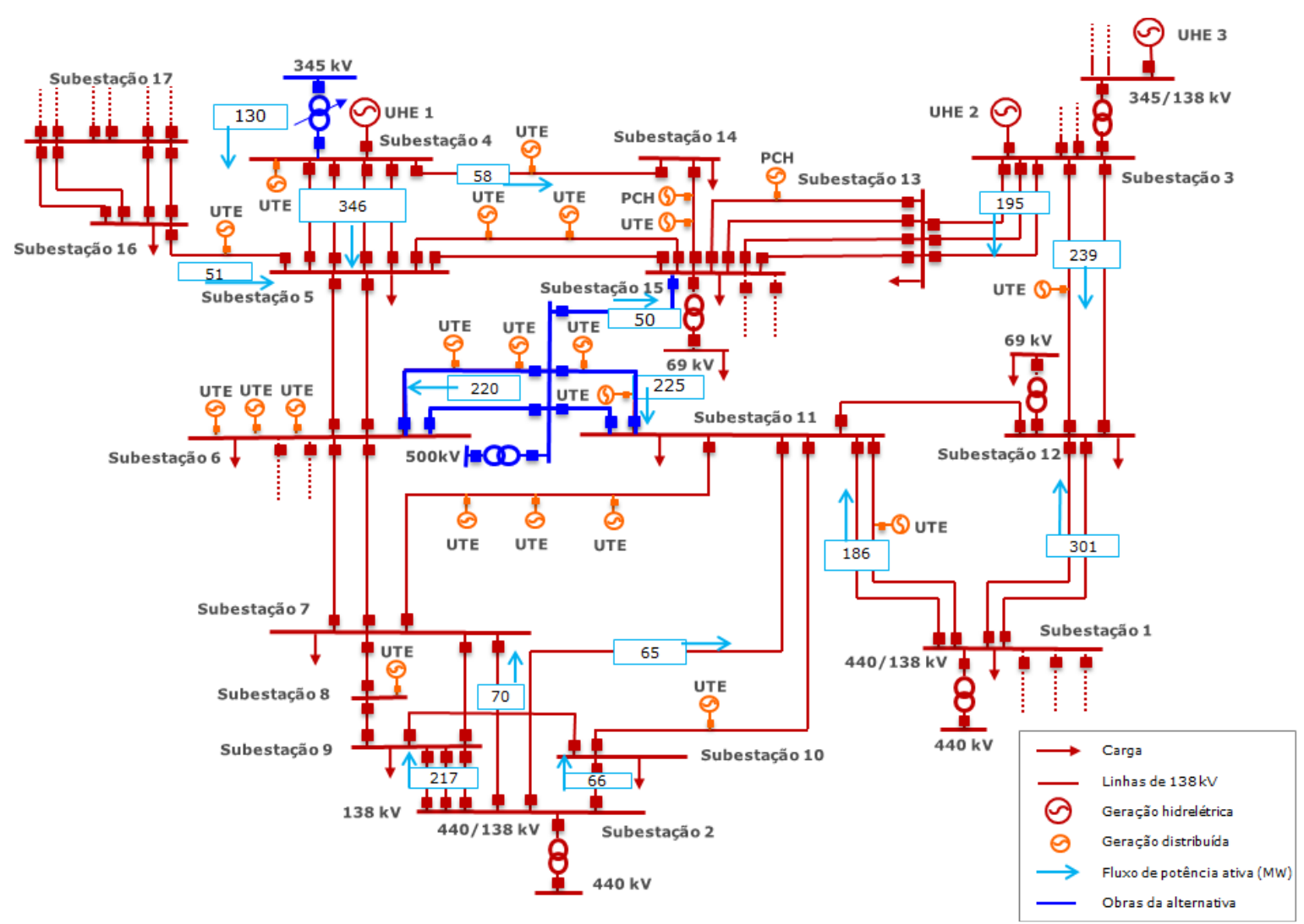

Fonte: Autor. 
Neste cenário de carga média e período de entressafra, a carga da área é atendida através das transformações de fronteira com a Rede Básica, que correspondem às subestações 1, 2, 3 e 4, além das usinas hidrelétricas conectadas nas subestações 3 e 4.

A nova subestação de conexão com o sistema de $500 \mathrm{kV}$ representa uma nova fonte para o sistema, reduzindo o carregamento das linhas de interligação com as demais fontes do sistema, proporcionando também a melhoria do perfil de tensão na região.

A figura 60 mostra para as linhas que apresentaram sobrecarga no sistema sem obras, o máximo carregamento percentual em relação à capacidade nominal, considerando a alternativa de conexão com o sistema de $500 \mathrm{kV}$.

Figura 60 - Alternativa $500 \mathrm{kV}$ - carregamento das linhas de 138 kV (\%)

Patamar de carga média - período de entressafra



Fonte: Autor.

A figura 61 apresenta os valores de tensão em pu nos barramentos de $138 \mathrm{kV}$ que apresentaram indicação de tensão no limite inferior para o sistema sem obras. 
Figura 61 - Alternativa 500 kV - tensão nos barramentos (pu) Patamar de carga média - período de entressafra

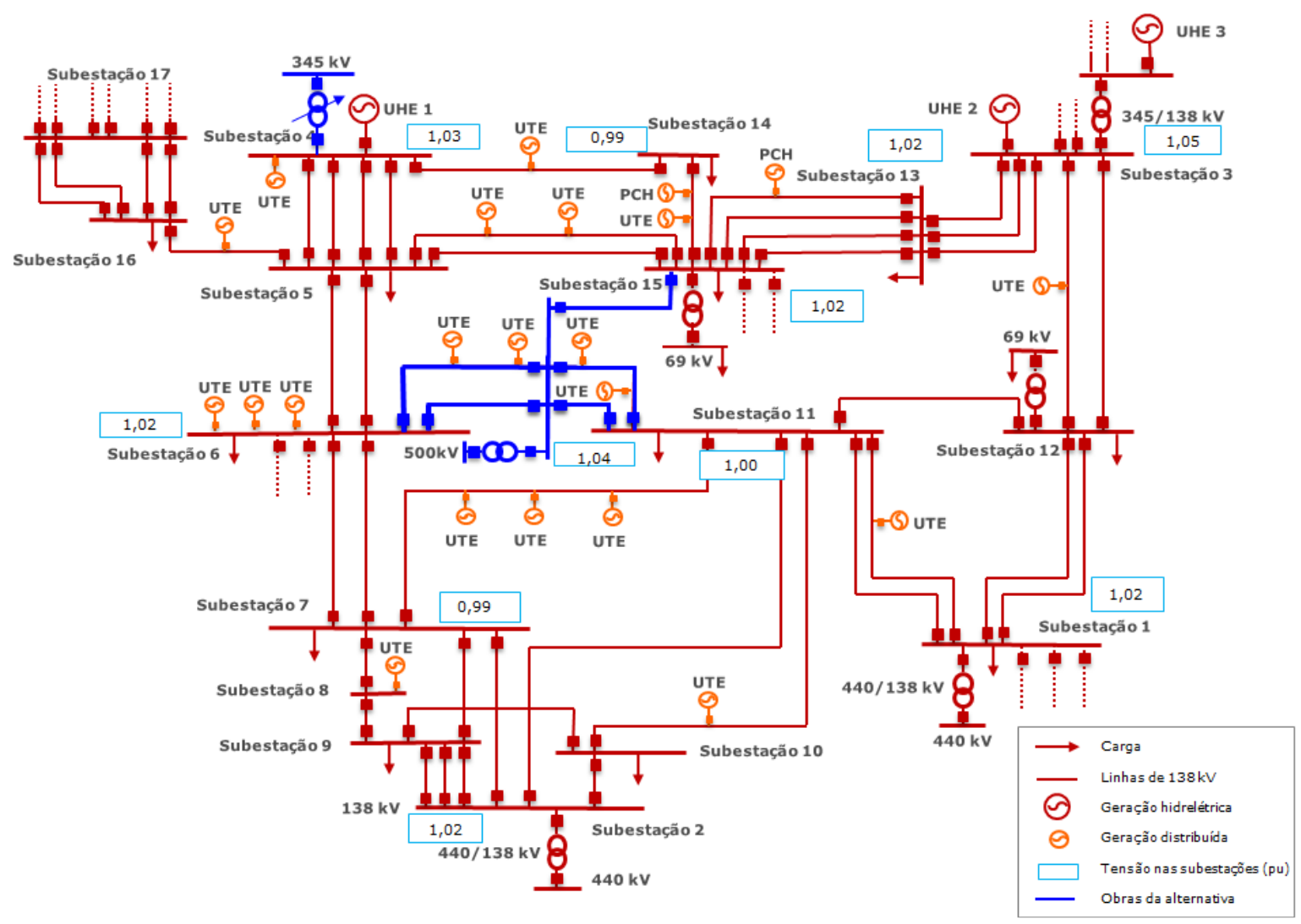

Fonte: Autor.

\subsubsection{Alternativa $500 \mathrm{kV}$ : carga leve - período de safra}

As figuras 62 e 63 apresentam os resultados das simulações no patamar de carga leve e período de safra das usinas a biomassa.

A figura 62 apresenta o fluxo de potência ativa nas linhas de interligação com as barras fontes do sistema. 
Figura 62 - Alternativa $500 \mathrm{kV}$ - fluxo de potência ativa (MW)

Patamar de carga leve - período de safra

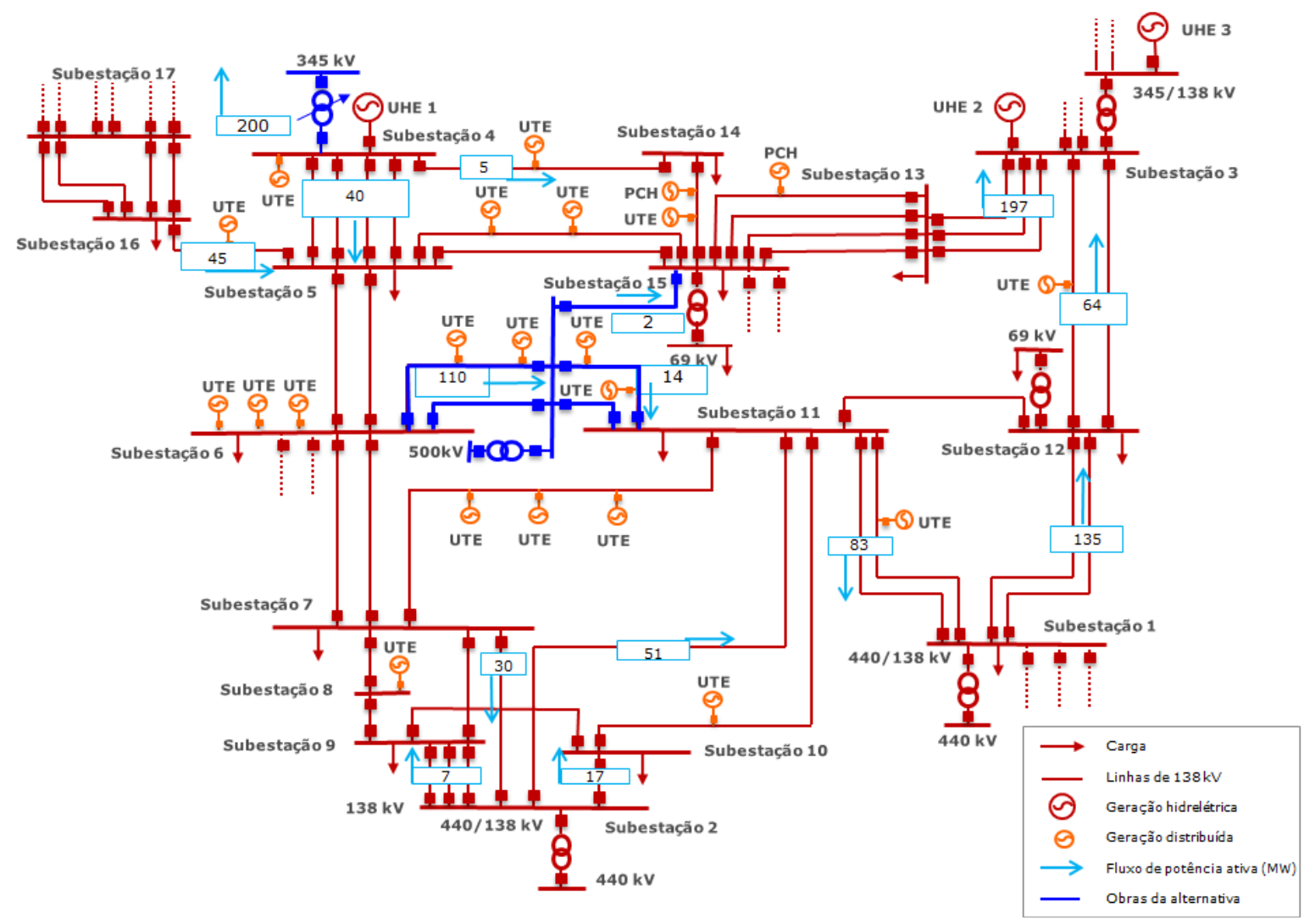

Fonte: Autor.

Neste cenário de carga leve e período de safra, a carga da área é atendida por parte da geração da usina hidrelétrica conectada na subestação 4, pela transformação de fronteira com a Rede Básica da subestação 2, além da geração distribuída conectada no sistema de $138 \mathrm{kV}$.

O transformador defasador realiza a inversão do fluxo de potência ativa do sistema de $138 \mathrm{kV}$ para o sistema de $345 \mathrm{kV}$.

Observa-se a inversão do fluxo de potência nas transformações de fronteira com a Rede Básica das subestações 1, 3 e nova subestação, em função do excedente de geração no sistema de $138 \mathrm{kV}$.

A figura 63 apresenta para as linhas que apresentaram sobrecarga no sistema sem obras, o máximo carregamento percentual em relação à capacidade nominal, considerando a alternativa de conexão ao sistema de $500 \mathrm{kV}$. 
Figura 63 - Alternativa 500 kV - carregamento das linhas de 138 kV (\%) Patamar de carga leve - período de safra

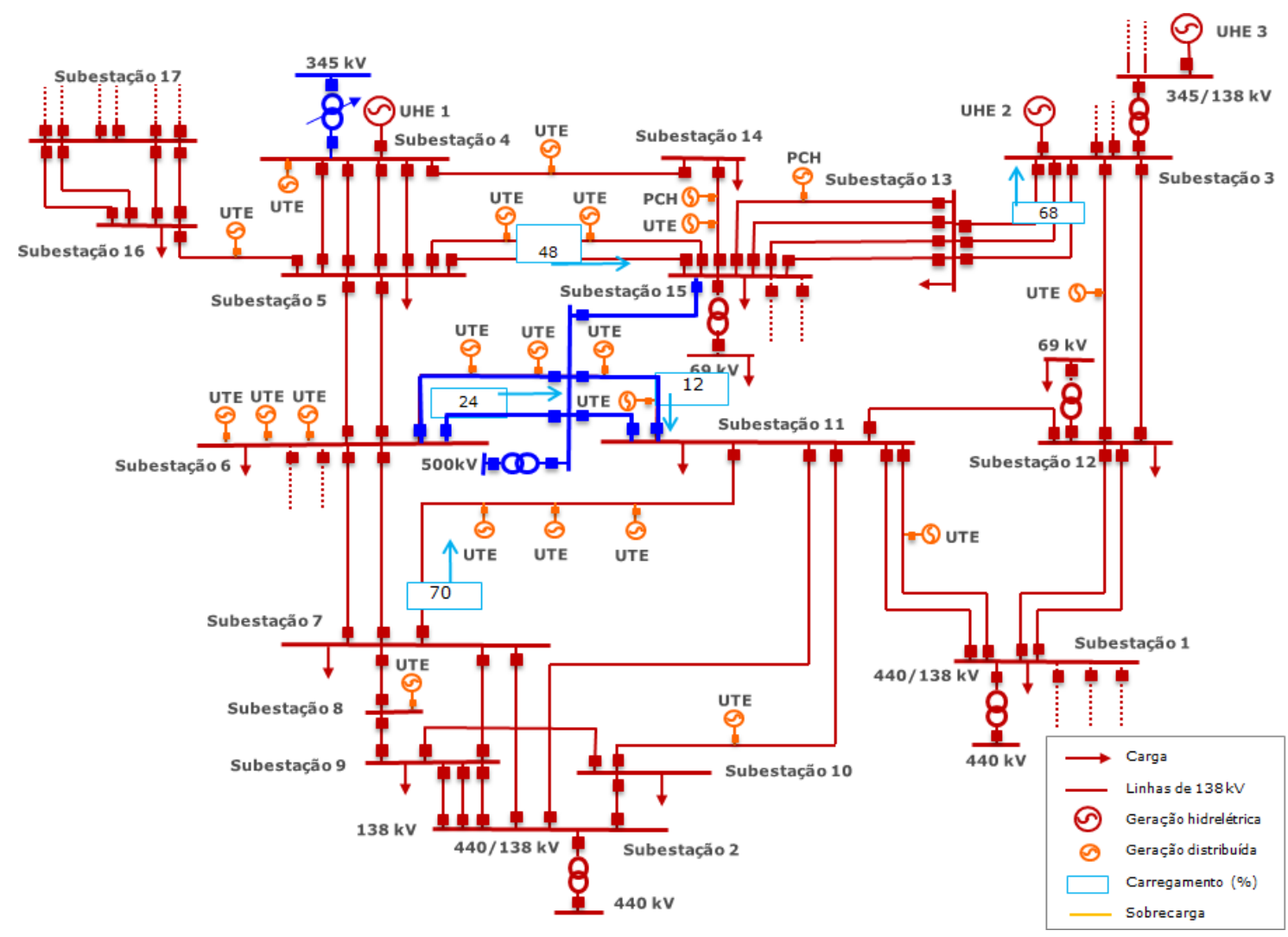

Fonte: Autor.

\subsection{Comparação de alternativas}

A aplicação dos dispositivos FACTS, apesar das vantagens relacionadas ao controle dos principais parâmetros do sistema elétrico e resposta instantânea para mudanças das condições operativas, apresenta restrição associada aos elevados custos destes equipamentos.

A alternativa utilizando o UPFC para controle de fluxo de potência e tensão no sistema de $138 \mathrm{kV}$ obteve efeito similar à alternativa com conexão ao sistema de 500 $\mathrm{kV}$, eliminando as restrições de carregamento das linhas e tensão nos barramentos.

As tabelas 4 e 5 apresentam as estimativas de custos de investimentos para as alternativas de aplicação do UPFC e de conexão do sistema de $500 \mathrm{kV}$ avaliadas. 
Para dimensionamento do UPFC, deve-se considerar que a potência ativa dos conversores corresponde à parcela real do produto entre a tensão série e corrente na linha controlada (DIZDAREVIC, 2002).

Considerando a condição de contingência analisada, com fluxo de potência na linha controlada pelo UPFC de $150 \mathrm{MW}$, e máxima tensão série de 0,4 pu obtida a partir das simulações realizadas, foi definida a potência ativa dos conversores de 11,5 MW e potência reativa de 90 Mvar, resultando na potência aparente mínima de 91 MVA para o UPFC.

Conforme Habur e O'Leary, e considerando um UPFC de 100 MVA, foi estimado o custo de U\$164,3/kVar (conforme gráfico da figura 32) para instalação do UPFC, sendo considerado o incremento de $30 \%$ que corresponde às taxas e impostos. Para conversão em reais, foi adotado o dólar a $R \$ 3,50$.

Tabela 4 - Alternativa de aplicação do UPFC - estimativa de custos

\begin{tabular}{|l|c|}
\hline \multicolumn{1}{|c|}{ Obras Alternativa UPFC } & Custo estimado (mil R\$) \\
\hline Unified Power Flow Controller (UPFC) 100 MVA & 74.757 \\
\hline $\begin{array}{l}\text { Construção da nova subestação 138 kV entre as linhas 6 e 11 (barra dupla } \\
\text { com 5 bays de linha e 1 bay de interligação de barras) }\end{array}$ & 20.500 \\
\hline $\begin{array}{l}\text { Reconstrução de 70 km da linha 138 kV entre as subestações 6 e 11 com } \\
\text { adequações nas subestações existentes ao longo da linha e terminais }\end{array}$ & 60.000 \\
\hline $\begin{array}{l}\text { Construção da linha 138 kV entre a nova subestação e a subestação 9 (100 } \\
\text { km de linha em circuito simples condutores 795 MCM) }\end{array}$ & 54.000 \\
\hline $\begin{array}{l}\text { Instalação de transformação 345/138 kV + transformador defasador 300 MVA } \\
\text { na subestação 4 }\end{array}$ & 25.000 \\
\hline \multicolumn{1}{|c|}{ Total - Alternativa UPFC } \\
\hline
\end{tabular}


Tabela 5 - Alternativa de conexão ao sistema de $500 \mathrm{kV}$ - estimativa de custos

\begin{tabular}{|l|c|}
\hline \multicolumn{1}{|c|}{ Obras Alternativa $500 \mathrm{kV}$} & Custo estimado (mil R\$) \\
\hline $\begin{array}{l}\text { Nova subestação entre as linhas } 6 \text { e } 11 \text { com instalação de } 2 \text { transformadores } \\
500 / 138 \mathrm{kV}-400 \mathrm{MVA}\end{array}$ & 127.000 \\
\hline $\begin{array}{l}\text { Reconstrução de } 70 \mathrm{~km} \text { da linha } 138 \mathrm{kV} \text { entre as subestações } 6 \text { e } 11 \text { com } \\
\text { adequações nas subestações existentes ao longo da linha e terminais }\end{array}$ & 60.000 \\
\hline $\begin{array}{l}\text { Construção da linha } 138 \mathrm{kV} \text { entre a nova subestação e a subestação } 15 \text { (28 } \\
\text { km de linha em circuito duplo condutores 477 MCM) }\end{array}$ & 18.000 \\
\hline $\begin{array}{l}\text { Instalação de transformação } 345 / 138 \mathrm{kV}+\text { transformador defasador } 300 \mathrm{MVA} \\
\text { na subestação } 4\end{array}$ & 25.000 \\
\hline Total - Alternativa $500 \mathrm{kV}$ & 230.000 \\
\hline
\end{tabular}

Considerando somente os custos de investimentos, as alternativas apresentaram valores equivalentes mesmo com o incremento referente a taxas e impostos, além da taxa de câmbio, da alternativa de aplicação do UPFC.

A tabela 6 apresenta as diferenças de perdas técnicas entre a configuração atual do sistema, a alternativa de aplicação do UPFC e a alternativa de conexão ao sistema de $500 \mathrm{kV}$, considerando os ajustes dos casos descritos anteriormente.

Salienta-se que estes valores são apenas indicativos em função da possibilidade de operação dinâmica do UPFC e variação do fluxo de potência no sistema, alterando também os valores das perdas técnicas.

Tabela 6 - Perdas incrementais das alternativas avaliadas [MW]

\begin{tabular}{|c|c|c|c|c|c|c|}
\cline { 2 - 6 } & Pesada safra & $\begin{array}{c}\text { Pesada } \\
\text { entressafra }\end{array}$ & Média safra & $\begin{array}{c}\text { Média } \\
\text { entressafra }\end{array}$ & Leve safra & $\begin{array}{c}\text { Leve } \\
\text { Entressafra }\end{array}$ \\
\hline Caso original & 22,8 & 46,3 & 23,9 & 41,7 & 50,9 & menor perda \\
\hline $\begin{array}{c}\text { Alternativa de conexão com } \\
500 \mathrm{kV}\end{array}$ & 1,5 & menor perda & 2,5 & menor perda & menor perda & 1,9 \\
\hline $\begin{array}{c}\text { Alternativa de aplicação do } \\
\text { UPFC }\end{array}$ & menor perda & 26,2 & menor perda & 21,2 & 6,9 & 1,0 \\
\hline
\end{tabular}

Observa-se a variação da alternativa referencial de perdas técnicas (menor perda) de acordo com o patamar de carga e período de safra ou entressafra. 
Nestas condições, a alternativa de 500 kV corresponde à alternativa com menores perdas totais.

A alternativa de aplicação do UPFC apresentou perdas inferiores à alternativa de 500 kV nos períodos de carga pesada e média na safra. Nos períodos de carga pesada e média na entressafra, a aplicação do UPFC apresentou perdas superiores à alternativa de $500 \mathrm{kV}$, devido principalmente às perdas na linha de interligação entre a nova subestação e a subestação 9.

Para determinação dos custos associados às perdas técnicas relativas a cada alternativa, deve ser considerada a duração de horas diária para cada patamar de carga, além do período de meses correspondente ao período de safra e entressafra, durante o horizonte de dez anos. Os valores são então obtidos a valor presente com taxa de retorno de $8 \%$ a.a. e custo para a energia de perdas de $193 \mathrm{R} \$ / \mathrm{MWh}$, valores do Custo Marginal de Expansão (EPE, 2016).

Com base nas perdas incrementais da tabela 6, a alternativa de aplicação do UPFC teria um custo adicional de perdas de aproximadamente $R \$ 59$ milhões quando comparado à alternativa de conexão com o sistema de $500 \mathrm{kV}$, resultando em um custo global (investimentos + perdas) $27 \%$ superior.

Porém, a operação dinâmica do UPFC permitiria a redução das perdas através da variação do fluxo de potência de acordo com a carga e geração do sistema a cada instante.

A aplicação do UPFC também apresentaria vantagens relacionadas à flexibilidade operativa, com possibilidade de mudança instantânea dos parâmetros controlados (fluxo de potência e nível de tensão) em casos de contingência, além do controle de demanda nas fronteiras com o sistema de transmissão. 


\section{CONCLUSÕES}

O programa ANAREDE, adotado pelos diversos agentes do setor elétrico brasileiro para estudos de fluxo de potência no Sistema Interligado Nacional, não dispõe de um modelo para o UPFC (equipamento da família FACTS existente no mercado).

Este trabalho discute e compara os modelos que poderiam ser utilizados no ANAREDE para representação do UPFC, apresentando uma formulação viável para implementação através dos modelos de equipamentos existentes no programa do CEPEL, com a combinação de um compensador estático e um transformador defasador. As análises comparativas demonstraram a eficiência da representação apresentada.

É conhecida a dificuldade em se encontrar uma condição prática de utilização do UPFC, em função do elevado custo ainda apresentado por este equipamento.

A partir da formulação dos modelos propostos, o trabalho discute a utilização do UPFC em uma rede real de $138 \mathrm{kV}$ que faz a conexão entre diferentes pontos de fronteira com a Rede Básica e possui uma grande quantidade de usinas a biomassa conectadas, analisando detalhadamente seu comportamento nas várias condições operativas deste sistema. Com base nesta análise pode-se verificar uma condição real para aplicação do UPFC, caso o conjunto de alternativas para expansão do sistema estivesse restrito à rede de $138 \mathrm{kV}$.

Entretanto, no caso particular da rede estudada, existe a alternativa de uma nova fonte com conexão ao sistema de $500 \mathrm{kV}$ localizada no centro do sistema de $138 \mathrm{kV}$, qualificando-a como alternativa promissora.

Com a aplicação do UPFC, assim como na alternativa de conexão com o sistema de $500 \mathrm{kV}$, foram eliminadas as restrições previstas no sistema sem obras, com redução do carregamento das linhas e melhoria do perfil de tensão no sistema.

Também foi verificada a possibilidade de controle de carregamento de linhas em condição de contingência através da mudança instantânea dos parâmetros controlados pelo UPFC. Outro benefício da aplicação do UPFC seria a possibilidade de controle de demanda nas fronteiras com o sistema de transmissão.

A alternativa de aplicação do UPFC apresentou custos de investimentos similares aos da alternativa de conexão com o sistema de 500 kV. Entretanto, nesta aplicação 
do UPFC a alternativa apresentou perdas superiores à conexão com o sistema de $500 \mathrm{kV}$, não considerando a possibilidade de operação dinâmica do UPFC que permitiria reduzir estes valores através do ajuste instantâneo do fluxo de potência de acordo com as condições do sistema.

A análise demonstrou as possibilidades e os benefícios associados à aplicação do UPFC para controle de tensão e fluxo de potência em sistemas com elevada quantidade de geração distribuída conectada que apresentam cenários bastante distintos ao longo do ano, demonstrando que, apesar das diversas alternativas possíveis para expansão do sistema, pode-se elaborar uma solução restrita ao sistema de 138 kV que viabilizaria a utilização do UPFC em um caso prático.

\subsection{Trabalhos futuros}

Apesar dos inúmeros temas associados ao estudo dos dispositivos FACTS, mais especificamente ao UPFC, abaixo são listadas algumas propostas:

- Análise dinâmica do UPFC.

- Comparação com alternativas utilizando outros equipamentos FACTS, como capacitores série controlados ou não.

- Redirecionamento de fluxo de potência e otimização de perdas.

- Estudo dos controles para atuação do UPFC.

- Alocação ótima de UPFC. 


\section{REFERÊNCIAS}

ACHA, E.; FUERTE-ESQUIVEL, C. Unified Power Flow Controller: a Critical Comparison of Newton-Raphson UPFC Algorithms in Power Flow Studies. IEEE Proc.-Gener. Transm. Distrib., IEEE, v.144, n.5, p.437-444, 1997.

ACHA, E. et al. FACTS Modelling and Simulation in Power Networks. England: John Wiley \& Sons, LTD, 2004. 403p.

AHMADNIA et al. New Modeling of UPFC for Power Flow Study and Setting Parameters to Increase Voltage Level and Reduce Power Losses. International Journal of Automation and Power Engineering, Iran, n.1, p.77-82, 2012.

AN, S.; CONDREN, J.; GEDRA, T. W. An Ideal Transformer UPFC Model, OPF First-Order Sensitivities, and Application to Screening for Optimal UPFC Locations. IEEE TRANSACTIONS ON POWER SYSTEMS, IEEE, v.22, n.1, p.6875, 2007.

ANEEL. Leilão de Transmissão 007/2014. Lote G - Relatório R1. Disponível em: <http://www.aneel.gov.br/aplicacoes/editais_transmissao>. Acesso em: 1 jan. 2016.

ARA, A. L.; KAZEMI, A.; NIAKI, S. N. Modelling of Optimal Unified Power Flow Controller (OUPFC) for optimal steady-state performance of power systems. Energy Conversion and Management, ECM, v.52, n.2, p.1325-1333, 2011.

ARNEZ, R. L. V.; ZANETTA, L. C. Unified Power Flow Controller (UPFC): its versatility in handling power flow and interaction with the network. Transmission and Distribution Conference and Exhibition , Asia Pacific, v.2, n.0, p.1338-1343, 2002.

BABU et al. Power Flow Analysis of a Power System in the presence of Interline Power Flow Controller (IPFC). Journal of Engineering and Applied Sciences, Asian Research Publishing Network, v.5, n.10, p.1-4, 2010.

B.H.CHANG et al. COMMISSIONING AND TESTING OF THE KANGJIN UPFC IN KOREA. CIGRÉ, PARIS, v.B4, n.211, p.-, 2004.

BIAN, J.; J.NELSON, R. UPFC APPLICATION ON THE AEP SYSTEM: PLANNING CONSIDERATIONS. IEEE Transactions on Power Systems, IEEE, v.12, n.4, p.1695$1701,1997$.

CHEN et al. An Approach to Embed Power Flow Control Model of UPFC into PSASP Based on User Program Interface Function. Journal of Computers, JCP, v.9, n.1, p.146-152, 2014.

CIGRE TASK FORCE 38.01.08 Modeling of Power Electronics Equipment (FACTS) in Load Flow and Stability Programs. France: Cigré, 1999. 105p. 
CIGRÉ TASK FORCE 14.27 Unified Power Flow Controller (UPFC). France: Cigré, 2000. 110p.

DIZDAREVIC et al. Converter rating powers of unified power flow controller. Power Engineering Society Summer Meeting, IEEE, v.1, n.7541136, p.603-309, 2002.

EPE - Empresa de Pesquisa Energética. Relatório "EPE-DEE-RE-124_2012-rev1 (Reavaliação atendimento à região nordeste da CPFL Paulista)_final", 2010.

EPE - Empresa de Pesquisa Energética. Relatório " No EPE-DEE-RE-010/2016-r0 (Custo Marginal de Expansão)", 2016.

FUERTE-ESQUIVEL, C.; AMBRIZ-PEREZ, H.; FUERTE-ESQUIVEL, C. A Comprehensive Newton-Raphson UPFC Model for the Quadratic Power Flow Solution of Practical Power Networks. IEEE TRANSACTIONS ON POWER SYSTEMS, IEEE, v.15, n.1, p.102-109, 2000.

GYUGYI, L. Unified power flow control concept for flexible AC transmission systems. Generation, Transmission and Distribution, IEE Proceedings C, IEE, v.139, n.4, p.323-331, 1992.

GYUGYI, L. Dynamic Compensation of AC Transmission Lines by solid-state synchronous voltage sources. IEEE Transactions on Power Delivery, IEEE, v.9, n.2, p.904-911, 1994.

GYUGYI, L. et al. The Unified Power Flow Controller: a new approach to power transmission control. IEEE Transactions on Power Delivery, IEEE, v.10, n.2, p.1085-1097, 1995.

GYUGYI, L.; K.SEN, K.; SCHAUDER, C. D. The Interline Power Flow Controller Concept: a new approach to power flow management in transmission systems. IEEE Transactions on Power Delivery, IEEE, v.14, n.3, p.1115-1123, 1999.

HINGORANL, N. G.; GYUGYI, L. Understanding FACTs. United States of America: IEEE Press, 2000. 432p.

HABUR, K.; O'LEARY, D. FACTS for cost effective and reliable transmission of electrical energy. SIEMENS.

HINGORANI, N. G. Power Electronics in Electric Utilities: Role of Power Electronics in Future Power Systems. PROCEEDINGS OF THE IEEE, IEEE, v.76, n.4, p.481-482, 1988.

IRAVANI,M.; NABAVI-NIAKI, A. Steady-State and Dynamic Models of Unified Power Flow Controller (UPFC) for Power System Studies. IEEE Transactions on Power Systems, IEEE, v.11, n.4, p.1937-1943, 1996.

L'ABBATE et al. Advanced Steady-State Models of UPFC for Power System Studies. Power Engineering Society Summer Meeting, IEEE, v.1, n.0, p.449-454, 
2002.

LIU, J.; MEHTA, P.; SONG, Y. Power injection modeling and optimal multiplier power flow algorithm for steady-state studies of unified power flow controllers. Electric Power Systems Research, EPSR, v.52, n.1, p.51-59, 1999.

NOROOZIAN et al. Use of UPFC for Optimal Power Flow Control. IEEE Transactions on Power Delivery, IEEE, v.12, n.4, p.1629-1634, 1997.

PADIYAR,K. R. FACTS CONTROLLERS IN POWER TRANSMISSION AND

DISTRIBUTION. India: NEW AGE INTERNATIONAL PUBLISHERS, 2007. 532p.

PAL, B.; REHTANZ, C.; ZHANG, X. Flexible AC Transmission Systems:

Modelling and Control. Germany: Springer, 2006. 383p.

PEREIRA, M. Otimização de Fluxo de Potência em Redes Elétricas com o UPFC. 2008. 120f. Tese (Doutorado em sistemas de potência) - Escola Politécnica da Universidade de São Paulo, São Paulo, 2008.

PEREIRA, M.; ZANETTA, L. C. A current based model for load flow studies with UPFC. IEEE Transactions on Power Systems, IEEE, v.28, n.2, p.677-682, 2013.

SADIKOVIC, R. Power Flow Control with UPFC, Technical Report. Power Systems \& High Voltage Laboratories (EEH), Zurich, v.0, n.0, p.1-20, 2003. Disponível em:

http://www.eeh.ee.ethz.ch/uploads/tx ethpublications/power flow control upfc.pdf

SCHAUDER et al. Operation of the Unified Power Flow Controller (UPFC) under practical constraints. IEEE Transactions on Power Delivery, IEEE, v.13, n.2, p.630639, 1998.

SIEMENS, CONVERTIBLE STATIC COMPENSATOR (CSC) FOR NEW YORK POWER AUTHORITY. TECHNICAL REPORT, EPRI, n.1001970, p.-, 2001.

SOOD, Y.; TIWARI, P. Efficient and optimal approach for location and parameter setting of multiple unified power flow controllers for a deregulated power sector. IET Generation, Transmission \& Distribution, IET, v.6, n.10, p.958-967, 2011.

TOKUNO, S.E.; ZANETTA, L. C. Análise de modelos do Unified Power Flow Controller (UPFC) para simulação de fluxo de potência. Conferência Brasileira sobre Qualidade da Energia Elétrica, 2015, Campina Grande.

TUMAY,M.; VURAL, A. M. Mathematical modeling and analysis of a unified power flow controller: a comparison of two approaches in power flow studies and effects of UPFC location. Electrical Power and Energy Systems, EPES, v.29, n.8, p.617-629, 2007.

WATANABE et al. Tecnologia FACTS - Tutorial. SBA Controle \& Automação, Brasil, v.9, n.1, p.39-55, 1998. 


\section{APÊNDICE - Resultados das simulações}

A seguir são apresentados os fluxos de potência ativa, reativa, carregamento percentual em relação à capacidade nominal das linhas e níveis de tensão nos barramentos das subestações, complementares aos dados apresentados no trabalho. Os valores de fluxo de potência correspondem à somatória da potência em todos os circuitos das linhas que interligam as subestações, indicação do sentido do fluxo de potência através das setas. O carregamento percentual apresentado corresponde ao maior carregamento dos circuitos das linhas em relação à sua capacidade nominal e emergência nestas condições.

\subsection{Sistema atual}

Figura 64 - Fluxo de potência ativa (MW) - carga média - período de entressafra

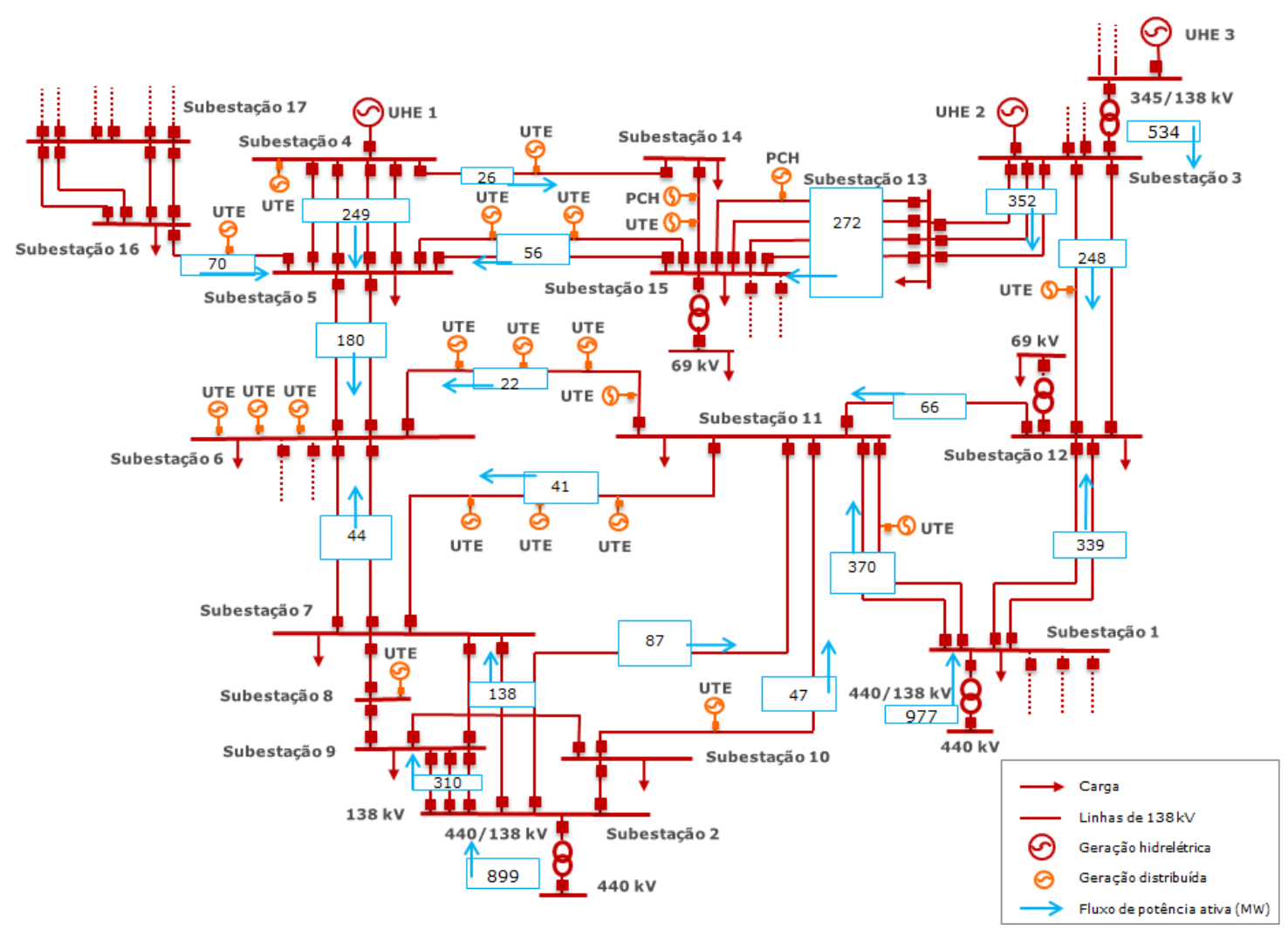

Fonte: Autor. 
Figura 65 - Fluxo de potência reativa (Mvar) - carga média - período de entressafra

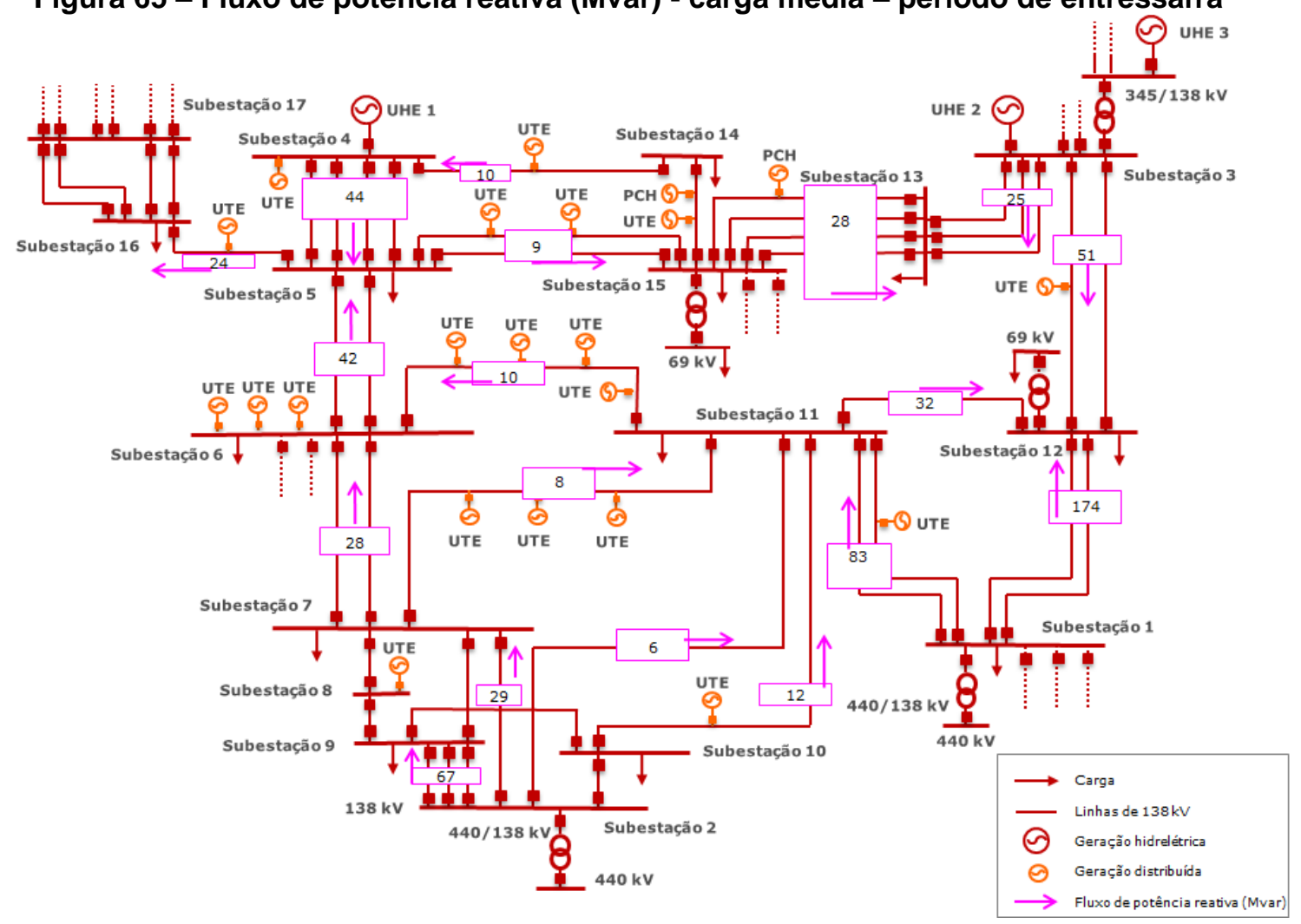

Fonte: Autor.

Figura 66 - Carregamento das linhas de 138 kV (\%) - carga média - período de entressafra



Fonte: Autor. 
Figura 67 - Tensão nos barramentos (pu) - carga média - período de entressafra

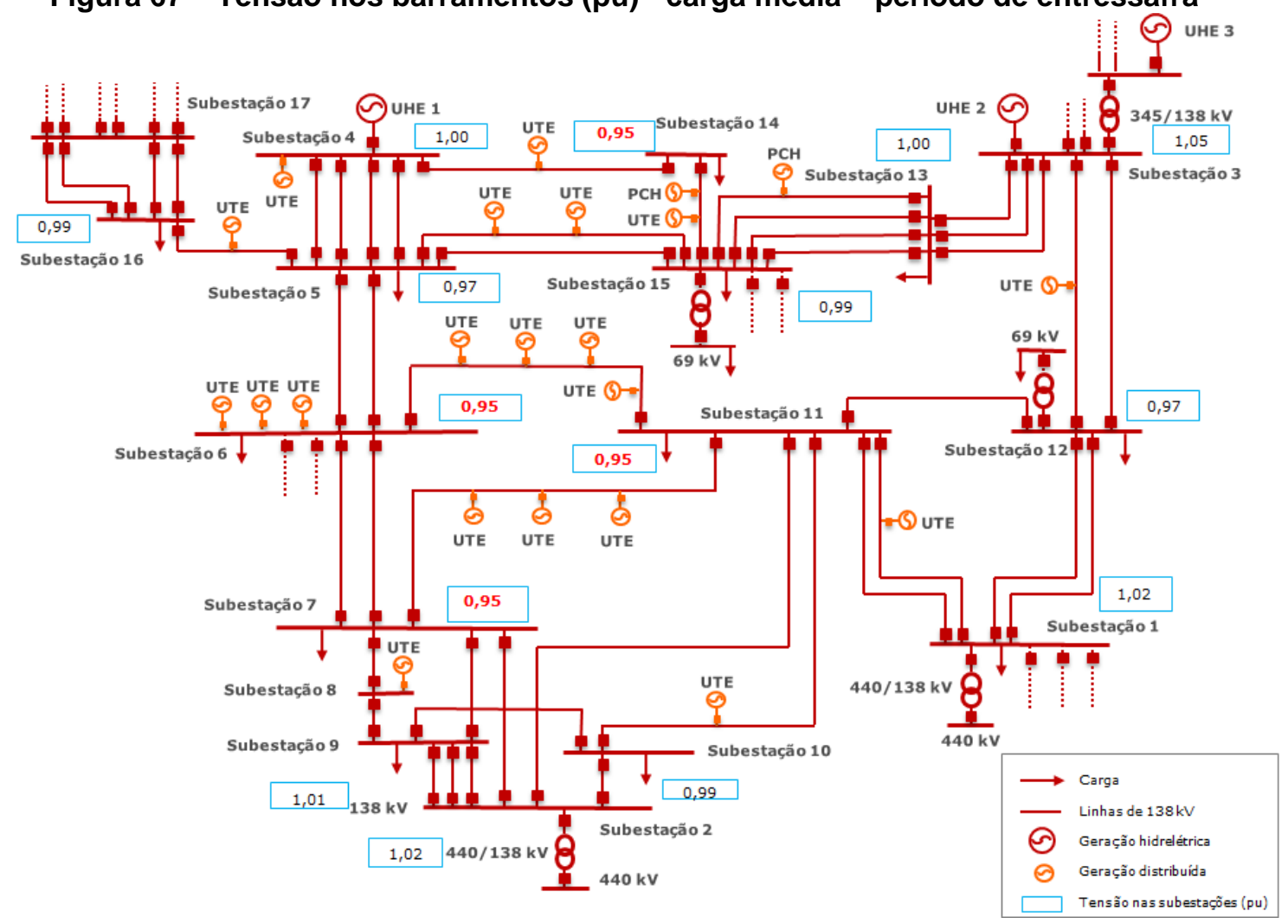

Fonte: Autor.

Figura 68 - Fluxo de potência ativa (MW) - carga leve - safra

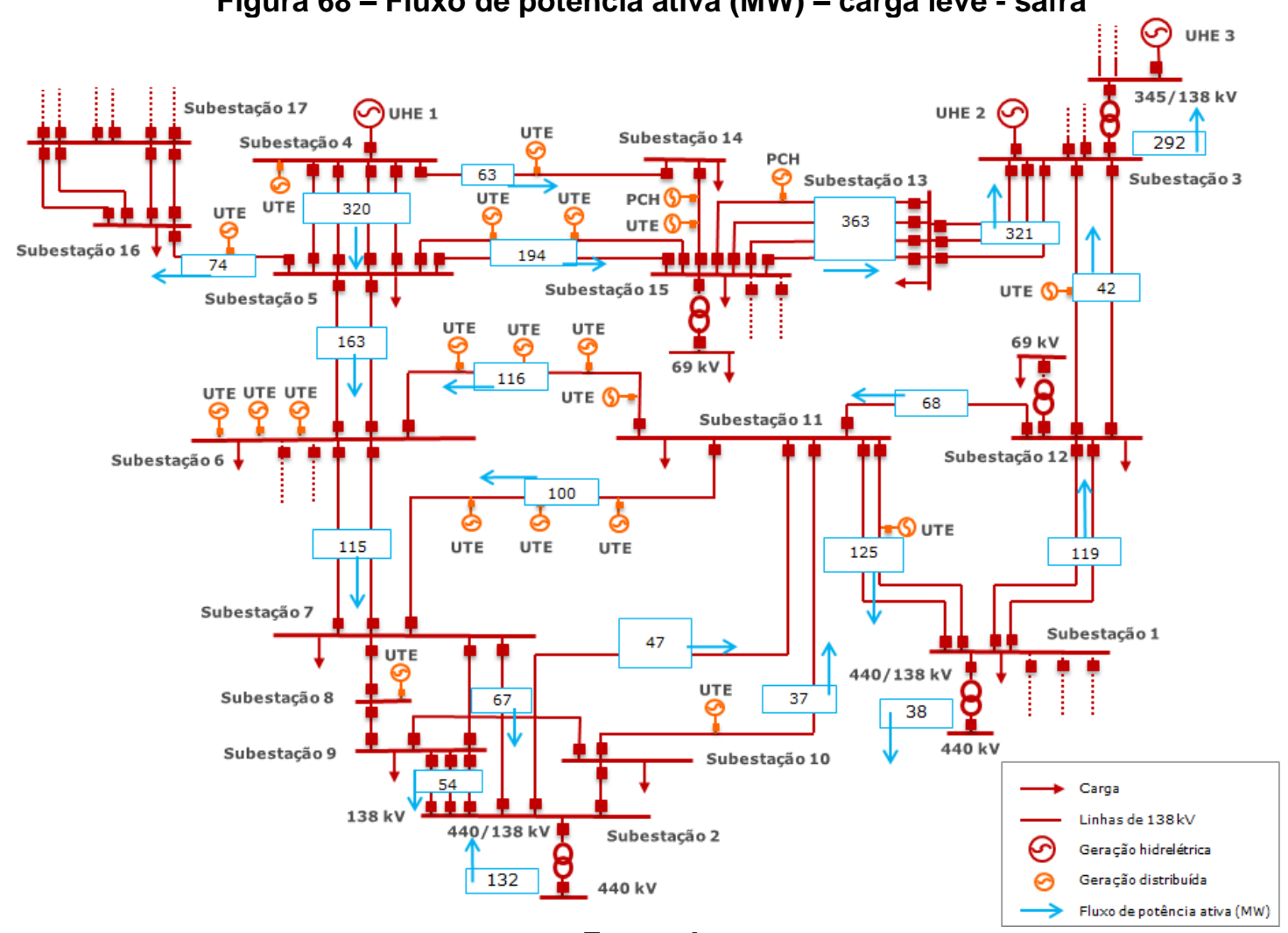

Fonte: Autor. 
Figura 69 - Fluxo de potência reativa (Mvar) - carga leve - período de safra

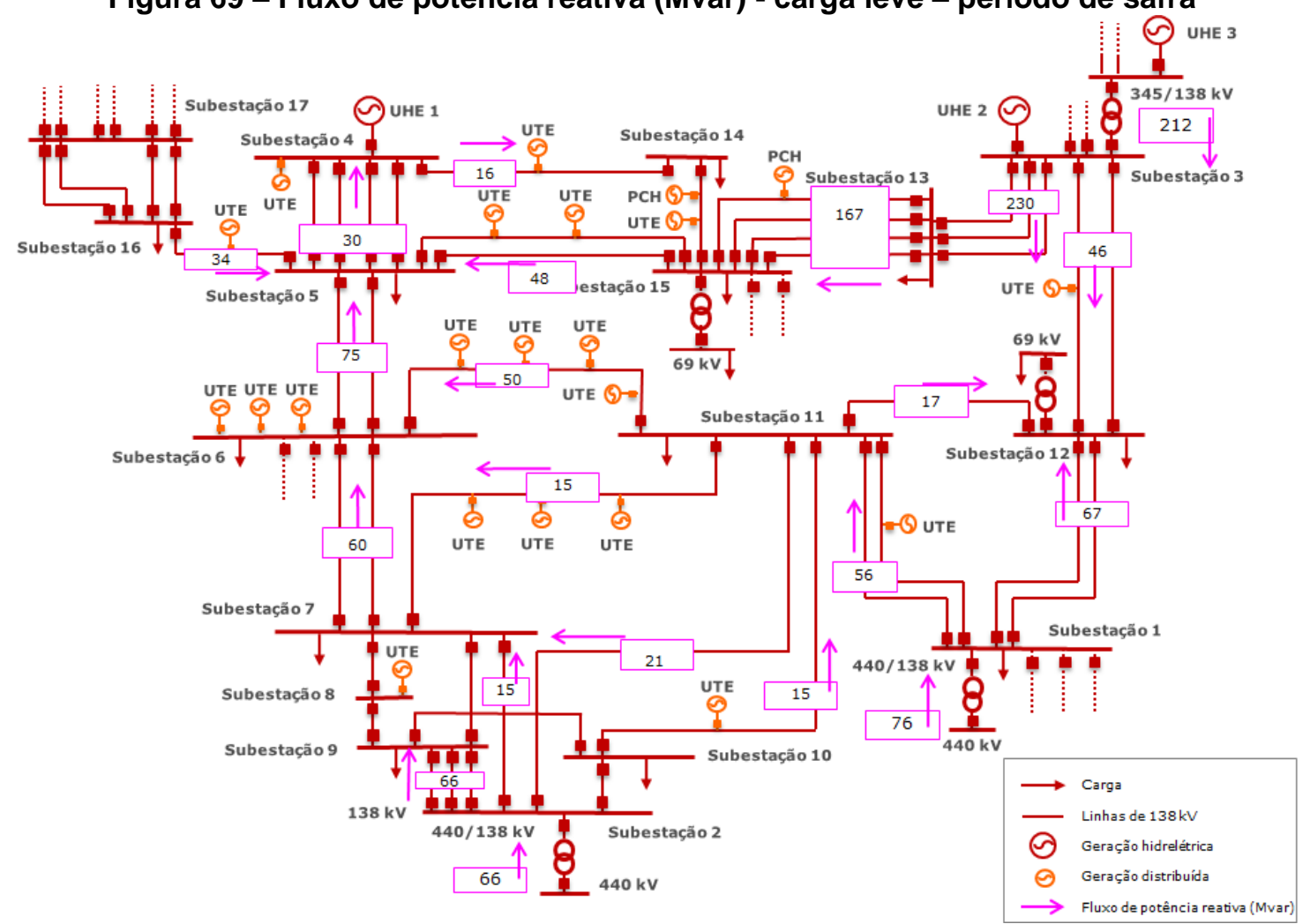

Fonte: Autor.

Figura 70 - Carregamento das linhas de $138 \mathrm{kV}(\%)$ - carga leve - período de safra

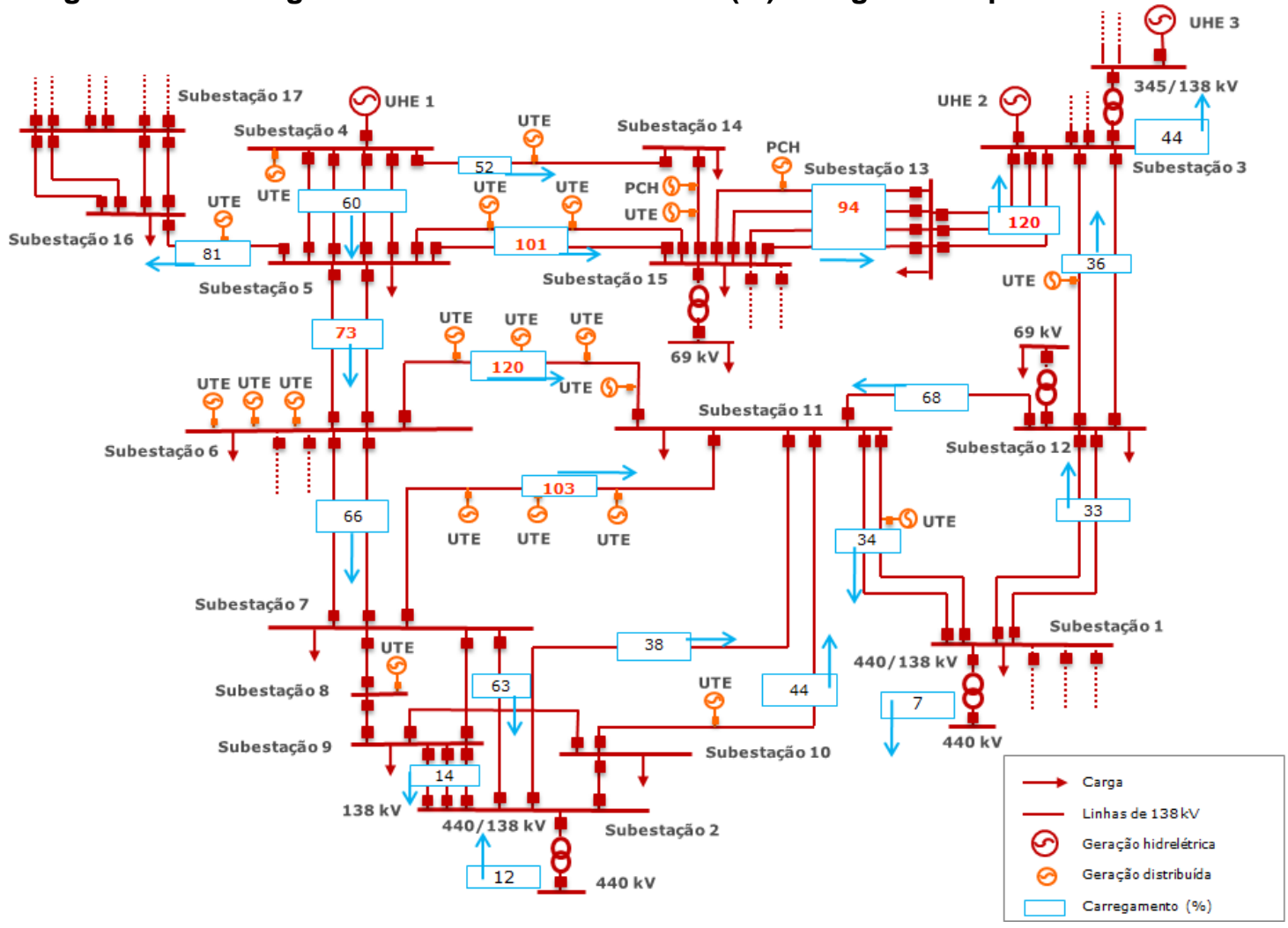

Fonte: Autor. 
Figura 71 - Tensão nos barramentos (pu) - carga leve - período de safra

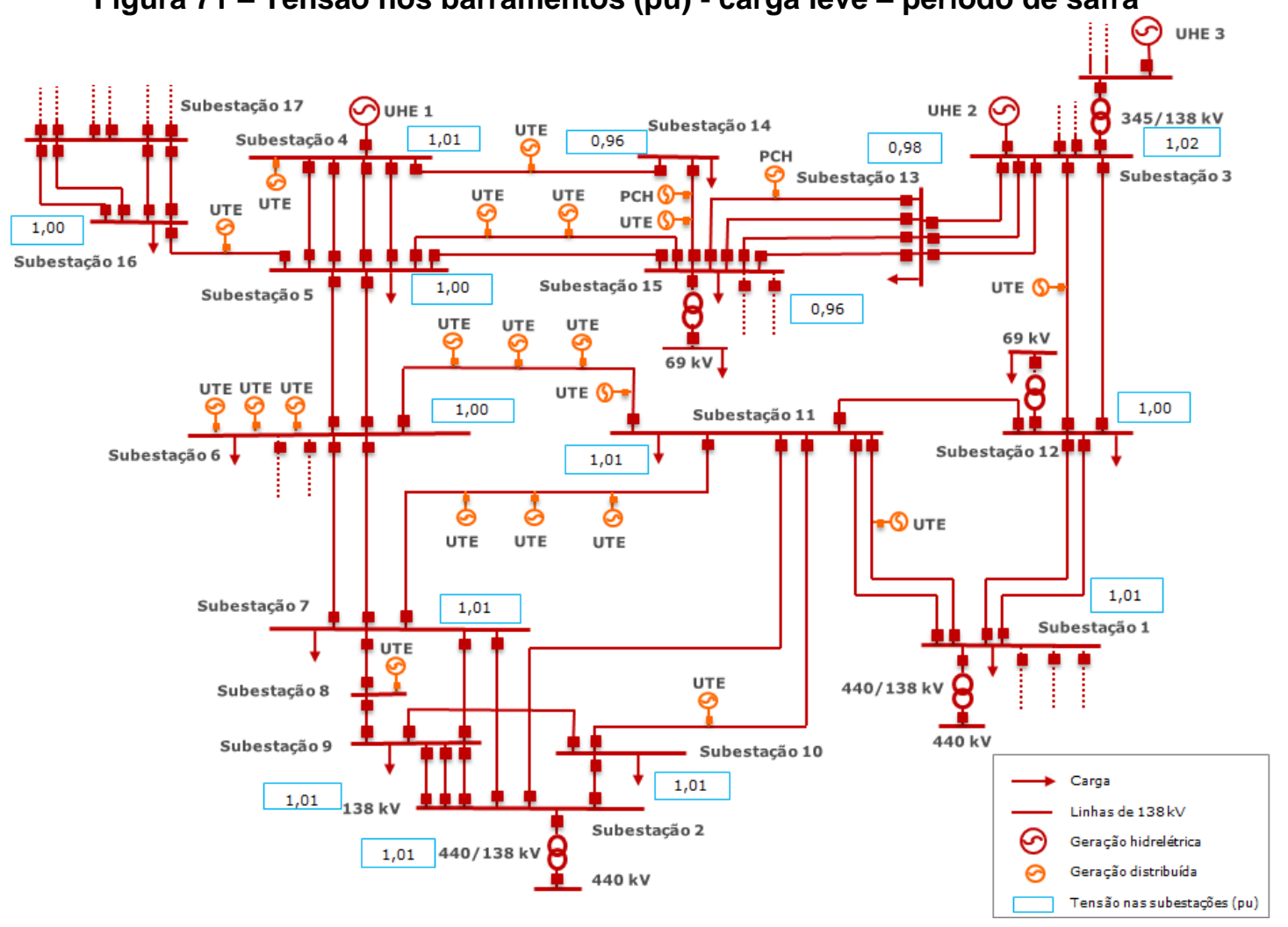

Fonte: Autor.

\subsection{Alternativa com UPFC}

Figura 72 - Alternativa com UPFC - Fluxo de potência ativa (MW) - carga média - entressafra

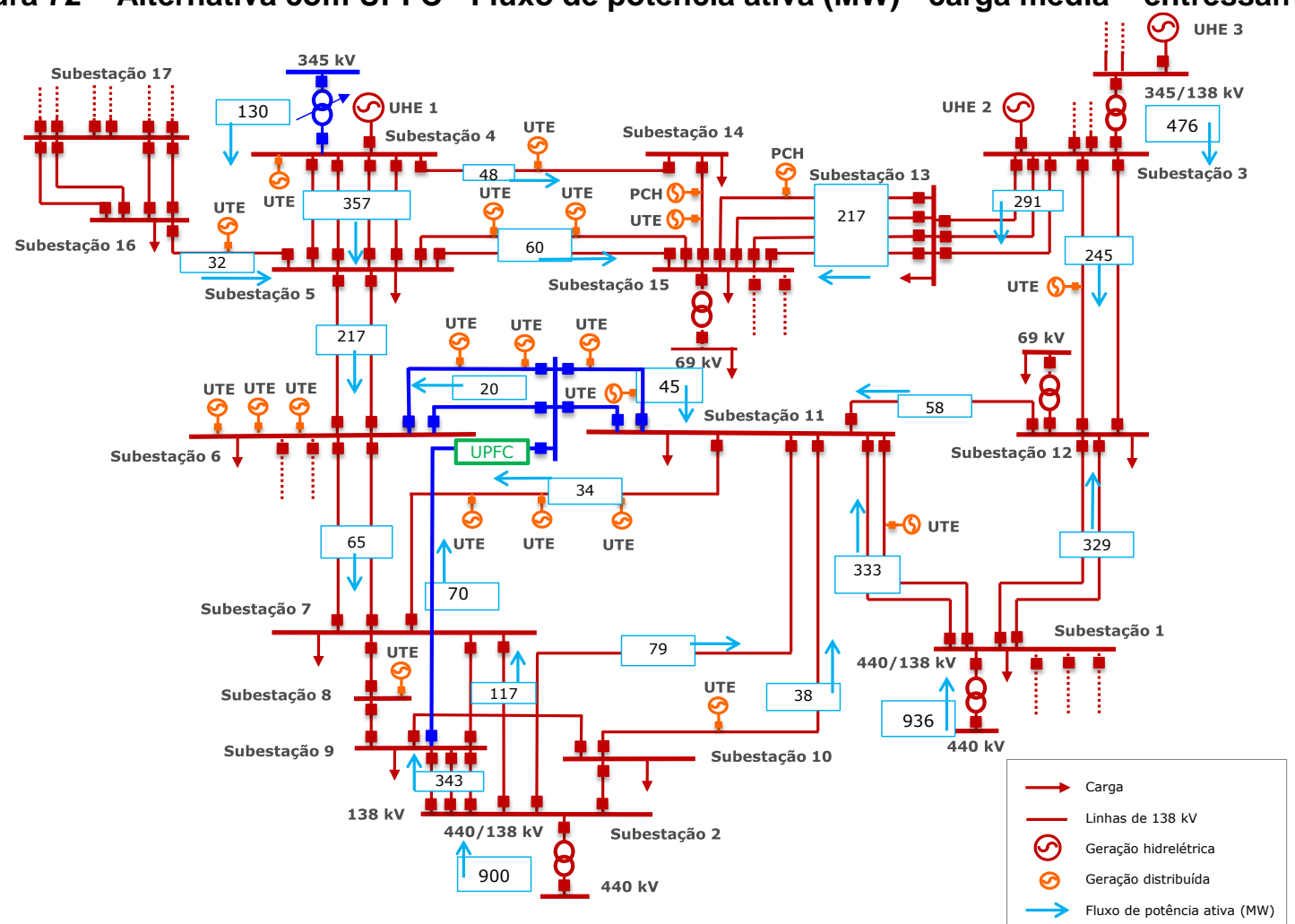

Fonte: Autor. 
Figura 73 - Alternativa com UPFC - Fluxo de potência reativa (Mvar) - carga média -entressafra

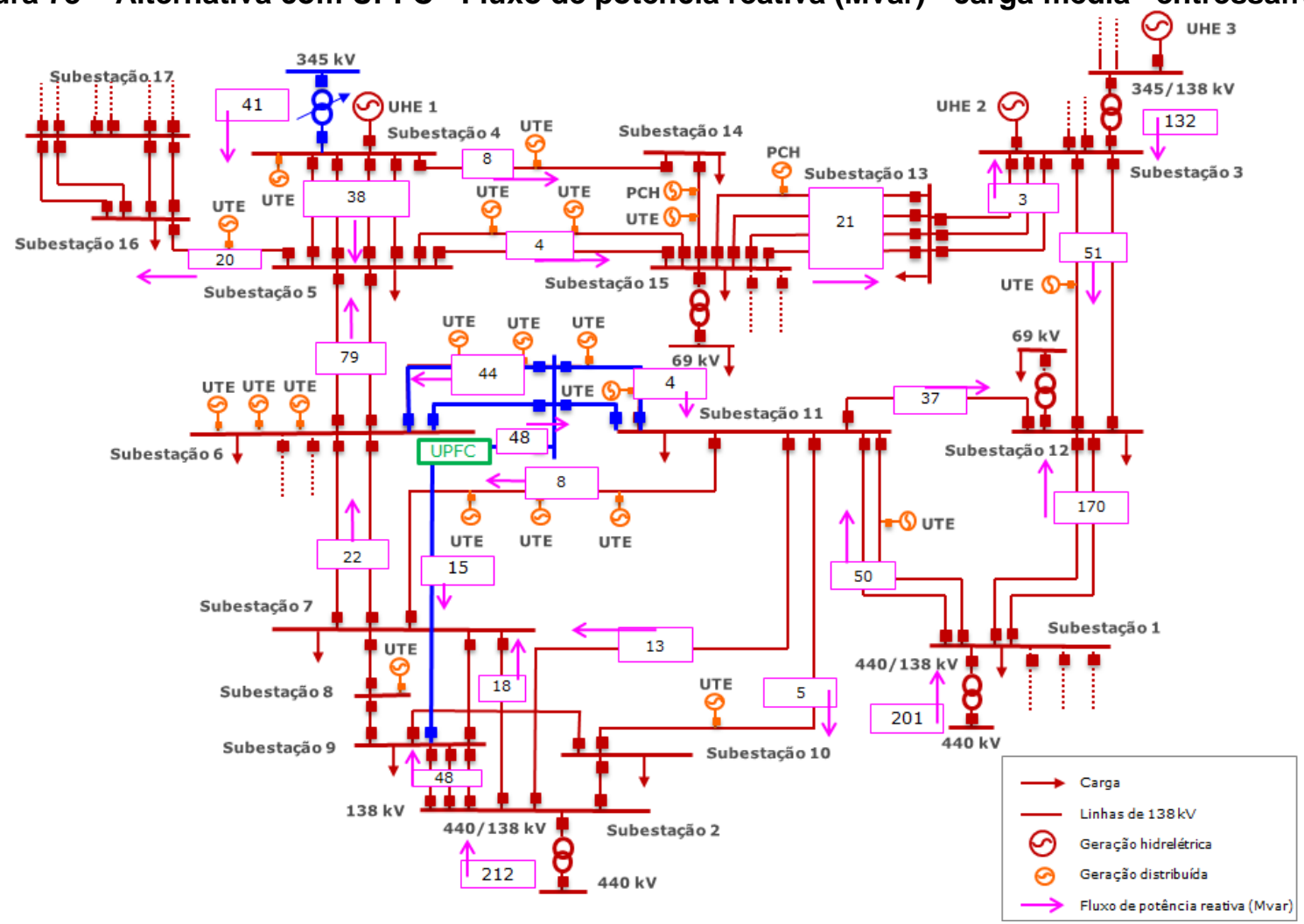

Fonte: Autor.

Figura 74 - Alternativa com UPFC - carregamento das linhas (\%) - carga média -entressafra

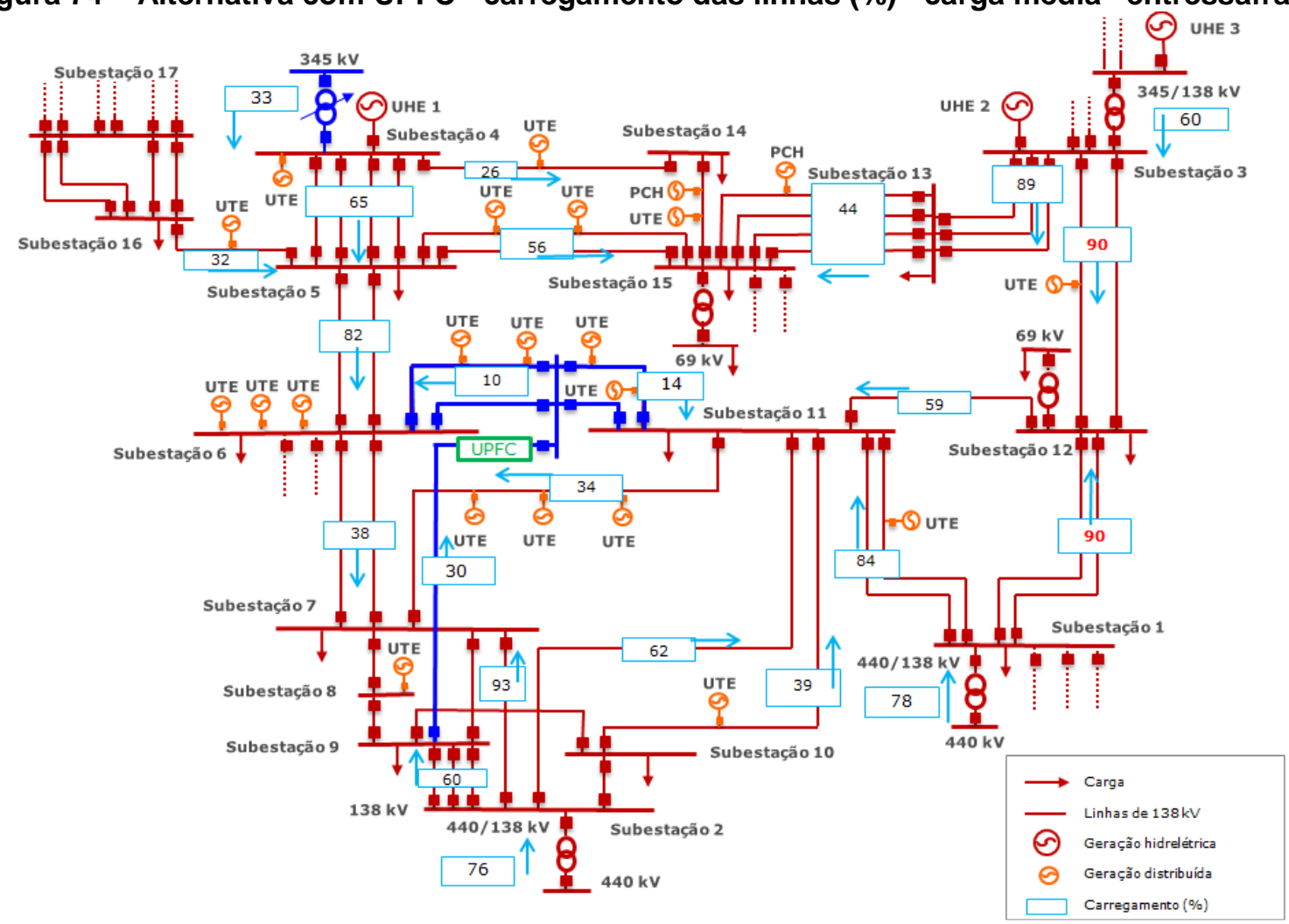

Fonte: Autor. 
Figura 75 - Alternativa com UPFC - tensão nos barramentos (pu) - carga média -entressafra

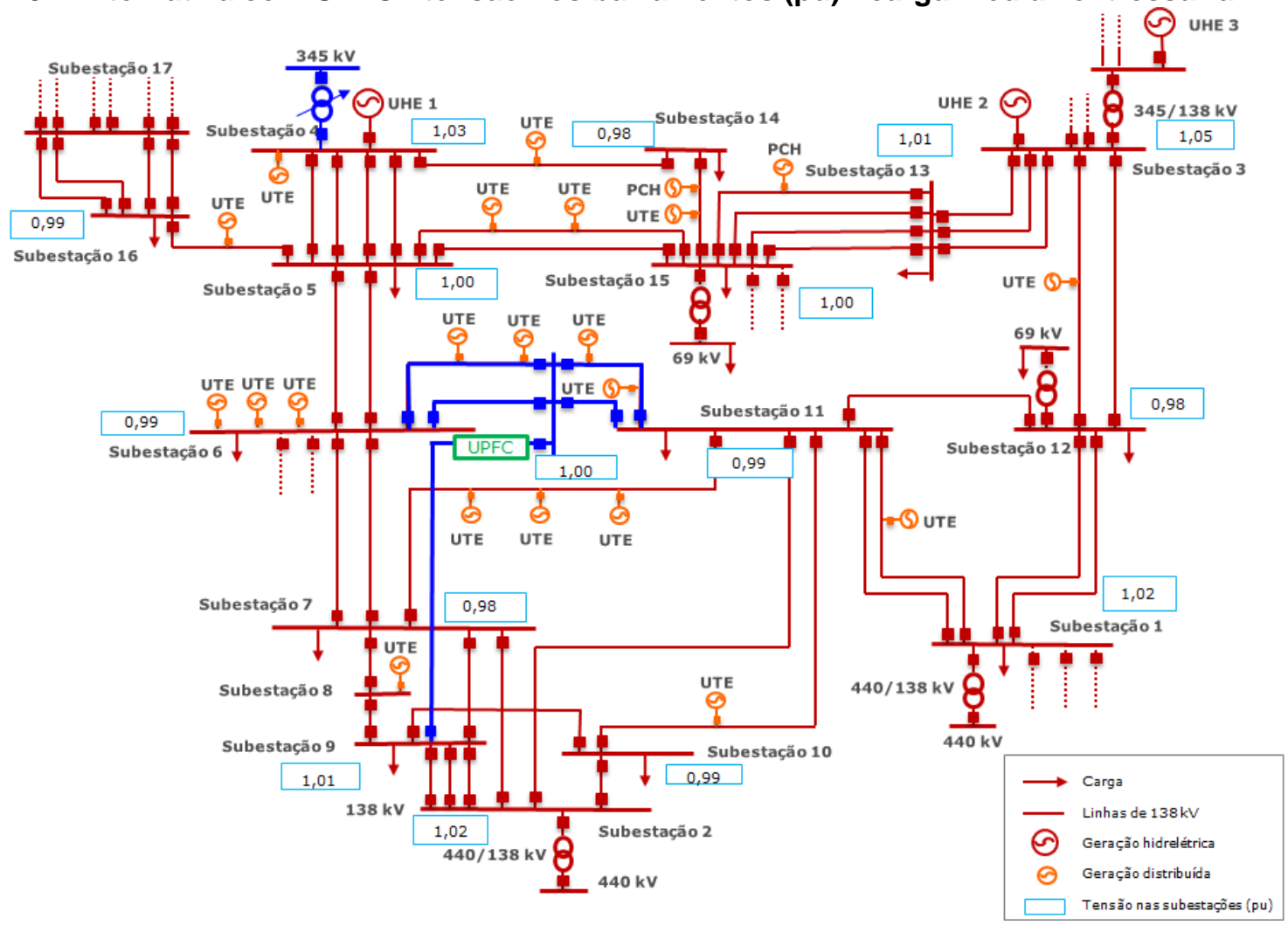

Fonte: Autor.

Figura 76 - Alternativa com UPFC - fluxo de potência ativa (MW) - carga leve - período de safra

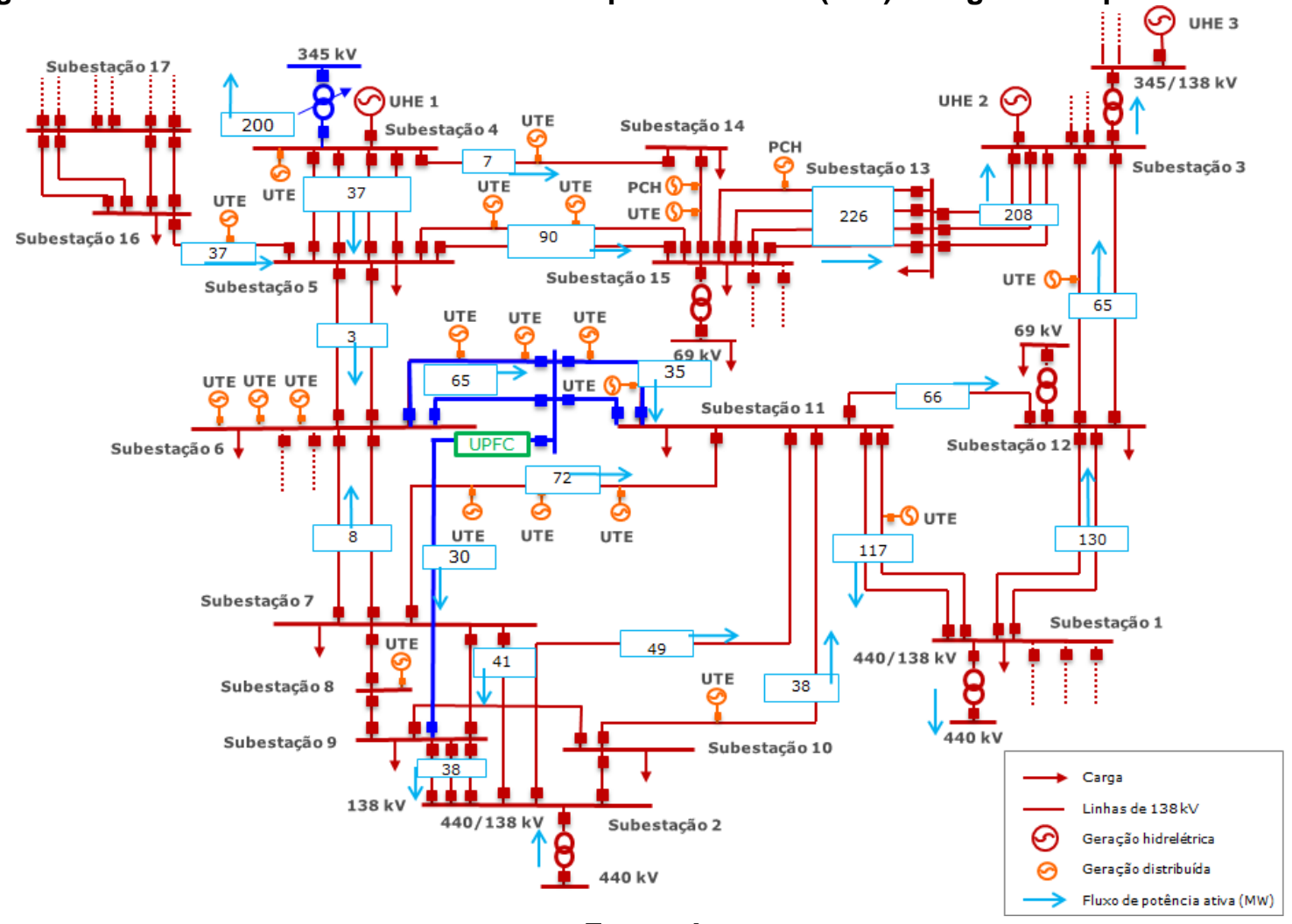

Fonte: Autor. 
Figura 77 - Alternativa com UPFC - fluxo de potência reativa (Mvar) - carga leve - safra

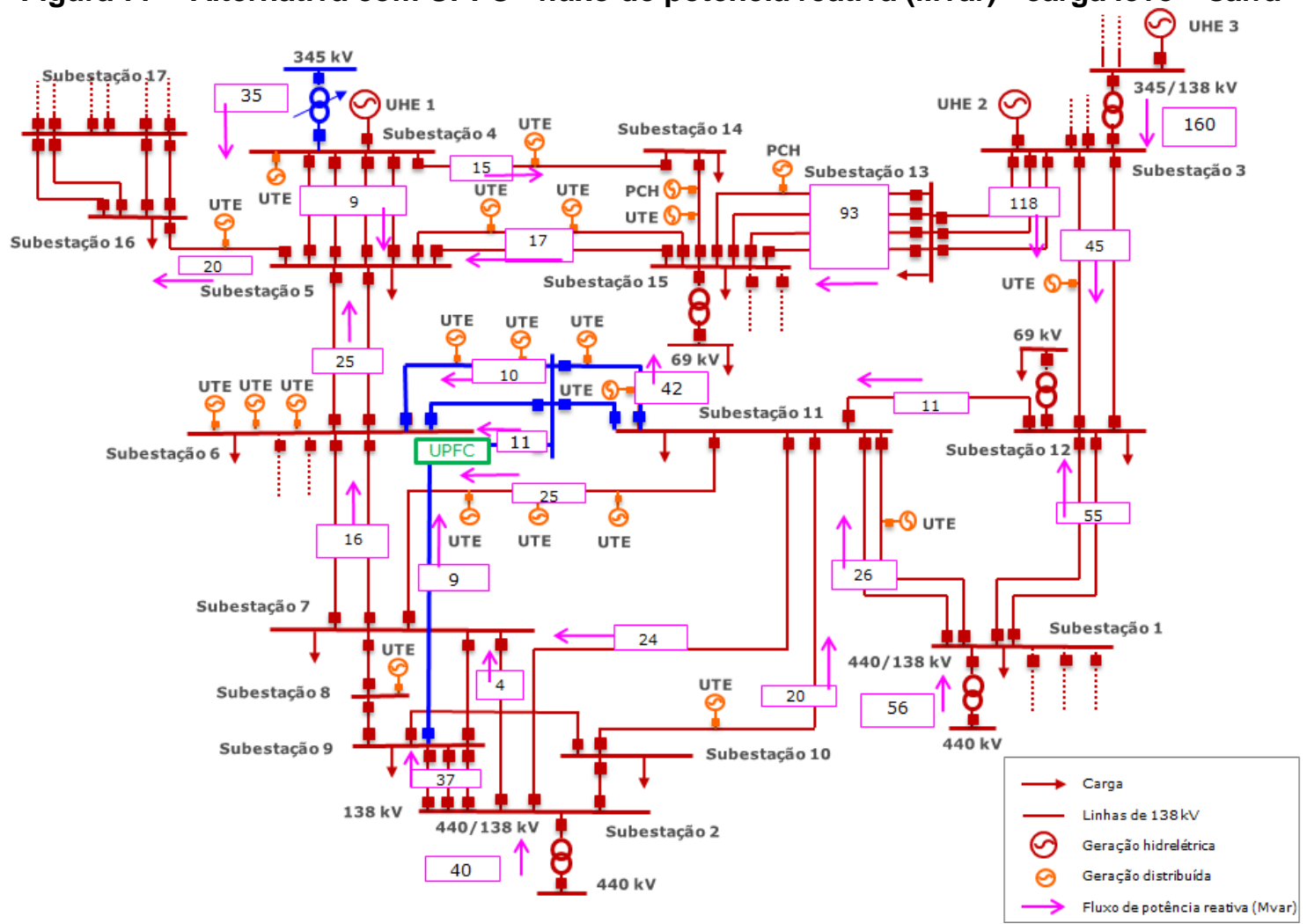

Fonte: Autor.

Figura 78 - Alternativa com UPFC - carregamento das linhas de 138 kV (\%) - carga leve -safra

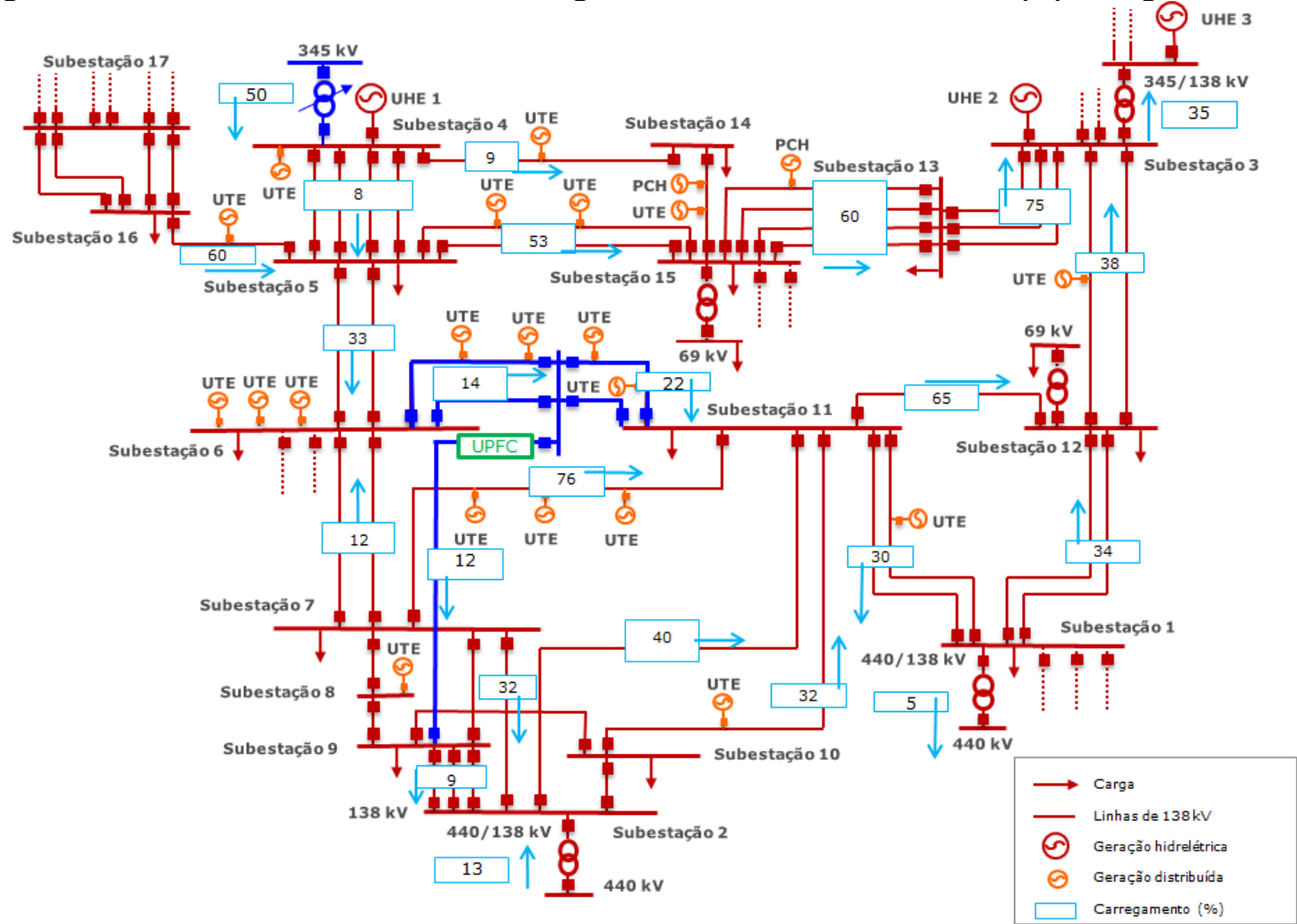

Fonte: Autor. 
Figura 79 - Alternativa com UPFC - tensão nos barramentos (pu) - carga leve - safra

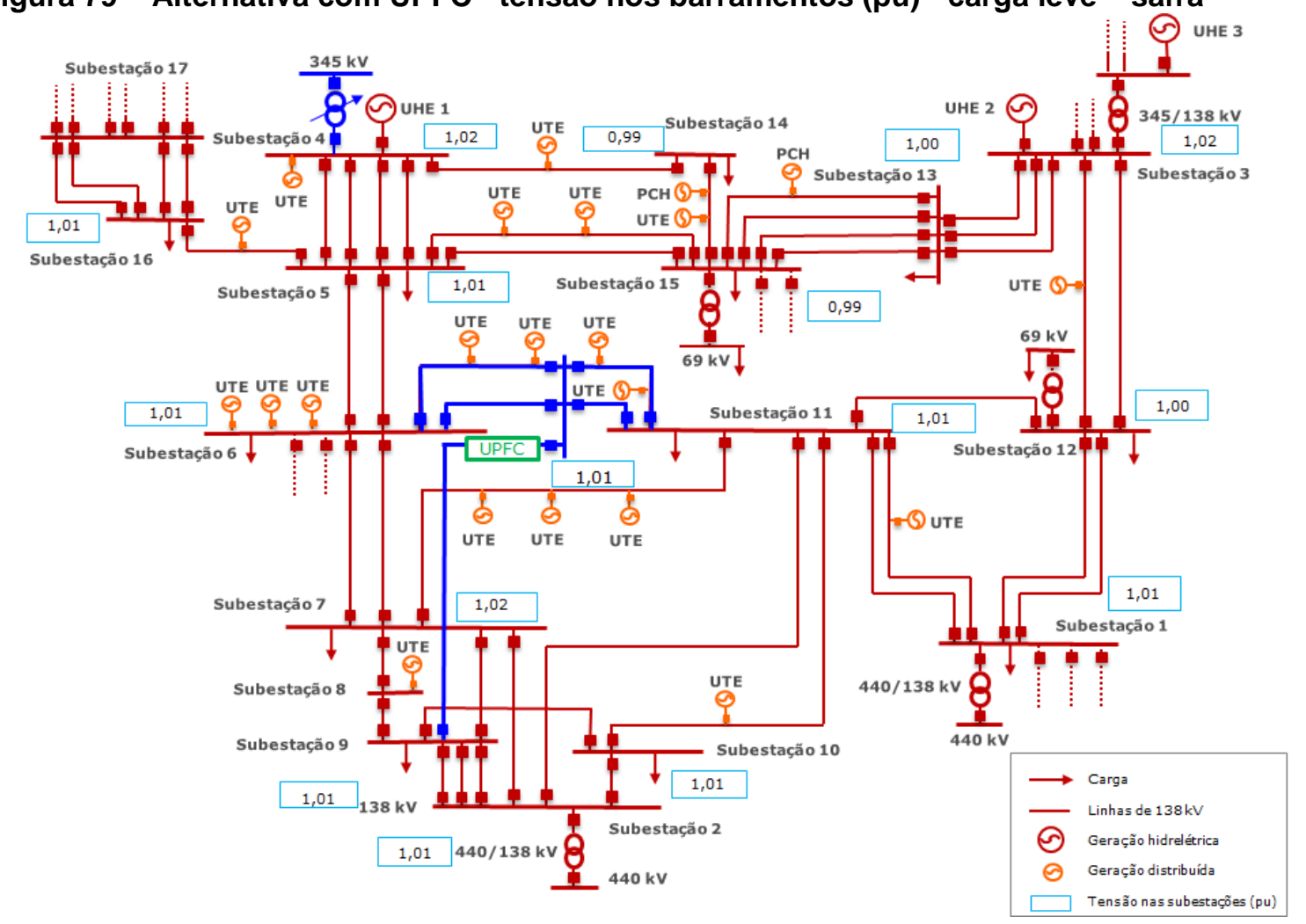

Fonte: Autor.

\subsection{Alternativa com conexão ao sistema de $500 \mathrm{kV}$}

Figura 80 - Alternativa 500 kV - fluxo de potência ativa (MW) - carga média - entressafra

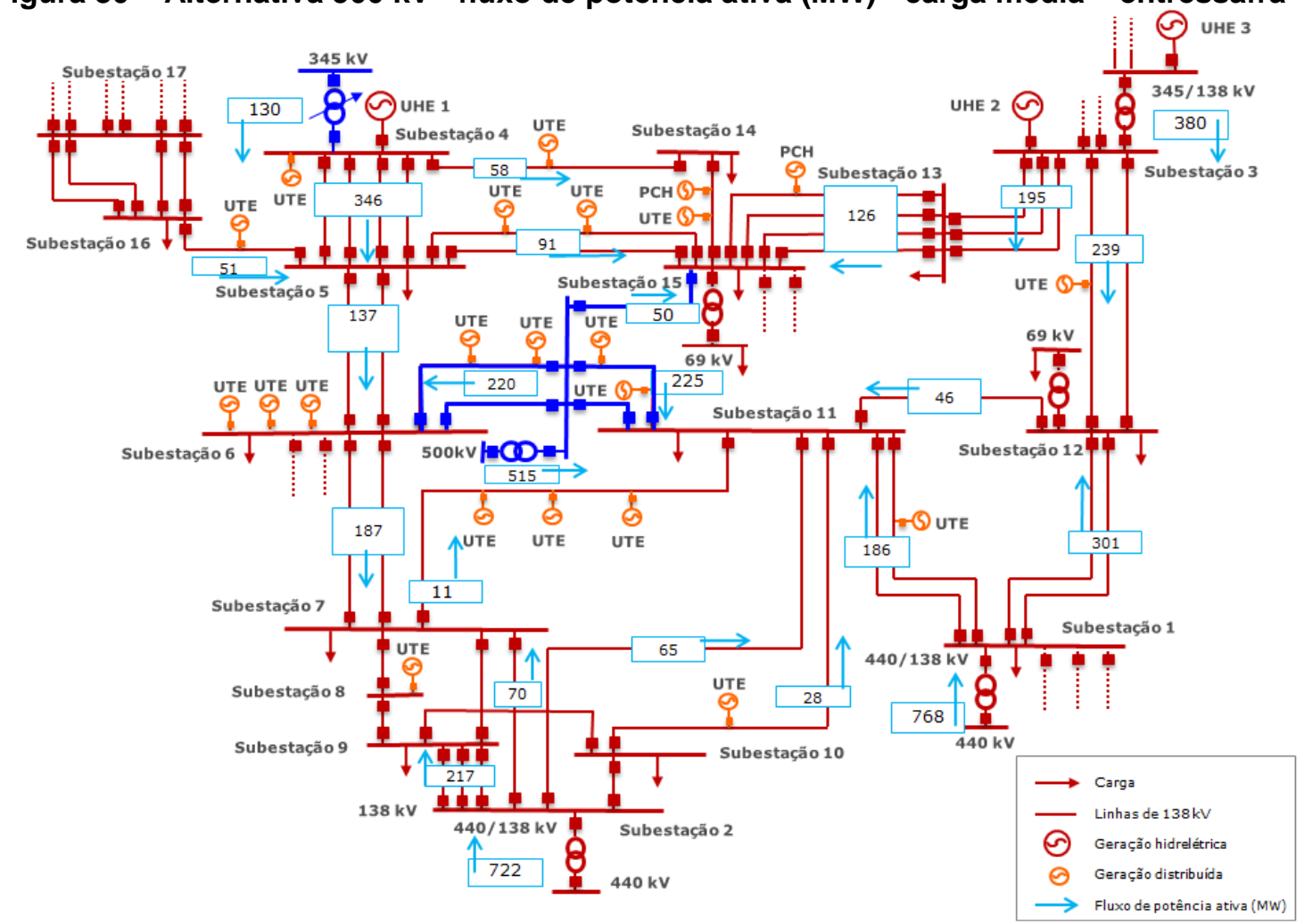

Fonte: Autor. 
Figura 81 - Alternativa 500 kV - fluxo de potência reativa (Mvar) - carga média - entressafra

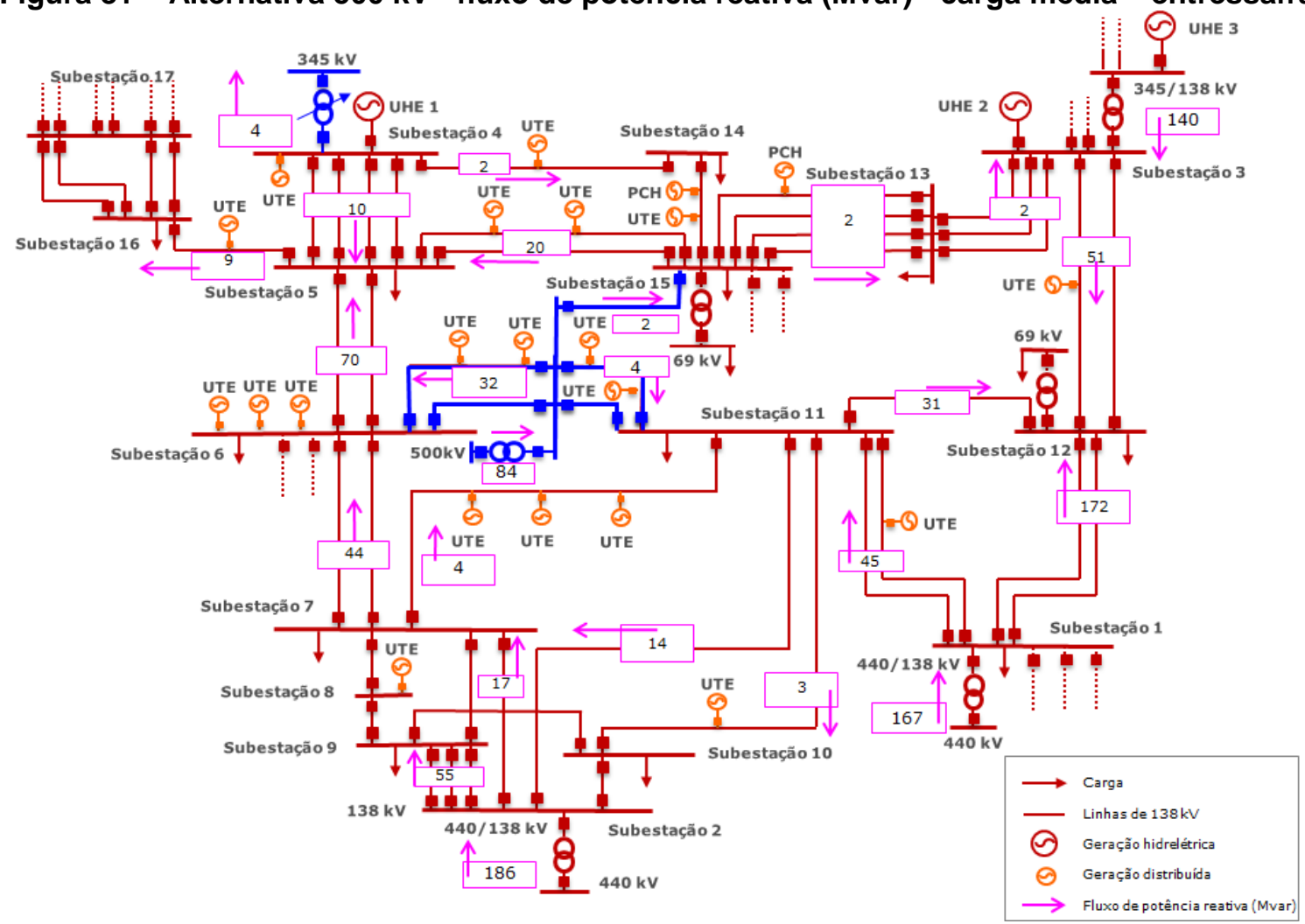

Fonte: Autor.

Figura 82 - Alternativa $500 \mathrm{kV}$ - carregamento das linhas de 138 kV (\%) - carga média entressafra



Fonte: Autor. 
Figura 83 - Alternativa 500 kV - tensão nos barramentos (pu) - carga média - entressafra

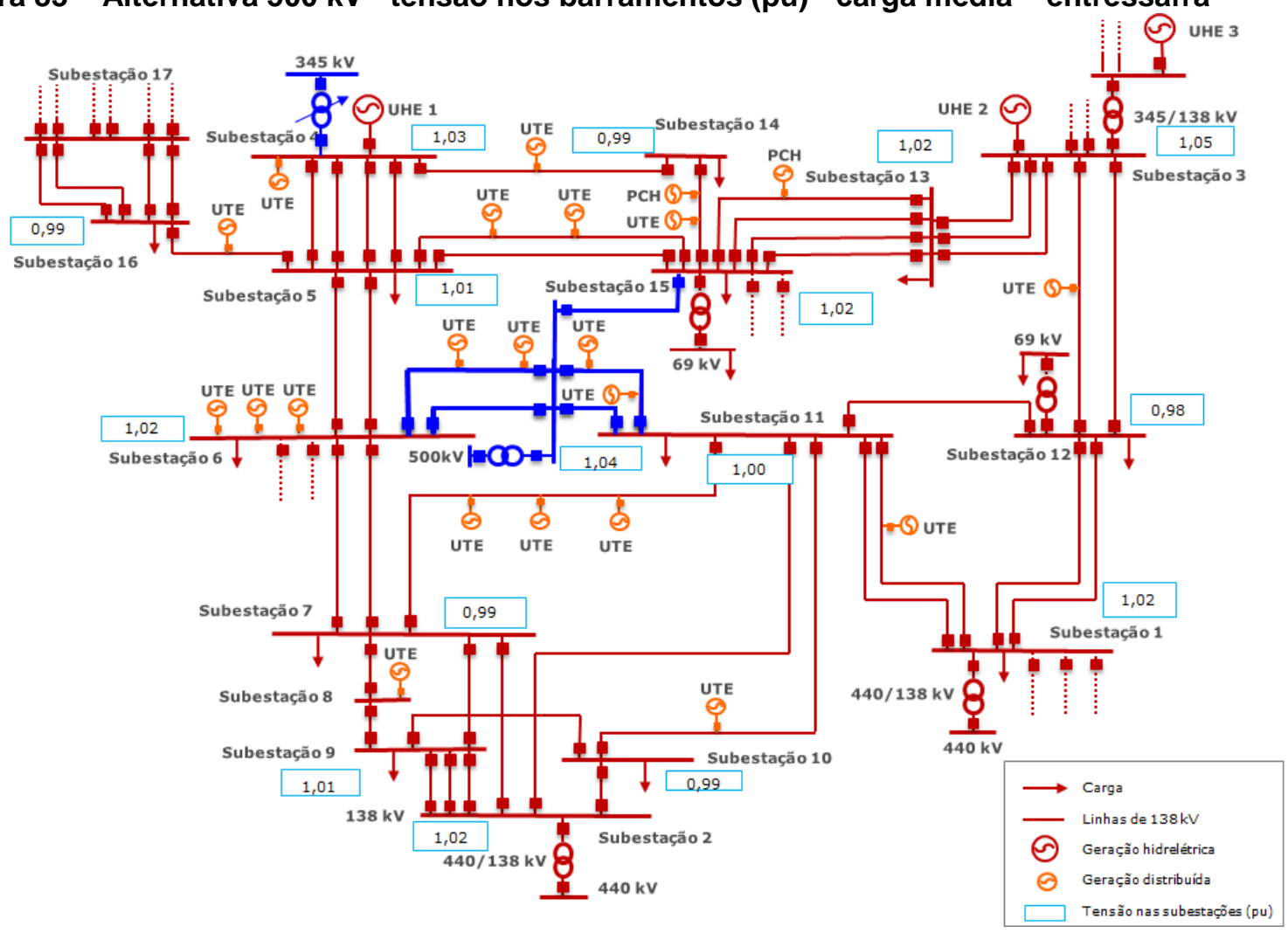

Fonte: Autor.

Figura 84 - Alternativa 500 kV - fluxo de potência ativa (MW) - carga leve - safra

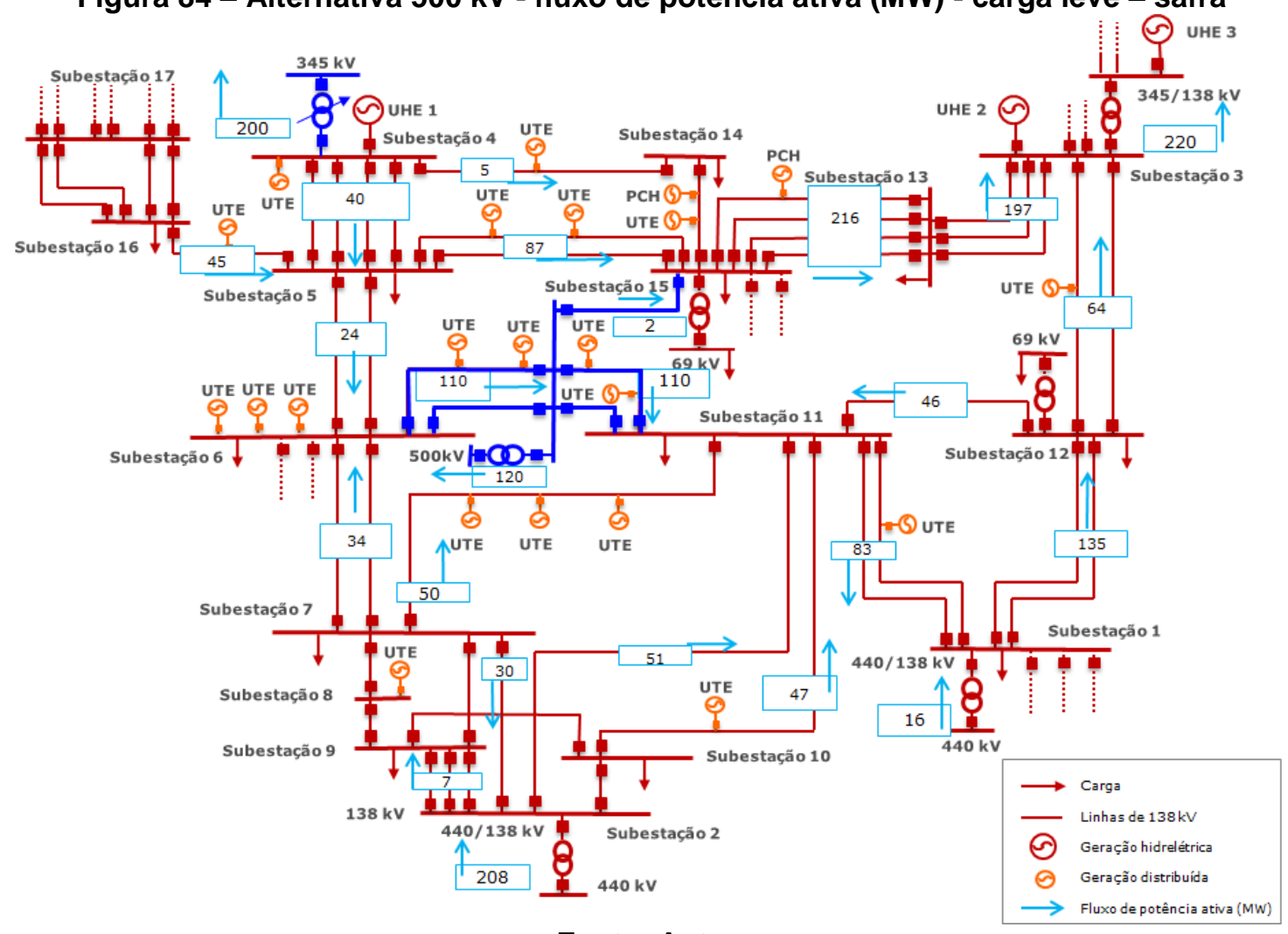

Fonte: Autor. 
Figura 85 - Alternativa $500 \mathrm{kV}$ - fluxo de potência reativa (Mvar) - carga leve - safra

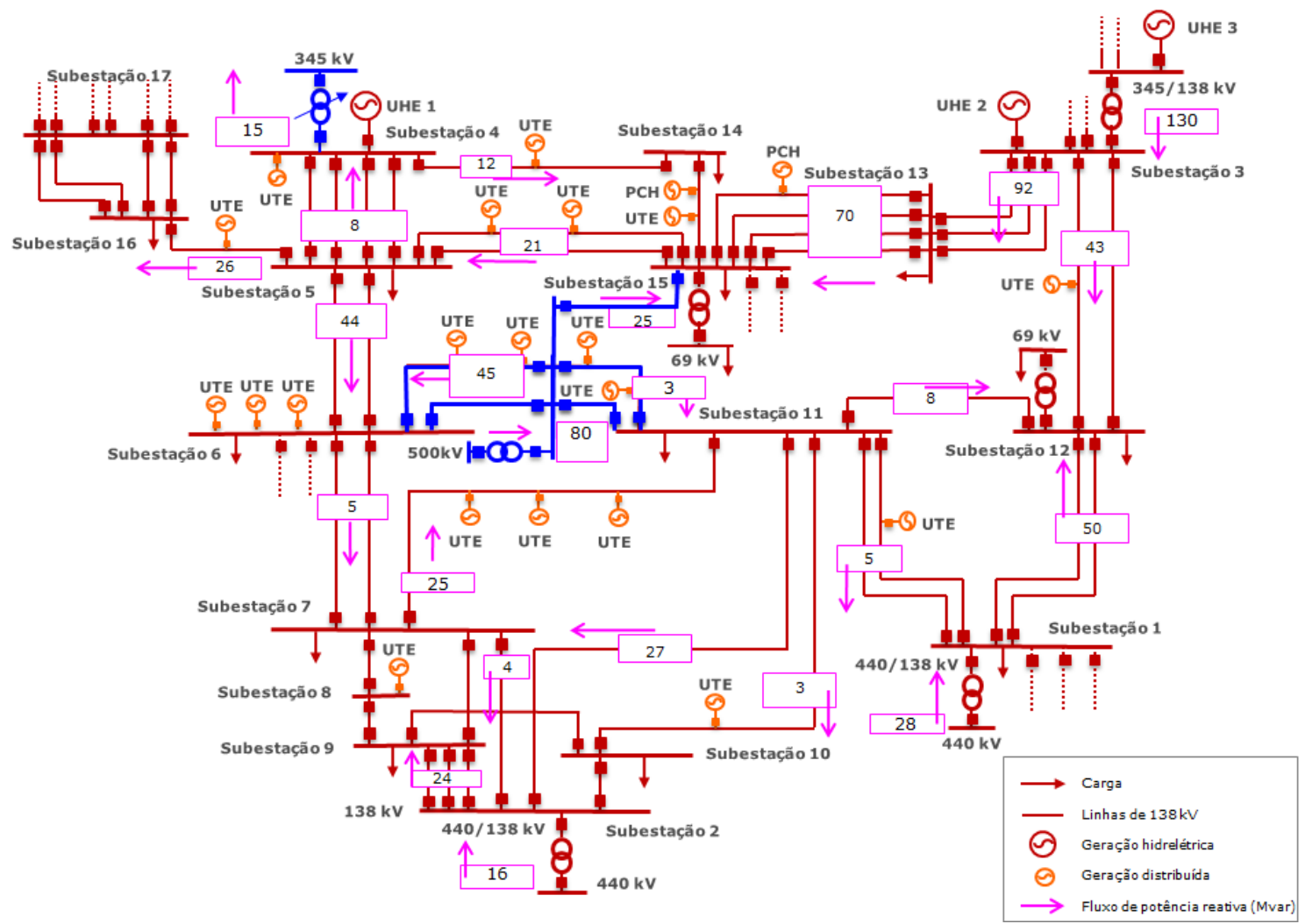

Fonte: Autor.

Figura 86 - Alternativa 500 kV - carregamento das linhas de 138 kV (\%) - carga leve - safra



Fonte: Autor. 
Figura 87 - Alternativa 500 kV - tensão nos barramentos (pu) - carga leve - safra

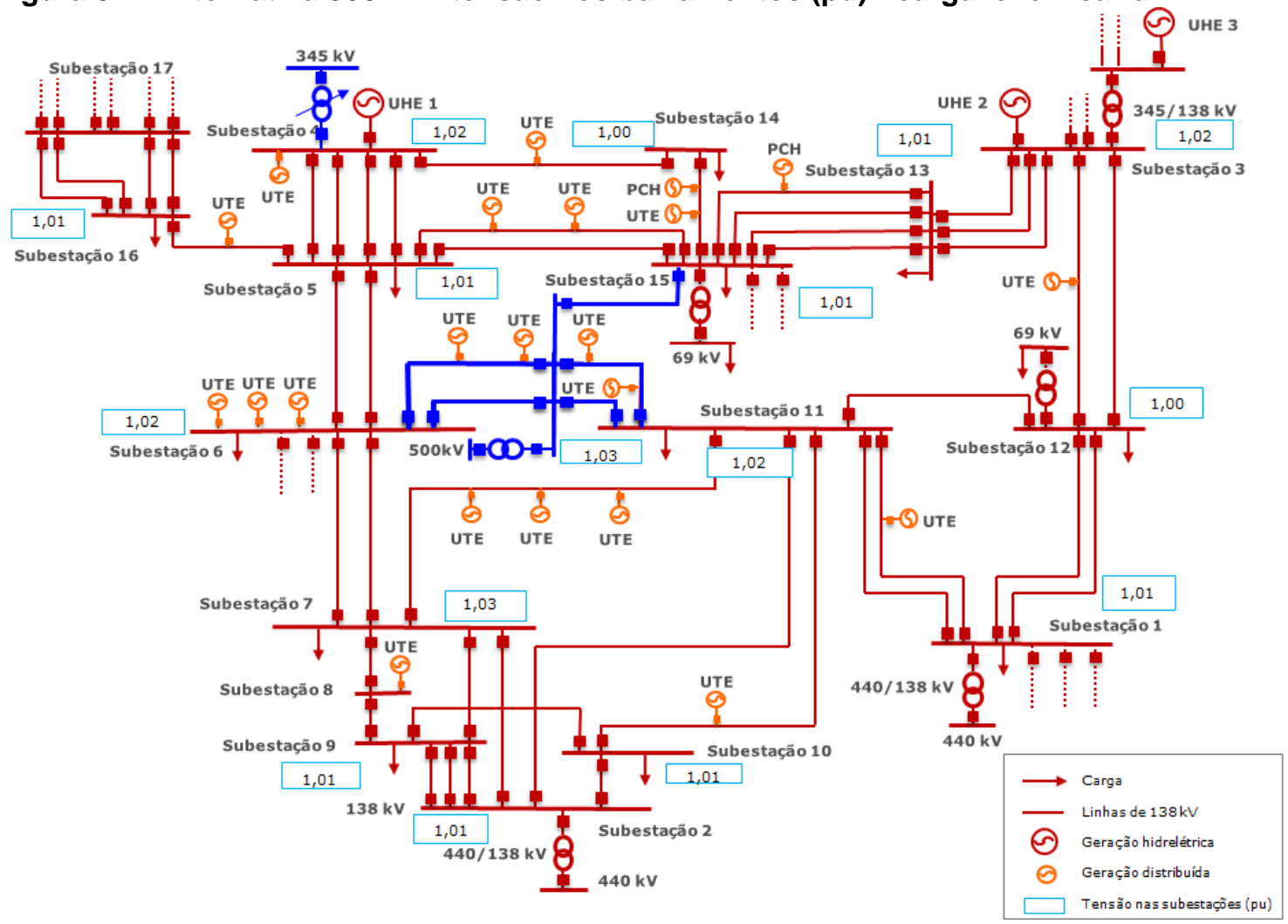

Fonte: Autor. 